Aus der Chirurgischen Universitäts-Kinderklinik München (Prof. Dr. W. Herzog).

\title{
Die Gaumenspalte und deren operative Behandlung.
}

Von Dr, Richard Drachter, Assistent der Klinik, Spezialarzt für Chirurgie. (Mit 62 Abbildungen.)

\section{Die verschiedenen bisher angewandten Operations- methoden und deren Klassifikation.}

Die zahlreichen Methoden, welche angegeben worden sind zur operativen Beseitigung der Gaumenspalte, lassen sich alle auf drei verschiedene Operationsprinzipien zurückführen. Das erste dieser Prinzipien ist das der Spalt-Überbrückung, das zweite das der Spalt-Ausfüllung, das dritte das des Aneinanderrückens der Spaltränder.

Dem ersten Versuche einer operativen Beseitigung der Spalte des harten Gaumens lag zugrunde das Prinzip der SpaltÜberbrückung. Krimer war der erste, der sich an die Lösung des schwierigen Problems heranwagte (1824); und wenn auch seine Methode heute nicht mehr geübt wird, so verdient sie doch vollste Beachtung und Anerkennung. Die Idee, den Spalt mittels mobilisierter, benachbarter Weichteillappen zu überbrücken, ist Krimers Verdienst. Die später von dem Eng. länder Lane beschriebene Methode schließt sich im Prinzip dem Krimerschen Verfahren an. Krimer überbrückte den Spalt dadurch, daß er die Weichteilüberzüge der Gaumenplatten nahe den Alveolarrändern ablöste, und die um die Spaltränder als ihre Basis um $180^{\circ}$ gedrehten Lappen in der Mittellinie durch die Naht vereinigte. Lane verwandte größere Lappen, welche die ganze Bekleidung des Alveolarfortsatzes und ev. sogar Teile der Wangenschleimhaut umfaßten; die um $180^{0}$ gedrehten Lappen legte er in eine künstlich hergestellte Tasche, welche im Bereich des harten Gaumens zwischen Schleimhaut-Periostbekleidung und knöcherner Gaumenplatte, im Bereich des weichen Gaumens zwischen nasaler und bukkaler Schleimhaut gelegen war. 
Eine andere Form der Spalt-Überbrückung hat uns v. Eiselsberg gezeigt, der bei einseitiger Spalte den Vomer um seine mit dem Spaltrand verwachsene Basis herunterklappte und den Vomerrand mit dem freien Spaltrand vereinigte.

Die souveräne Vertreterin aller Überbrückungsmethoden ist das Verfahren nach Bernhard v. Langenbeck: die Ablösung der mukös-periostalen Gaumenplattenüberzüge an den Alveolarrändern und deren Verschiebung nach der Mitte der Spalte mit nachfolgender Vereinigung der angefrischten Ränder durch die Naht.

Zahlreich sind die Methoden, die auf dem Prinzip der Spalt-Ausfüllung basieren; es sollen nur kurz erwähnt werden: die Ausfüllung des Spaltes nach Gersuny mittels Zungenlappens, nach NuBbaum-Rotter mittels Stirn-Nasenlappens, nach v. Eiselsberg mittels Hautlappens aus dem Unterarm, nach Rose mittels Lappens aus der Lippe, nach Délorme und Thiersch mittels Wangenlappens, nach Kraske durch die hypertrophische untere Muschel. Und endlich sei hier erwähnt gleichsam als Paradigma der Ausfüllungsmethoden - das Einheilen des kleinen Fingers in den Spalt nach dem Vorgehen von v. Eiselsberg.

Haben die beiden genannten Operationsprinzipien manche Berührungspunkte miteinander, und könnte man vielleicht das eine oder andere der zu der Ausfüllungsmethode gerechneten Verfahren ebensogut der Überbrückungsmethode zuweisen, so stellt das oben als drittes Operationsprinzip aufgeführte Vorgehen ein von den genannten völlig differentes Verfahren dar.

Die Beseitigung der Gaumenspalte durch Aneinanderrücken der Spaltränder ist eine Methode, die besonders im letzten Jahrzehnt viel gepflegt und empfohlen wurde, und die sich vor allem an die Namen Brophy, Helbing, Codivilla und Schoemaker knüpft. Diesen schloß sich in allerjüngster Zeit Kärger an, der aus der Berliner Chirurgischen Klinik eine Modifikation der Brophyschen Methode empfiehlt.

Neu ist indessen die Idee der gegenseitigen Annäherung der Spaltränder keineswegs. Auf ihr beruht vielmehr das älteste von allen Verfahren zur Beseitigung der Gaumenspalte, nämlich der Versuch der alten Chirurgen, die Annäherung der Spaltränder 
auf unblutigem Wege durch permanenten Druck von außen zu erreichen. In neuerer Zeit hat $\mathrm{Kredel}$ diese Idee weiter verfolgt, und teilt mit, daß er vor ca. 20 Jahren schon Versuche angestellt habe, die bezweckten, einen Druck gegen die Oberkieferhälften auszuüben, ,mittels Pelotten, die außen auf die Wange gelegt wurden und deren bruchbandartige Federn ihren Stützpunkt hinten am Nacken hatten“. Zu brauchbaren Resultaten ist Kredel mit diesem Verfahren jedoch nicht gekommen.

Aber auch eine Methode auf blutige Weise diese gegenseitige Annäherung der Spaltränder zu bewerkstelligen, ist sehr frühen Datums und geht zurück auf Dieffenbach. Dieffenbach schlug 1826 vor, die knöchernen Spaltränder einander dadurch zu nähern, daß man die knöchernen Gaumenplatten mittels Meißels am Übergang in die Alveolarfortsätze linear durchtrennen und mittels Silberdrahtes zusammenziehen solle; dieses theoretisch durchaus rationelle Vorgehen soll nach Lexer besonders in Frankreich Anhänger gefunden haben.

Jüngeren Datums dagegen sind die Methoden nach Brophy, Helbing, Codivilla und Schoemaker, sowie deren Modifikationen. - Brophy preßt im frühesten Kindesalter, „,solange die Knochen noch nachgiebig sind", beide durch den Spalt getrennte Oberkieferknochen aneinander und fixiert sie in ihrer neuen Lage durch Silberdrähte; ev. muß dieses Aneinanderpressen mittels eigens konstruierter Zange geschehen, oder, wenn auch damit die vollkommene Verschließung des Spaltes nicht möglich ist, müssen beide Alveolarfortsätze vom Oberkiefer mittels Meißels getrennt und dadurch nach der Mittellinie verschieblich gemacht werden.

Ein anderes Verfahren aber wird zu Unrecht gelegentlich als „Brophysche Modifikation des v. Langenbeckschen Verfahrens" bezeichnet; bei diesem fälschlich als Brophysche Modifikation bezeichneten Verfahren handelt es sich um eine Abhebelung der Gaumenplattenüberzüge nicht von den Alveolarrändern, sondern von den Spalträndern aus, und um ein Herunterklappen der abgelösten Lappen bis etwa zur Horizontalen. Ich betone, daß Langenbeck 1864 nicht nur genau diese Methode beschrieben und an Illustrationen erläutert hat, sondern auch schon damals dem dieser Methode anhaftenden Nachteil des schweren 


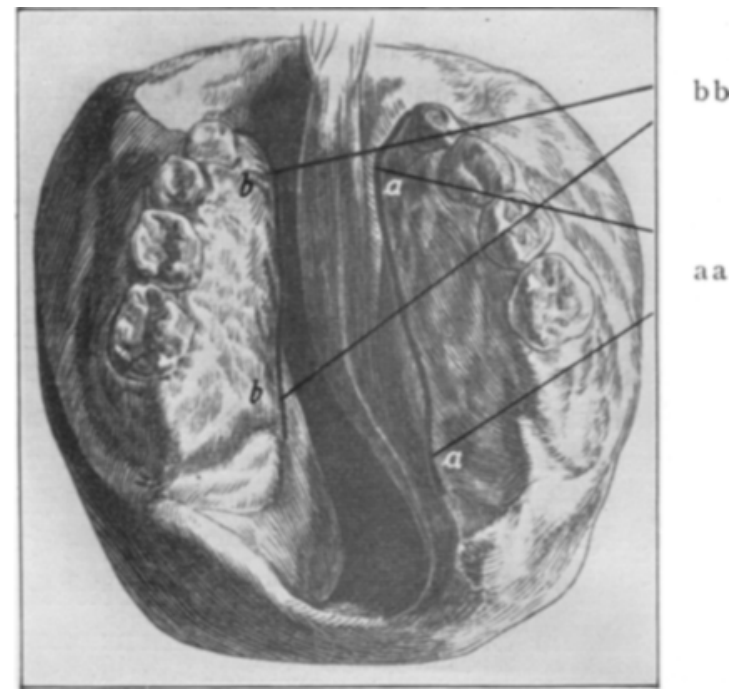

Fig. 1. (Nach Langenbeck.) Ablösung der mukös-periostalen Überzüge von den Spalträndern aus (bb, a a).

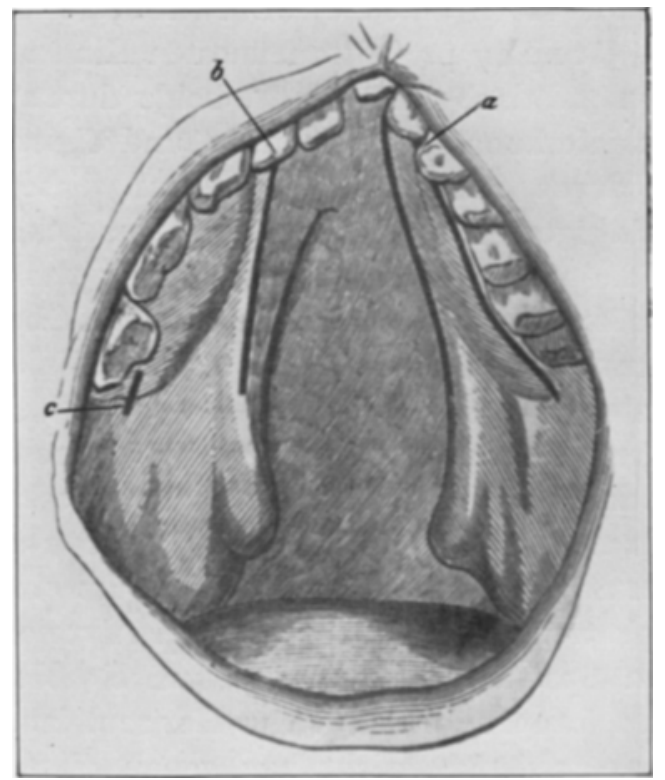

Fig. 2. (Nach Langenbeck.) Rechts ist die Ablösung mit Hilfe der Methode der „unterbrochenen Seiteneinschnitte" (c) vom Spaltrand aus erfolgt. 
Ablösens der Überzüge vom Spaltrand aus durch seine „,Methode der unterbrochenen Seiteneinschnitte" abzuhelfen suchte. Demnach handelt es sich bei dieser Art des Vorgehens lediglich um ein ursprünglich von Langenbeck schon empfohlenes, bei Steilstellung der Gaumenplatten anzuwendendes Verfahren (vgl. Fig. I u. 2). Die von Brophy dabei verwendeten Bleistreifen gehören nicht zu dem Verfahren als solchem.

Helbing, der sonst Anhänger des v. Langenbeckschen Verfahrens ist, durchmeißelte in einem Falle, in welchem sich

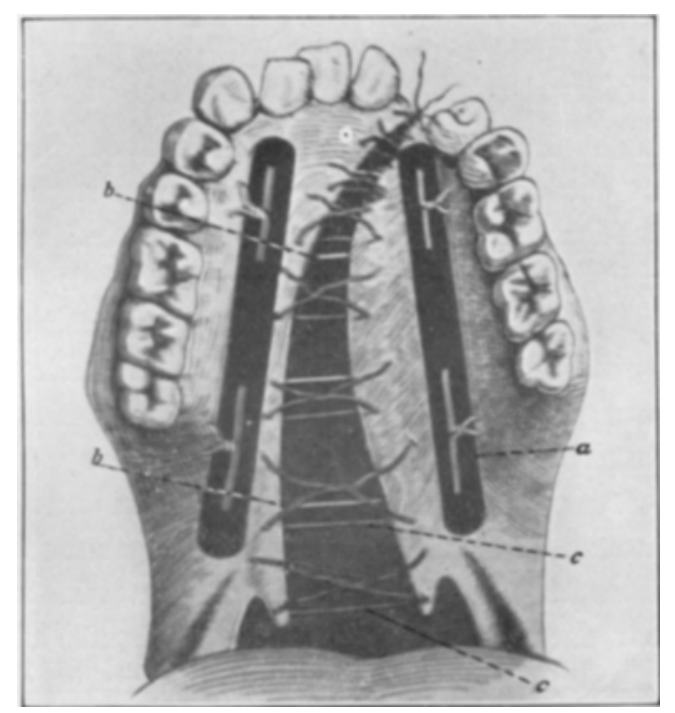

Fig. 3. (Nach Brophy.) Das irrtümlicherweise als „Brophysche Modifikation des von Langenbeckschen Verfahrens" bezeichnete, ursprünglich von Langenbeck empfohlene (vgl. Fig. I) Vorgehen.

letzteres aus besonderen Gründen nicht durchführen ließ, submukös den Processus zygomaticus ossis maxillaris von der bukkalen Schleimhautumschlagfalte aus in der Höhe des II. Prämolarzahnes; bei stärkerem Druck ließ sich darnach die rechte Oberkieferhälfte der linken so weit nähern, daß die Spalte fast vollkommen geschlossen war; durch Silberdrähte wurde die Annäherung der Oberkieferhälften festgehalten.

In noch ausgiebigerer Weise mobilisierte Codivilla den Oberkiefer; er machte eine osteoplastische Resektion des rechten 
Oberkiefers an dessen infraorbitaler Portion nach präventiver Unterbindung der Carotis externa, und konnte darnach die rechte Oberkieferhälfte gegen die linke verschieben.

Schoemaker mobilisierte mittels Meißels Alveolarfortsätze samt Gaumenplatten und erreichte dadurch den VerschluB der Spalte.

Kärger hat nach einer Modifikation des Brophyschen Verfahrens operiert; zunächst wird der Spalt im Alveolarfortsatz geschlossen, im übrigen nach der Brophyschen Methode vorgegangen.

\section{Anatomie und Maßverhältnisse der Gaumenspalte.}

Nach diesem kurzen Überblick über die wichtigsten bisherigen Operationsverfahren erhebt sich die Frage, welches von den genannten Operationsprinzipien - zunächst vom rein theoretischen Standpunkt aus - das rationellste sei. Das noch am meisten geübte Verfahren gehört der Überbrückungsmethode an. Wenig geübt sind die Ausfüllungsmethoden. Dagegen werden für die Berechtigung des Aneinanderrückens der Spaltränder wichtige Gründe vorgebracht. Schon im Jahre I 782 hat Oehme darauf hingewiesen, daß der Oberkiefer bei mit Lippenspalte geborenen Kindern übermäßig breit sei. In neuerer Zeit hat der Amerikaner Brophy diese Behauptung wiederholt und sich noch näher über das angebliche „Zuviel“" an Breite ausgesprochen. Brophy ist nämlich der Ansicht, daß bei Gaumenspalten ,der Oberkiefer auseinandergewichen und um die Spaltbreite zu breit sei". Erwiese sich diese Anschauung als richtig, so würde das Prinzip des Aneinanderrückens der Spaltränder vom rein theoretischen Standpunkte aus dadurch eine starke Stütze erfahren. Eine Bestätigung der von Oehme und Brophy vertretenen Ansicht an der Hand eingehender Untersuchungen habe ich in der Literatur nicht finden können. Es ist vielmehr geradezu auffallend, wie wenig sich die Autoren bisher über die Maßverhältnisse, besonders die Breitenverhältnisse des Oberkiefers bei Gaumenspalte geäußert haben. Auch in der klassischen Arbeit von Langenbeck finden sich nur spärliche diesbezügliche Bemerkungen. In dem Kapitel über die Formverschiedenheiten der Gaumenspalte äußert sich Langenbeck insofern zu der in 
Rede stehenden Frage, als er hier die Befürchtung ausspricht, „es müßte aus einem Zusammengedrängtwerden beider Oberkieferhälften durch Kompressorien allerdings ein Engerwerden der Spalte, zugleich aber auch ein neuer Formfehler des Oberkiefers entstehen". Wenn man versucht wäre, aus dieser Befürchtung zu schließen, daß $\mathrm{L}$ a n g e $\mathrm{n}$ be c $\mathrm{k}$ den gespaltenen Oberkiefer etwa für normal breit angesehen habe, so geht aus der im Jahre I 864 von Langenbeck erschienenen Arbeit mit Bestimmtheit hervor, daß dem nicht so ist; in dieser Arbeit zitiert nämlich Langenbeck die von Oehme aufgestellte Behauptung und glaubt dieselbe bestätigen zu sollen.

Wichtige Untersuchungen über die Formen der Gesichtsund Schädelknochen an Schädeln mit Gaumenspalten besitzen wir von Engel. Die Resultate Engels sind für uns besonders insofern von hohem Werte, als sie zeigen, in welch weitgehendem Maße die verschiedenen Gesichts- und Schädelknochen bei Gaumenspalte in Mitleidenschaft gezogen sind. Besonders auffallend ist das Auseinanderrücken der verschiedenen Skeletteile am vorderen Schädelabschnitt (Hueter). Als normale Distanz der Foramina infraorbitalia z. B. gilt nach Engel beim Neugeborenen $2,4 \mathrm{~cm}$, während derselbe Autor bei Wolfsrachen eine Distanz von $3,3 \mathrm{~cm}$ fand; für die Entfernung zwischen den obersten Stellen der Jochbeinoberkieferverbindung fand Engel statt $3 \mathrm{~cm}$ $3,67 \mathrm{~cm}$ und für die der untersten Stellen dieser Verbindung statt $5 \mathrm{~cm} 5,36 \mathrm{~cm}$. Der Nasenfortsatz des Stirnbeins ist bei Wolfsrachep I,9 cm, normalerweise $1,44 \mathrm{~cm}$ breit. Die Entfernung der Tubera frontalia ist von 4,86 auf $5,4 \mathrm{~cm}$ vermehrt. Bemerkenswert ist auch die Gestaltsveränderung der Orbitae, deren Höhe bei Gaumenspalten der Breite gleich wird, während normalerweise die Höhe 2,02, die Breite $2,35 \mathrm{~cm}$ beträgt. Bei uniund bei bilateralen Gaumenspalten sollen nach' Engel Differenzen in der Größe der Orbitae fast immer nachzuweisen sein. Auch auf die Knochen der Schädelbasis erstreckt sich die Abnormität. Die Gaumenflügel des Keilbeins haben eine besonders schräge Stellung und stehen weiter voneinander ab, als unter gewöhnlichen Verhältnissen; die Foramina ovalia des Keilbeins sind $3,6 \mathrm{~cm}$, bei Wolfsrachen $3,8 \mathrm{~cm}$ voneinander entfernt. Die Lamina cribrosa liegt tiefer als normal unter dem höchsten Punkt 
der oberen Orbitalplatte und soll an dem vorderen Teil sehr breit entwickelt sein.

Von den neueren Autoren macht auch Helbing keine detail. lierten Angaben bezüglich der Breitenverhältnisse des Oberkiefers bei angeborener Gaumenspalte; einer von Brophy stammenden Ansicht jedoch, daß die Gaumenüberzüge nur durch ihre veränderte schräg gestellte Lagerung eine Spalte bewirken, stimmt Helbing nicht für alle Fälle bei. Nebenbei möchte ich übrigens darauf hinweisen, daB die eben zitiertc Brophysche Anschauung zu der oben von demselben Autor vertretenen Behauptung -nämlich, daß bei Gaumenspalten der Oberkiefer auseinandergewichen und um die Spaltbreite zu breit sei - in einem gewissen Widerspruch steht.

Neumann spricht von Messungen, die ergeben haben, daß es sich bei Gaumenspalten nicht um normal breite Kiefer handelt, bei denen ein wirklicher Defekt in Form der Spalte bestehe, sondern daß 3 die Kieferhälften annähernd normale Breite besitzen und vielmehr nur um die Breite der Spalte auseinanderstehen; infolgedessen sei ein solcher Oberkiefer tatsächlich zu breit.

Schoemaker scheint die Brophyschen Anschauungen zu akzeptieren; jedenfalls hat er seinen Operationsplan in Über. einstimmung mit diesem aufgebaut; er schreibt: „Kann man also die Maxillarhälften zusammenbringen, dann wird der Gaumen auch von normaler Breite." Offenbar legt Schoemaker auch großen Wert auf die angebliche Steilstellung der Gaumenplatten, was aus folgender Äußerung dieses Autors hervorgeht: „Die Erfahrung mit dem Kind N. N. lehrt uns aber auch, wo eigentlich das Material herkommt, das auch bei ganz großen Spalten einen so breiten Gaumen macht. Das ganze Geheimnis liegt in der Schiefstellung der nicht aneinandergewachsenen Processus palatini. Bringt man diese in die horizontale Lage, dann stellt es sich heraus, daß sie breiter waren, als man vermutet hatte." Weiter bespricht Schocmaker einen Fall, der nach seiner Methode operiert wurde; die Spalte betrug I I mm Breite, nach der Operation o mm; der Abstand der Alveolarfortsätze mit $3,7 \mathrm{~cm}$ aber blieb unverändert. Schoemaker fügt diesem Berichte bei : „Die Ehrlichkeit gebiete ihm zu sagen, daß dies nicht immer so sei; Tatsache sei aber, daß, wenn eine Verschmälerung des 
Gaumens vorkomme, diese geringer sei, als die Verschmälerung der Spalte."

Diese spärlichen Angaben bezüglich wichtiger anatomischer Größen- und Maßverhältnisse, sowie besonders auch des den

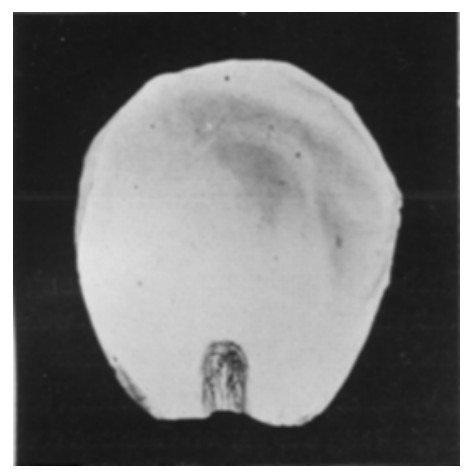

Fig. 4 .

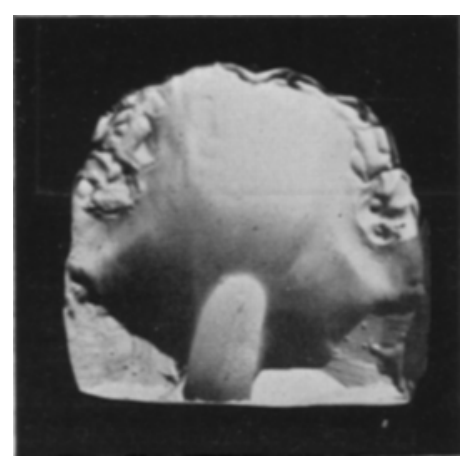

Fig. 5 .

Fig. 4. Kieferabdruck eines 5 Monate alten Mädchens; Spaltung des weichen Gaumens inkl. Zäpfchens. Keine Hasenscharte.

Fig. 5. Kieferabdruck eines 2 jährigen Knaben; Spaltung eines Teiles des harten, des ganzen weichen Gaumens inkl. Zäpfchens. Keine Hasenscharte.

Spalt bedingenden Moments in Fällen von Spaltbildung des Oberkiefers sind bei dem Fehlen exakter Messungen nicht aus-

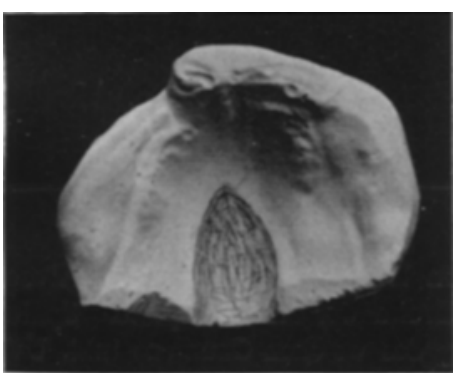

Fig. 6.

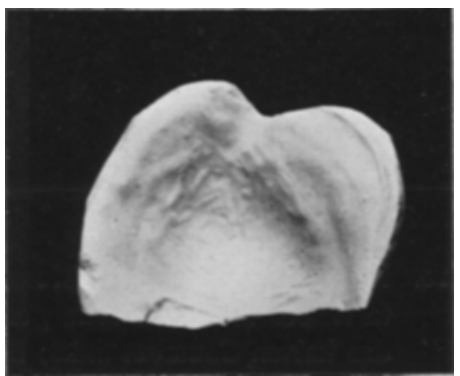

Fig. 7 .

Fig. 6. Kieferabdruck eines 8 Monate alten Knaben. Einkerbung des Alveolarfortsatzes rechts; Spaltung des größten Teiles des harten, des ganzen weichen Gaumens, inkl. Zäpfchens. Hasenscharte II. Grades rechts.

Fig. 7. Kieferabdruck eines 9 Monate alten Mädchens. Einkerbung des Alveolarfortsatzes links; Hasenscharte II. Grades links. (Keine Gaumenspalte.) 


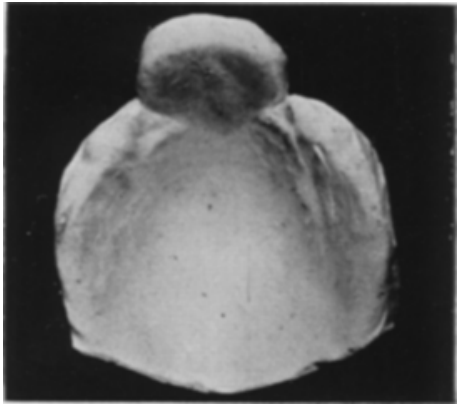

Fig. 8.

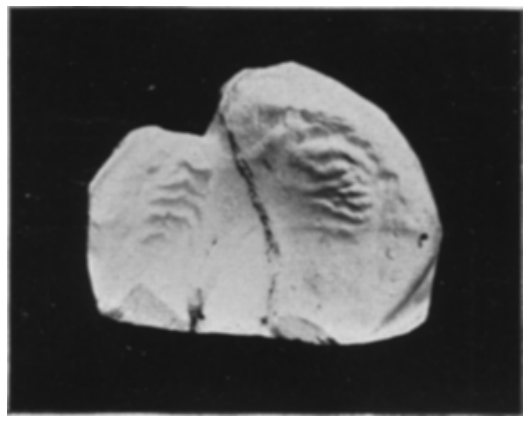

Fig. 9.

Fig. 8. Kieferabdruck eines 6 Monate alten Knaben, doppelseitige Einkerbung des Alveolarfortsatzes mit leicht prominentem Zwischenkiefer. Harter u. weicher Gaumen intakt. Hasenscharte II. Grades rechts, III. Grades links.

Fig. 9. Kieferabdruck eines 6 Mon. alt. Knaben. Spaltung d. Alveolarfortsatzes rechts mit geringer Breite der Alveolarspalte. Spaltung des harten Gaumen rechts; Spaltung des weichen Gaumens ink1. Uvula. (Hasenscharte II. Grades rechts.)

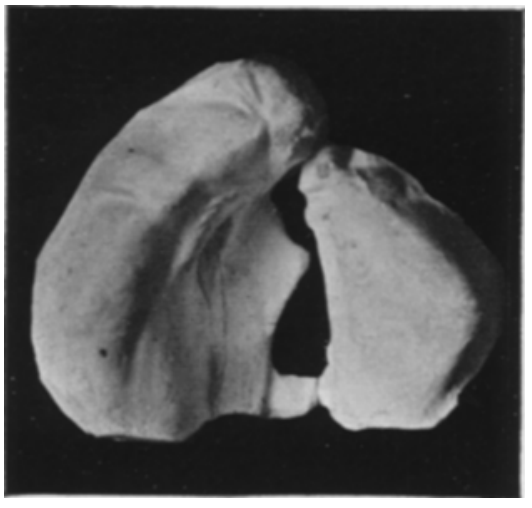

Fig. 10.

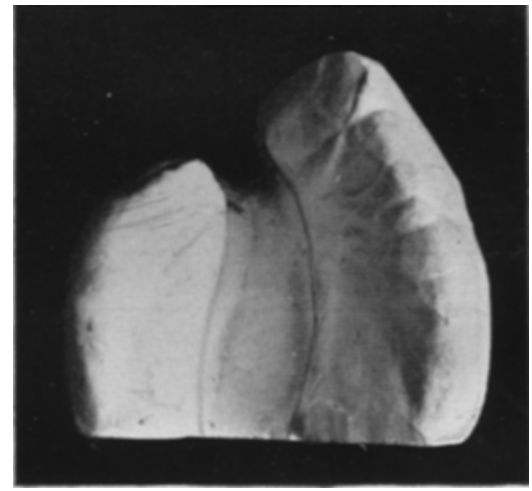

Fig. II.

Fig. Io. Kieferabdruck eines 6 Monate alten Knaben. Spaltung des Alveolarfortsatzes links mit sehr geringer Breite der Alveolarspalte. Spaltung des harten Gaumens links; Spaltung des weichen Gaumens inkl. Uvula. (Hasenscharte III. Grades links.)

Fig. Ir. Kieferabdruck eines 16 Monate alten Mädchens. Spaltung des Alveolarfortsatzes rechts. Spaltbreite im Alveolarfortsatz $1,0 \mathrm{~cm}$. Die linke Seite überragt in ihrem Alveolarteil die rechte in der Sagittalebene um $0,7 \mathrm{~cm}$. Grenze von Zwischenkiefer und linkem Alveolarfortsatz noch zu erkennen. Spaltung des harten Gaumens rechts; des weichen Gaumens inkl. Uvula. Parallele Gaumenplattenränder. Hasenscharte III. Grades rechts. 
reichend, um auf Grund derselben die Frage nach dem rationellsten therapeutischen Vorgehen bei angeborener Gaumenspalte zu beantworten. Bei der großen Formverschiedenheit der in Rede stehenden MiBbildung und der Fülle der in jedem einzelnen Falle verschiedenen speziellen Verhältnisse erscheint mir ein Eingehen auf die wichtigsten - im weiteren Verlauf dieser Abhandlung immer wiederkehrenden Einzelheiten - an der Hand der häufigsten Gaumenspaltentypen sehr am Platze. Soweit den Abbildungen kein besonderer diesbezüglicher Vermerk beigefügt ist, beziehen sie sich durchwegs auf eigene Beobachtungen.

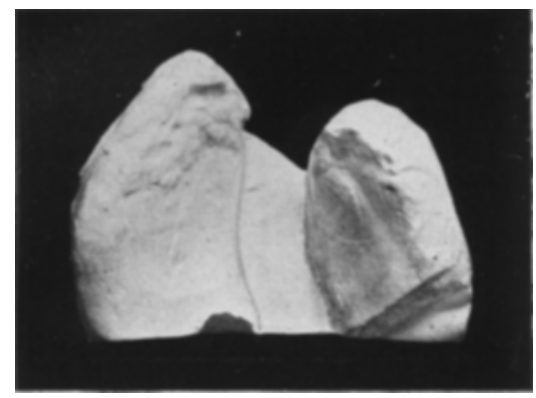

Fig. 12.

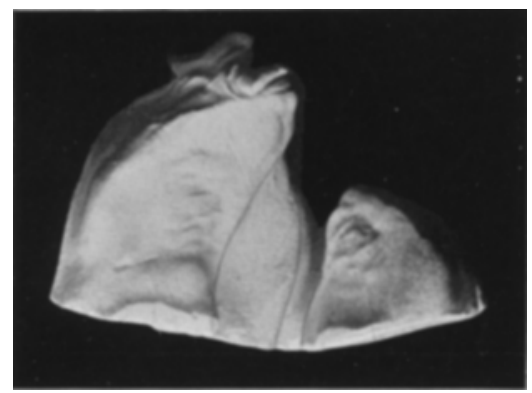

Fig. 13.

Fig. I 2. Kieferabdruck eines 51/2 Mon. alten Mädchens. Spaltung des Alveolarfortsatzes links. Breite der Alveolarspalte $\mathrm{I}, 0 \mathrm{~cm}$. Die rechte Seite überragt in ihrem Alveolarteil die linke in der Sagittalebene um $0,5 \mathrm{~cm}$. Spaltung des harten Gaumens links, d. weichen Gaumens inkl. Uvula. Vomer horizontal, sehr breit. Parallele Gaumenplattenränder. Hasenscharte III. Grades links.

Fig. 13. Kieferabdruck eines I I Mon. alten Knaben. Spaltung des Alveolarfortsatzes links. Breite Alveolarspalte. Die rechte Seite überragt in ihrem Alveolarteil die linke nach vorne um mehr als I cm. Spaltung des harten Gaumens links. Spaltung des weichen Gaumens inkl. Uvula. Vomer horizontal; stark verbreitert. Grenze 2wischen rechter Gaumenplatte und Vomer sichtbar. Hasenscharte III. Grades links (von anderer Seite ohne Erfolg operiert).

An Hand dieser Typen unterscheide ich drei Hauptformen von Gaumenspalten:

I. Die nicht durchgehende (oder einfache) Gaumenspalte.

Diese Gruppe umfaßt die Fälle, in welchen eine Spaltung des harten und weichen Gaumens oder auch nur des letzteren vorliegt. Dabei ist nicht von Belang; ob der harte Gaumen ganz oder nur 
teilweise gespalten ist, ob eine Einkerbung des Alveolarfortsatzes besteht oder nicht. In selteneren Fällen dieser Gruppe kann die Spaltung des harten Gaumens eine doppelseitige sein. Hasenscharte I., II. oder III. Grades kann vorhanden sein oder fehlen.

2. Die einseitig durchgehende Gaumenspalte.

Im Gegensatz zu der erstgenannten Gruppe ist bei dieser auch der Alveolarfortsatz gespalten: Die Spalte geht also durch den Oberkiefer in seiner ganzen Länge durch, d. h. sie geht nicht nur

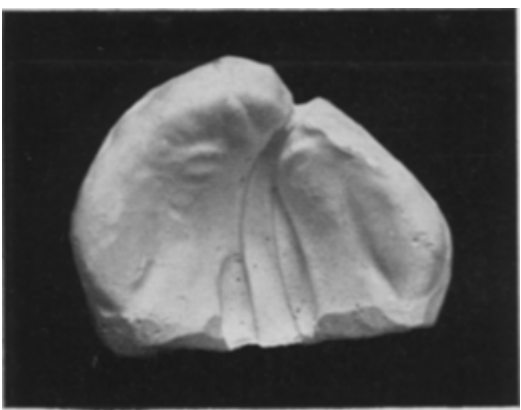

Fig. I4.

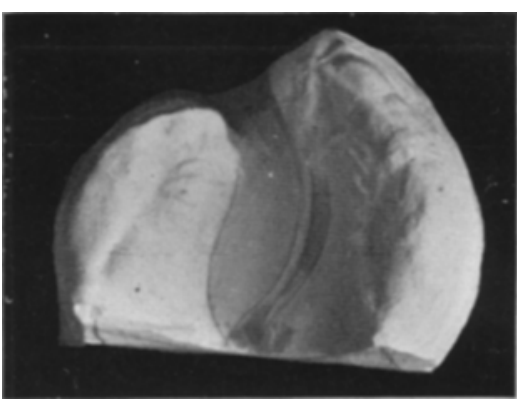

Fig. I 5 .

Fig. 14. Kieferabdruck eines $7 \frac{1}{2}$ Monate alten Knaben. Spaltung des Alveolarfortsatzes links; geringe Breite der Alveolarspalte. Spaltung des harten Gaumens, weichen Gaumens inkl. Uvula. Der harte Gaumen ist links in ganzer Ausdehnung gespalten; rechts hat sich der Vomer in seinem vorderen Teil mit dem größten Teil der rechten Gaumenplatte vereinigt. Hasenscharte II. Grades links.

Fig. 15. Kieferabdruck eines 9 Monate alten Knaben. Ähnlicher Fall, wie der in Fig. 14 abgebildete. Spaltung des Alveolarfortsatzes rechts. Spaltung des harten und weichen Gaumens inkl. Uvula. Der harte Gaumen ist rechts in ganzer Ausdehnung gespalten; links sind nur etwa die zwei hinteren Drittel des harten Gaumens gespalten. Parallele Gaumenplattenränder. Spaltung des weichen Gaumens inkl. Uvula. Hasenscharte III. Grades rechts.

durch den weichen und harten Gaumen, sondern auch noch durch den Alveolarfortsatz. Gewöhnlich liegt in diesen Fällen eine Hasenscharte III. Grades auf der Seite der Alveolarspalte vor; von allen Spaltbildungen des Oberkiefers haben wir diese Form der Mißbildung weitaus am häufigsten beobachtet. Keineswegs selten liegt bei den zu dieser Gruppe gehörigen Fällen eine Spaltung des harten Gaumens der anderen Seite vor (Fig. I4, I5, I6). 


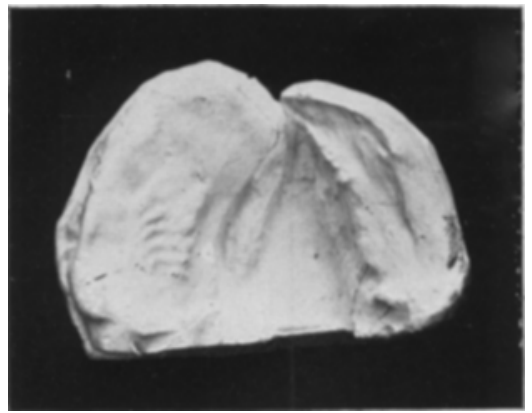

Fig. 16 .

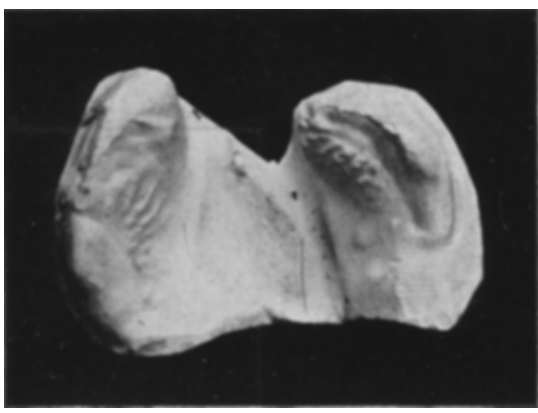

Fig. 17.

Fig. I6. Kieferabdruck eines 5 Monate alten Knaben. Spaltung des Alveolarfortsatzes links. Spaltung des harten und weichen Gaumens inkl. Uvula. Links ist der harte Gaumen in ganzer Ausdehnung gespalten, rechts hat sich der Vomer mit seinem vordersten dem rechten Giaumenplattenrand angelegt. Parallele Gaumenplattenränder. Spaltung des weichen Gaumens inkl. Uvula. Hasenscharte III. Grades links.

Fig. 17. Kieferabdruck eines 4 Monate alten Knaben. Spaltung des Alveolarfortsatzes und harten Gaumens links. Spaltung des weichen Gaumens inkl. Uvula. Die Alveolarspalte klafft weit; die rechte Seite überragt die linke in der Sagittalebene. Vomer horizontal; verbreitert. Große absolute, kleine relative Spaltbreite (cf. S. 32). Hasenscharte III. Grades links. Parallele Spaltränder.

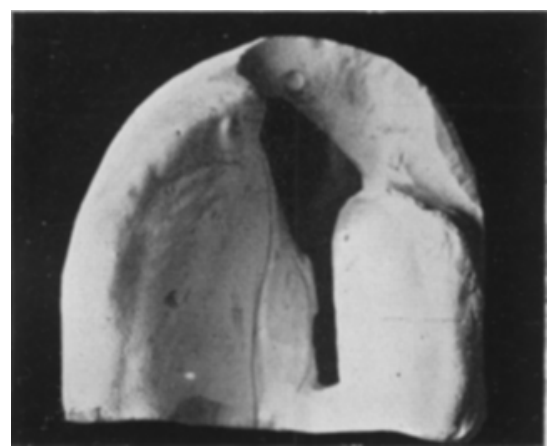

Fig. 18.

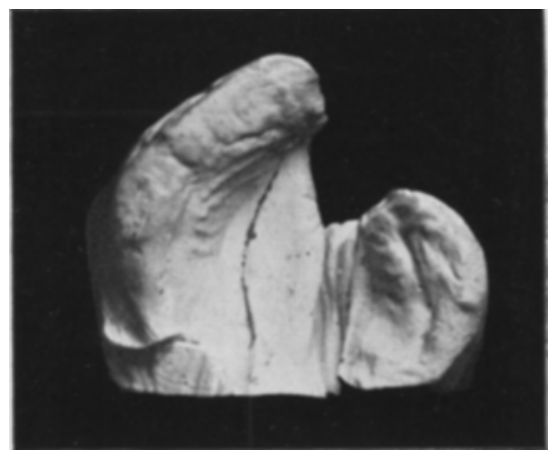

Fig. 19.

Fig. 18. Kieferabdruck eines 7 Monate alten Mädchens. Spaltung des Alveolarfortsatzes und harten Gaumens links. Spaltung des weichen Gaumens inkl. Uvula. Die Alveolarspalte klafft weit. Der rechte Alveolarfortsatz, der sich mit dem Zwischenkiefer vereinigt hat, überragt den linken nach vorne fast um $\mathrm{I} \mathrm{cm}$. Vomer horizontal, verbreitert. Große absolute, kleine relative Spaltbreite. Hasenscharte III. Grades links. Parallele Spaltränder.

Fig. I9. Kieferabdruck eines I Monat alten Knaben. Linksseitige „durchgehende Gaumenspalte“. Der rechte Alveolarfortsatz (inkl. Zwischenkiefer) überragt den linken in der Sagittalebene um $\mathbf{r}_{1 / 4}-\mathbf{I} \frac{1}{2} \mathrm{~cm}$. Weites Klaffen der Alveolarspalte. Vomer horizontal, verbreitert. Große absolute, kleine relative Spaltbreite. In der relativen Spalte ist die hypertrophische untere Muschel deutlich zu erkennen. Parallele Spaltränder. Hasenscharte III. Grades links. 


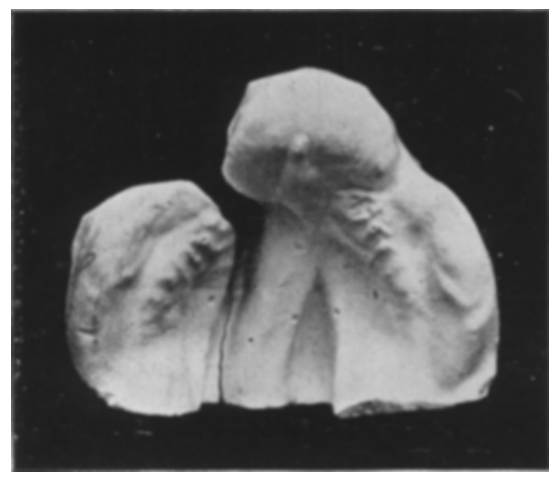

Fig. 20. Kieferabdruck eines I I 1/2 Monate alten Knaben. Linksseitige „durchgehende Gaumenspalte". Vorstehen des rechten Alveolarfortsatzes über den linken in der Sagittalebene. Weites Klaffen der Alveolarspalte. Vomer horizontal, größte Breite I,I $\mathrm{cm}$. Große absolute mittlere relative Spaltbreite. Parallele Spaltränder. Hasenscharte III. Grades links.

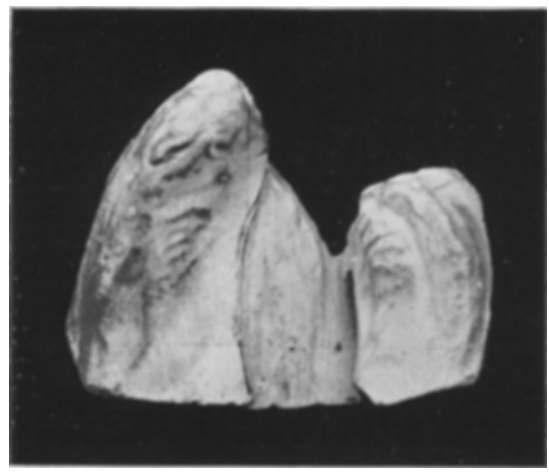

Fig. 21. Kieferabdruck eines $5 \frac{1 / 2}{2}$ Monate alten Knaben. Durchgehende Gaumen * spalte rechts. „Einkerbung des Alveolarfortsatzes“ links. Spaltung ungefähr der hinteren Hälfte des harten Gaumens links; geringe Prominenz des Zwischenkiefers. Vomer verbreitert, horizontal. Doppelseitige Hasenscharte II. Grades. 
3. Die doppelseitig durchgehende Gaumenspalte.

Diese ist dadurch charakterisiert, daß sich der Zwischenkiefer mit keiner der beiden Alveolarhälften vereinigt hat; dasselbe gilt von dem Vomer, er hat sich mit keinem der beiden Gaumenplattenränder vereinigt. Gewöhnlich besteht in diesen Fällen ein exzessives Längenwachstum des Vomer, so daß dieser mit dem $Z$ wischenkiefer weit über die Alveolarfortsätze der beiden Oberkieferhälften vorsteht (Fig. 22). Fast immer besteht doppelseitige Hasenscharte III. Grades.

Die eben gegebene Einteilung der Gaumenspalten soll hauptsächlich praktischen Gesichtspunkten Rechnung tragen. Eine Unterscheidung von durchgehender und nicht durchgehender Gaumenspalte ist jedenfalls insofern geboten, als sich wohl die meisten Autoren darüber einig sein werden, daß für die Behandlung der letzteren Gruppe die eingangs erwähnten „Knochenoperationen" entbehrt werden können.

Sollen exakte Messungen an Kiefern mit oder ohne Gaumenspalte vorgenommen werden, so bedarf es in jedem einzelnen Falle der Herstellung eines möglichst naturgetreuen Gipsabdruckes. Diesen erhält man in einfacher Weise dadurch, daß man eine bei ca. 50-60 $0^{\circ}$ erweichende Masse fest gegen den Gaumen andrückt und sodann das erstarrte Negativ mit Alabastergips ausgießt. Alle Maße, die wir brauchen, werden an dem Gipsmodell genommen.

Objekt der Messungen für diese Arbeit waren: Abstand der Alveolarfortsätze, d. h. größte Entfernung beider voneinander, Breitenverhältnisse der Gaumenplatten, Winkelstellung derselben, Spaltbreite und Spaltform, Verhalten von Vomer und Zwischenkiefer, sowie Bestimmung des Umfangs des Gaumenbogens. Die in Tabelle I angeführten Fälle von nicht durchgehender Spaltbildung waren - wie es meist bei dieser Gruppe der Fall ist alle so gelagert, daß Spaltbreite und Spaltform, Vomer und Zwischenkiefer eine Berücksichtigung nicht erforderten. Besonders hervorgehoben werden muB noch, da $B$ von ,durchgehenden Gaumenspalten" nur solche Fälle zu den Messungen verwendet werden durften, an denen noch' keinerlei Eingriffe vorgenommen worden waren; insbesondere durfte die Operation der 
Hasenscharte noch nicht vorgenommen worden sein, da, wie wir sehen werden, durch diese umwälzende Veränderungen hervorgerufen werden. Bei Fällen mit nicht durchgehender Spalte dagegen ist die Operation der Hasenscharte praktisch ohne Bedeutung. Dic als ,Abstand der Alveolarfortsätze“ in den Tabellen angegebenen Maße bezeichnen die größte Entfernung der höchsten Prominenz des Processus alveolaris der rechten Seite von einem entsprechenden Punkte der linken. Diese Entfernung wird in einfacher Weise dadurch bestimmt, daß man die Spitzen eines Tasterzirkels auf die entsprechenden Punkte des Kiefergips-

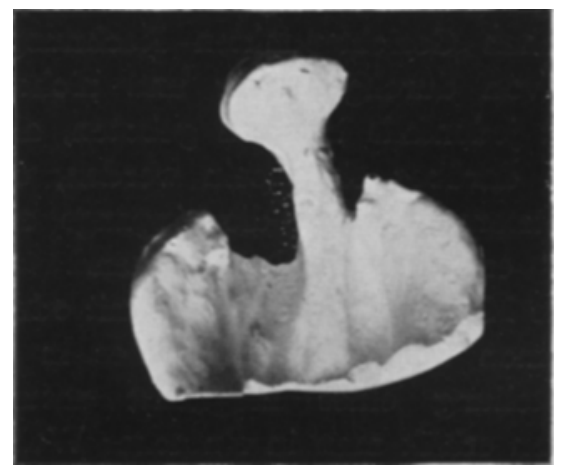

Fig. 22. Kieferabdruck eines I Tag alten Knaben. Doppelseitig durchgehende Gaumenspalte. Excessives Längenwachstum des Vomer. Vorspringen der Zwischenkiefer. Vomer etwas mehr dem linken Gaumenplattenrand genähert. Große absolute Spaltbreite. Doppelseitige Hasenscharte III. Grades. Parallele Spaltränder.

modells aufsetzt und an einem mit Millimetereinteilung versehenen Metallmaß die Entfernung der Zirkelspitzen direkt abliest; sind schon Zähne vorhanden, so werden die Zirkelspitzen zwischen den Tubercula der Zahnkrone der beiden Molares II aufgesetzt. In ähnlich einfacher Weise läßt sich größte und kleinste Breite der Gaumenplatten am Gipsmodell bestimmen. Dasselbe gilt für die Bestimmung der Spaltbreite und der Vomerbreite.

Etwas komplizierter gestaltet sich die Bestimmung des Neigungswinkels der Gaumenplatten; aber auch diese läßt sich mit ziemlicher Zuverlässigkeit ausführen, wie mir zahlreiche Kontrollen ergeben haben. Wir können die Neigung der Gaumen- 
platten entweder auf eine Horizontale oder auf eine Vertikale beziehen. Beide Verfahren ergeben gleichwertige Resultate. Ich habe meinen diesbezüglichen Angaben den Winkel zugrunde gelegt, der von einer durch den Processus alveolaris gedachten senkrechten Ebene und der Gaumenplatte der betreffenden Seite eingeschlossen wird. Die Messung dieses Winkels gestaltet sich folgendermaßen :

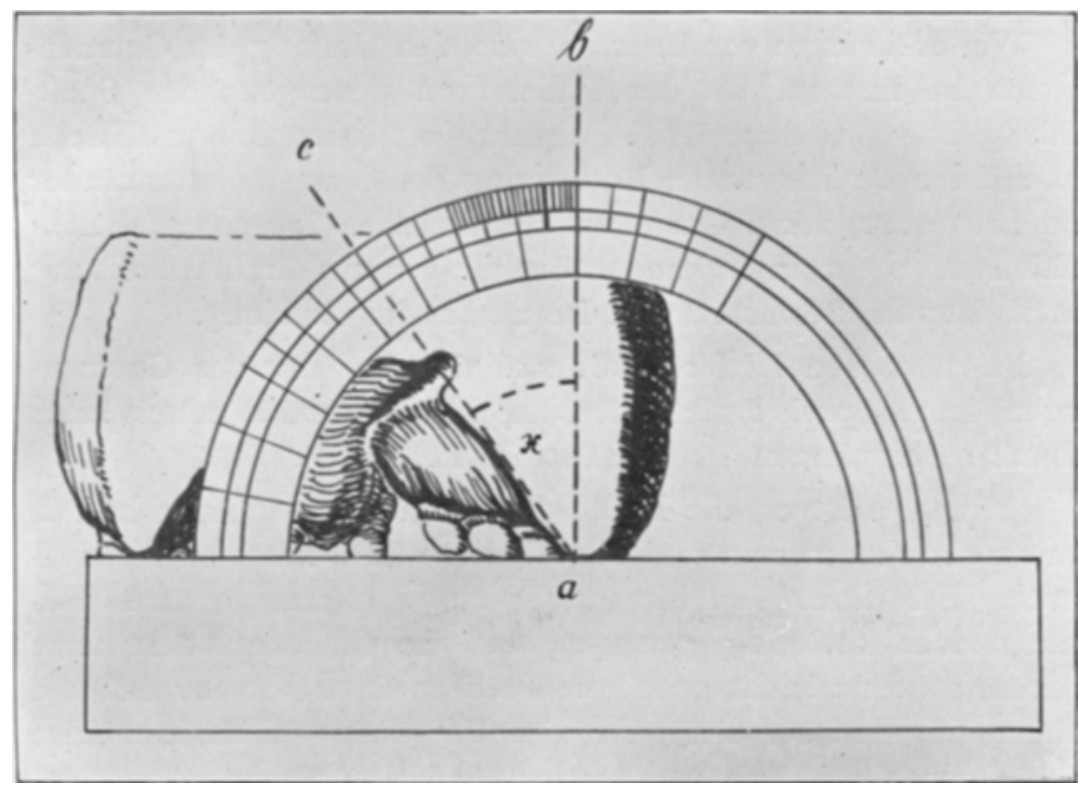

Fig. 23. $a b=$ Vertikale durch den Processus alveolaris. $a c=$ Richtung der rechten Gaumenplatte. $\Varangle x=$ Neigungswinkel der rechten Gaumenplatte.

Aufzeichnung der genannten Vertikalen auf das (von rückwärts gesehene) Gipsmodell. Markierung der auf diesem sich als scharfe Linie präsentierenden Gaumenplatte. Anlegen des Winkelmessers an das Gipsmodell; direkte Ablesung des gesuchten Winkels (Fig. 23).

Einfacher ist die Bestimmung des Gaumenplatten-Neigungswinkels eines normalen, noch' zahnlosen Kiefers. Man geht zu diesem Zwecke so vor, daß man zuerst die Entfernung der Alveolarfortsätze mißt, und diese Strecke als Gerade zu Papier 
bringt. Nun mißt man am Gipsmodell mittels Tasterzirkels die Entfernung von Gaumenmitte und dem eben schon benützten Punkte des Alveolarfortsatzes aus; mit dieser Entfernung beschreibt man um die Endpunkte der Geraden je einen Kreisbogen; wo sich beide Kreisbogen schneiden, ist die Spitze des zu konstruierenden gleichschenkeligen Dreiecks. Neigungswinkel der Platten sowie Gaumenhöhe können sofort abgelesen oder berechnet werden.

Weiterhin kann von Interesse sein, den Umfang des Gaumenbogens zu kennen. In den Fällen von durchgehender Spaltbildung habe ich diese Größe dadurch bestimmt, daß ich Breite der rechten Gaumenplatte, Entfernung der Gaumenplattenränder und Breite der linken Gaumenplatte addierte. Die so erhaltenen Zahlen sind recht genaue und stehen mit den aus direkter Messung mittels Bandmaßes erhaltenen Resultaten im Einklang.

Bei normalen Kiefern läßt sich der Umfang des Gaumenbogens leicht durch direkte Messung am Gipsmodell mittels eines schmalen, biegsamen Bandmaßes feststellen.

Bequemer ist es, die Breite der einen Gaumenplatte mittels Tasterzirkels zu messen und die erhaltene Zahl mit 2 zu multiplizieren. Bei dieser Art Messung wird ja allerdings dem Umstande nicht Rechnung getragen, da $\beta$ die Gaumenplatten keine ebenen, sondern leicht gebogene Flächen darstellen, so daß die Zahlen, die man bei dieser Art des Vorgehens erhält, eine Idee zu klein werden.

Die genauesten, am besten miteinander übereinstimmenden Größenangaben bezüglich Umfang des Gaumenbogens, Gaumenhöhe und Neigungswinkel der Gaumenplatten wird man für normale Kiefer auf rechnerischem Wege erhalten. Durch die drei Spitzen des gleichschenkeligen Dreiecks läßt sich nämlich stets ein Kreis legen; der über den beiden Seiten des Dreiecks liegende Kreisausschnitt deckt sich ziemlich genau mit dem Umfang des Gaumenbogens und läßt sich - ebenso wie die übrigen gesuchten Größen - aus der Länge der Dreiecksbasis und der Länge der beiden Seiten berechnen.

Diese Messungen an normalen Kiefern mußte ich vornehmen, um Vergleichswerte für unsere an Kiefern mit Gaumenspalte 
gewonnenen Messungsresultate zu bekommen. Es ist mir nicht bekannt geworden, auch nicht aus dem Studium der zahnärztlichen Literatur, daß solche für unsere $Z$ wecke erforderlichen Größenbestimmungen an normalen Kiefern in der Literatur niedergelegt sind. Insbesondere habe ich zahlreiche (über 150) $^{\circ}$ solche Messungen an Kiefergipsabdrücken von Säuglingen im Alter von wenigen Stunden bis zu einem Jahr - gemacht. Ungefähr dieselbe Anzahl von Kiefergipsabdrücken wurde von Kindern im Alter von I bis I 4 Jahren angefertigt. Die im folgenden als Normalwerte angegebenen Zahlen beziehen sich auf die an den eben genannten Modellen vorgenommenen Messungen.

„,Durchgehende Gaumenspalten“ und ,nicht durchgehende Gaumenspalten" wurden getrennt behandelt, entsprechend den wichtigen anatomischen Unterschieden zwischen den beiden Gruppen der Mißbildung. Im Vordergrunde des Interesses stehen natürlich die an den Fällen von „durchgehender Spalte“ erhobenen Befunde; ich beginne deshalb mit der Analyse der in Tabelle I angeführten Fälle.

GröBter Abstand der Alveolarfortsätze.

Das Alter dieser Patienten bewegte sich zwischen einem Tag und I6 Monaten. Diesen jeweiligen Altersunterschieden entsprachen die Schwankungen bezüglich Körpergewicht und Körpergröße. Analog den bekannt verschieden großen Distanzen der Alveolarfortsätze gleichaltriger, normaler Individuen, ergab sich auch bei meinen Messungen an Kindern mit durchgehender Gaumenspalte, daß nicht der jüngste oder körperlich am wenigsten entwickelte Patient die kleinste, der älteste und kräftigste aber etwa die größte Distanz der Alveolarfortsätze aufwies; vielmehr war der Patient mit 3,6 cm gegenseitigem Alveolarabstand ein sehr kräftiges, 8 Monate altes Kind, während mehrere $\mathrm{Pa}$ tienten mit 4,2 cm Alveolardistanz im Alter von $4 \frac{1}{2}, 5$ und I $1 / 2$ Monaten körperlich absolut und relativ weniger entwickelt waren, als der erstgenannte Patient. Es handelte sich also zunächst darum, nachzuweisen, innerhalb welcher Grenzen die Distanz der Alveolarfortsätze bei ,gesunden“ Säuglingen schwankte. Zu diesen Zwecke habe ich an Kindern im Alter von I Tag bis I Jahr die mittlere Größe des Alveolarabstandes für jeden der 
ersten 12 Lebensmonate berechnet; aus den so erhaltenen Zahlen wurde dann die durchschnittliche Distanz der Alveolarfortsätze bei Kindern im ersten Lebensjahre bestimmt. Die Differenz in den Alveolarabständen des ersten und des I2. Lebensmonats betrug $0,6 \mathrm{~cm}$; als durchschnittlichen, normalerweise größten Abstand der Alveolarfortsätze erhielt ich für das erste Lebensjahr die Zahl 3,13. Demnach dürfen wir Alveolarabstände bei Säuglingen mit Differenzen bis zu o,6 cm als „normale“ oder innerhalb physiologischer Grenzen schwankende bezeichnen; damit soll aber nicht auch gesagt sein, daß eine beispielsweise um I $\mathrm{mm}$ größere Schwankung schon eine pathologische Kieferbildung verrate.

Bei den Fällen mit durchgehender Gaumenspalte differierten die entsprechenden Zahlen - wie erwähnt - ebenfalls um $0,6 \mathrm{~cm}$; sie schwankten aber in einer erheblich höheren Breite, nämlich zwischen $3,6 \mathrm{~cm}$ als minimalstem und $4,2 \mathrm{~cm}$ als maximalstem Abstand der Alveolarfortsätze.

Die Berechnung des Mittelwertes für den Alveolarabstand der in Tabelle I angeführten Fälle ergibt die Zahl 3,9 cm. Daraus folgt: „Der gröBte Abstand der Alveolarfortsätze ist bei im ersten Lebensjahre stehenden Kindern mit durchgehender Gaumenspalte durchschnittich $0,8 \mathrm{~cm}$ größer als bei gleichalterigen Kindern mit normalem Oberkiefer."

\section{Breite der Gaumenplatten.}

Von Wichtigkeit ist die Frage, wie es sich bei durchgehender Gaumenspalte verhält bezüglich der Breite der Gaumenplatten. Mit der Beantwortung dieser Frage erfahren wir, ob die Spalte durch eine eventuelle geringe Breite der einen oder beider Gaumenplatten ganz oder teilweise ursächlich zu erklären sei. Diese Vermutung ist schon wiederholt geäußert worden, während meines Wissens eine übermäßig große Breite der Gaumenplatten bei durchgehenden Spaltbildungen des Oberkiefers noch nicht behauptet wurde. In Tabelle I ist diese Frage schon beantwortet; wir brauchen nur die Durchschnittswerte zu berechnen. Die richtigen Werte erhalten wir in diesem Falle aber nicht dadurch, daß wir lediglich die rechte Gaumenplattenbreite mit der linken 
vergleichen, wir müssen vielmehr bei den Fällen einseitig durchgehender Spalte stets die Seite der Spalte der ,gesunden“ Seite, d. h. der nicht gespaltenen Seite gegenüberstellen. Für die Fälle doppelseitig durchgehender Spalte fällt diese Maßregel weg; in diesen Fällen sind beide Platten gewöhnlich gleich breit.

Unter Zugrundelegung der in Tabelle I verzeichneten Fälle erhalten wir (unter Weglassung des Falles 2)

I. als Gaumenplattenbreite der Spaltseite I,76 cm,

als Gaumenplattenbreite der nicht gespaltenen Seite $1,9 \mathrm{~cm}$,

2. als Gaumenplattenbreite normaler Oberkiefer gleichalteriger Kinder erhalten wir $\mathrm{r}, 82 \mathrm{~cm}$,

d. h.: „Summe der Gaumenplattenbreiten bei Spaltung des Oberkiefers $(3,66 \mathrm{~cm})=$ der Summe der Gaumenplattenbreiten des normalen Oberkiefers",

oder mit anderen Worten:

„Bei einseitig durchgehender Gaumenspalte sind die Gaumenplatten von normaler Breite, somit an der Spaltbildung hinsichtlich ihrer Breite nicht ursächlich beteiligt."

Neigungswinkel der Gaumenplatten.

Diese werden in der oben beschriebenen Weise bestimmt und sind zu beziehen auf eine durch den Alveolarfortsatz gelegte vertikale Ebene. Nicht Neigungswinkel der rechten und linken Seite, sondern der Spaltseite und der nicht gespaltenen Seite sind in Parallele zueinander zu setzen. Die durch direkte Messung (vgl. Fig. 23) erhaltenen Zahlen sind auf 5 bzw. o auf- oder abgerundet, je nachdem die am Winkelmesser abgelesene Zahl dieser oder jener Endung näher lag.

Auf diese Weise erhielt ich:

I. als Neigungswinkel der nicht gespaltenen Seite $50^{\circ}$,

2. als Neigungswinkel der gespaltenen Seite $43^{\circ}$,

3. als Gaumenplatten-Neigungswinkel im I. Lebensjahr unter normalen Kieferverhältnissen dagegen ergab sich ein Winkel von $5^{\circ}$.

Die seit langem von verschiedenen Autoren vertretene Ansicht, daß bei Gaumenspalte eine vermehrte Steilstellung der 
Gaumenplatten vorhanden sei, besteht somit für die Fälle durchgehender Gaumenspalte zu Recht.

Wie die Zahlen lehren, ist die Steilstellung der Gaumenplatte der Spaltseite eine entschieden ausgesprochenere als auf der andern Seite. Aber auch die Gaumenplatte der nicht gespaltenen Seite steht steiler als die normale Gaumenplatte. Unter den von mir untersuchten Säuglingskiefern bewegten sich die Neigungswinkel der Gaumenplatten zwischen 45 und $65^{\circ}$. Bei Gaumenspalten dagegen, wie die Tabelle I zeigt, zwischen 35 und $55^{\circ}$.

Hier wie dort beträgt also die Schwankungsbreite ca. $20^{\circ}$. Sie bewegt sich aber bei Gaumenspalten in höheren Breiten.

Die Gaumenplatte der nicht gespaltenen Seite steht demnach durchschnittlich ungefähr $8^{\circ}$, die Gaumenplatte der Spaltseite aber ungefähr $15^{\circ}$ steiler als dic Gaumenplatte eines normalen Kiefers.

Spaltbreite und Spaltform.

Da uns jetzt auf Grund der bisherigen Messungen Abstand der Alveolarfortsätze, Breite und Neigungswinkel der Gaumenplatten bekannt sind, so können wir uns die Spaltbreite - in derselben frontalen Ebene, in der die Breite der Gaumenplatten gemessen wurde - leicht konstruieren. Die im folgenden angegebenen Maße beziehen sich jedoch auf direkte Messungen der Spalte mittels Tasterzirkels und bezeichnen den jeweils größten Abstand der Gaumenplattenränder voneinander.

Bei Fällen von doppelseitig durchgehender Spalte kann über den Begriff „Spaltbreite“ eine verschiedene Auffassung nicht bestehen, insofern eben hierunter nur der Abstand der Gaumenplattenränder voneinander verstanden werden kann. Anders liegen die Verhältnisse in den Fällen nur einseitig durchgehender Spalte. Bei dieser Form der Spaltbildung sind: Abstand der Gaumenplattenränder und eigentlicher Spalt durchaus keine synonymen Begriffe. Denn gewöhnlich hat sich in diesen Fällen der Rand der einen Gaumenplatte vollkommen mit dem Vomerrand der betreffenden Seite vereinigt, so daB Gaumenplatte und Vomer zusammen einen Teil des Mundhöhlendaches bilden. Nur an der verschiedenen Färbung der Gaumenplatte und Vomer überziehenden Schleimhaut läßt sich bei einfacher Inspektion die Grenze 
zwischen beiden ziehen. Eine strenge Unterscheidung zwischen Abstand der Gaumenplattenränder und eigentlichem Spalt ist aber unbedingt notwendig, da wir bei dem operativen Verschluß der "Gaumenspalte“ den Schleimhautüberzug des Vomer gewöhnlich nicht verwenden können und deshalb bei Außerachtlassen der genannten Unterscheidung die „Spalte“ viel zu eng taxieren würden; dieser Irrtum wäre um so größer, je horizontaler und je breiter der Vomer im einzelnen Fall entwickelt ist. Am besten werden diese Verhältnisse illustriert durch Fig. 24.

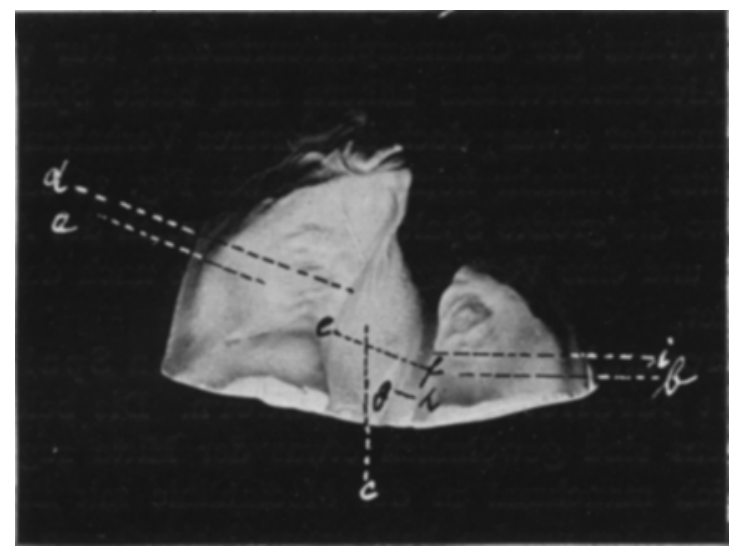

Fig. 24. a) rechte Gaumenplatte, b) linke Gaumenplatte, c) Vomer, d) Grenze vom rechten Gaumenplattenrand und Vomer, i) linker Gaumenplattenrand, ef) Entfernung der Gaumenplattenränder =absolute Spaltbreite, gh) eigentlicher Spalt im engeren Sinn = relative Spaltbreite.

Der Kürze und Präzise des Ausdrucks halber schlage ich deshalb vor, für beide Begriffe besondere Benennungen einzuführen, und den Abstand der Gaumenplattenränder als ,absolute Spaltbreite", den Spalt im engeren Sinne dagegen als „,relative Spaltbreite“ zu bezeichnen.

Wie aus Tabelle I hervorgeht, schwankt die absolute Spaltbreite in ziemlich weiten Grenzen, nämlich zwischen I und $1,7 \mathrm{~cm}$. Die absolute Spaltbreite ist abhängig von der Entfernung der Alveolarfortsätze einerseits, der Breite und dem Neigungswinkel der Gaumenplatten andererseits. Uns ein richtiges Bild von dem Charakter der Spaltbildung und besonders auch von den technischen Schwierigkeiten einer operativen Behandlung zu geben, 
dazu ist allein geeignet die absolute Spaltbreite. Die relative Spaltbreite ist abhängig von der absoluten Spaltbreite einerseits, von der Breite und Stellung des Vomer andererseits. Nur Gaumenplatten und Vomer beteiligen sich an der Bildung des Daches der Mundhöhle; die über oder besser gesagt in der relativen Spalte an der Schädelbasis liegenden Teile können nicht zum Mundhöhlendach gerechnet werden.

Hinsichtlich der Form der absoluten Spalte beobachten wir bei den durch äußere Eingriffe irgendwelcher Art noch nicht beeinflußten Fällen von durchgehender Spalte einen annähernd parallelen Verlauf der Gaumenplattenränder. Nur vorn im Bereich des Alveolarfortsatzes nähern sich beide Spaltränder gewöhnlich einander etwas; doch ist letzteres Verhalten keineswegs ein konstantes; vielmehr kommen - wie Fig. 36 zeigt - auch Fälle vor, wo die größte Spaltbreite im Bereich des Alveolarfortsatzes liegt, und eine Verjüngung der Spalte nach dem Zäpfchen zu stattfindet.

Die „normale Form“ der absoluten Spalte jedoch ist die mit parallelen Spalträndern. Die beiden Hälften des Zäpfchens sind gewöhnlich etwas der Mitte zugekehrt und berühren sich manchmal in der Medianlinie mit ihren Enden. Wie wir noch sehen werden, hat letztere Beobachtung eine gewisse Bedeutung; ich werde bei der Besprechung des Einflusses der Hasenschartenoperation auf die Konfiguration der Spalte hierauf noch zu sprechen kommen.

Die Konfiguration der relativen Spalte ist abhängig von dem Verhalten des Vomer. Bei der außerordentlichen Verschiedenheit desselben hinsichtlich Neigung, Breite und Form ergeben sich entsprechend mannigfaltige Unterschiede in der relativen Spaltform; praktisch kommt jedoch weder der Breite noch der Form der relativen Spalte eine Bedeutung zu, da wir sowohl bei der Langenbeckschen Behandlungsmethode als auch bei den neueren Annäherungsmethoden nur mit der absoluten Spaltbreite rechnen bzw. rechnen sollten. Soweit die Spalte im Bereich des Alveolarfortsatzes liegt, kommt auch dem Zwischenkiefer eine große Bedeutung bezüglich Breite und Form dieses Teils der Spalte zu. Nach dem Gesagten kann man hier nur von einer absoluten Spaltbreite sprechen. 
Vomer.

Auch das Verhalten des Vomer ist - wie erwähnt ein außerordentlich wechselndes. Regelmäßig aber beobachten wir eine auffallende Verbreiterung desselben; besonders auffallend ist diese in den Fällen einseitig durchgehender Spalte; in den Fällen doppelseitig durchgehender Spalte dagegen verläuft - wie Langenbeck schreibt - ,der Vomer gewöhnlich als roter rundlicher Balken von hinten nach vorn mitten durch den Oberkieferspalt und ist vorn mit einem rundlichen Knoten oder Wulst den völlig isoliert stehenden Ossa intermaxillaria verbunden". Die Schleimhaut des Vomer ist leicht von der Gaumenschleimhaut zu unterscheiden; sie ist dünner und sitzt der Unterlage fester auf, als dies bei den Gaumenplattenüberzügen der Fall ist. Nach vorn geht der Vomer in den freistehenden (doppelseitig durchigehende Spalte) oder den mit dem Alveolarbogen der einen Seite verbundenen Zwischenkiefer über. Das häufig beobachtete Vorstehen des Zwischenkiefers in den Fällen doppelseitig durchgehender Spalte führt Langenbeck auf ein exzessives Längenwachstum des Vomer zurück. Die Formverschiedenheiten des Vomer werden am besten durch die $\mathrm{Ab}$ bildungen der oben angeführten Gaumenspalttypen demonstriert.

\section{$Z$ wischenkiefer.}

Der Zwischenkiefer präsentiert sich in den Fällen doppelseitig durchgehender Spalte als weit in der Sagittalebene vorspringender, seitlich mehr oder weniger leicht beweglicher Pürzel. Der diesem aufliegende Oberlippenteil ist oft nur von geringen Dimensionen. In den häufigeren Fällen einseitig durchgehender Spalte ist der Zwischenkiefer mit dem Alveolarfortsatz der einen Seite verbunden; diese Verbindung ist im allgemeinen eine um so festere und vollkommenere, je älter das betreffende Individuum ist. Schon kurze Zeit post partum ist die Grenze von Zwischenkiefer und Alveolarfortsatz der betreffenden Seite nicht mehr deutlich zu erkennen, läßt sich aber mit Hilfe der Röntgenstrahlen leicht feststellen. Wie weit im einzelnen Falle diese Vereinigung von Zwischenkiefer und Alveolarfortsatz fortgeschritten ist, gewinnt praktische Bedeutung 
bei der beabsichtigten Verschließung der Alveolarspalte mit Hilfe der Hasenschartenoperation.

\section{Umfang des Gaumenbogens.}

Der Umfang des Gaumenbogens ist abhängig von der Entfernung der Alveolarfortsätze, dem Neigungswinkel und der Breite der Gaumenplatten. Somit setzt sich der Gaumenbogenumfang bei durchgehender Spalte zusammen aus der Summe der Breite beider Gaumenplatten + absoluter Spaltbreite. Wie oben sich ergeben hat, sind die Gaumenplatten bei durchgehender Spalte von normaler Breite; bekannt ist ferner die durchschnittliche Spaltbreite; addieren wir also letztere zum durchschnittlichen Umfang normaler Gaumenbogen, so müssen wir ungefähr die aus Tabelle I zu berechnende Durchschnittszahl für den Gaumenumfang erhalten.

Die Fälle nicht durchgehender Spaltbildung sind in Tabelle II angeführt; Fall $\mathrm{I}-4$ betrifft Patienten, die noch im ersten Lebensjahre stehen, während sich die übrigen Fälle auf verschiedene Lebensalter verteilen.

Den nicht so hochgradigen anatomischen Veränderungen bei nicht durchgehender Gaumenspalte entsprechen die sich mehr den normalen Verhältnissen nähernden Zahlen der Tabelle II. Soweit Abweichungen von den normalen Verhältnissen bestehen, sind sie den für die durchgehenden Spalten beschriebenen analog; ich kann mich deshalb nach dem Gesagten darauf beschränken, auf Tabelle II zu verweisen.

\section{Die unter dem Einfluß der vereinigten Oberlippe sich vollziehenden anatomischen Veränderungen der Spaltbildung.}

Bevor ich im Einzelnen auf die Veränderungen eingehe, welche sich unter dem Einfluß des durch die Hasenschartenoperation erzeugten Lippendruckes an dem gespaltenen Oberkiefer vollziehen, muB ich noch einige Bemerkungen über die Hasenschartenoperation selbst vorausschicken. Welche von den zahlreichen Methoden im einzelnen Falle Anwendung findet, ist in bezug auf die im folgenden zu erörternden Verhältnisse nicht von ausschlaggebender Bedeutung. Persönlich habe ich 
nach Mirault-Langenbeck, nach Wolff, nach Hagedorn und nach Malgaigne operiert; alle diese und andere Methoden führen dieselben typischen Veränderungen der Spaltbildung herbei, vorausgesetzt, daß die Operation gelungen, d.h. die Lippenspalte durch dieselbe beseitigt wurde. Als unmittelbare Folge der Operation ist allen genannten Methoden gemeinsam eine mehr oder weniger starke Spannung der Oberlippe. Diese Spannung, die wir therapeutisch verwerten können und müssen, hat eine doppelte Ursache. Einmal hat nämlich an sich schon ein Defekt der Oberlippe vorgelegen, der durch die unvermeidliche „Anfrischung" der Lippenspaltränder noch vergrößert wurde, und andererseits muß die neue Oberlippe noch einen verschieden großen Spalt im Alveolarfortsatz überbrücken. Besonders von der Beschaffenheit dieser Kieferspalte, näherhin von deren Breite hängt der Grad der postoperativen Lippenspannung ab. Daß dem so ist, geht am deutlichsten daraus hervor, daß nach Schluß einer Lippenspalte - auch einer III. Grades — ohne das gleichzeitige Vorhandensein einer Spalte im Alveolarfortsatz — die Spannung der Lippe gleich null, oder doch nur eine minimale ist. Sie entspricht eben lediglich der Größe des in der Oberlippe vorhanden gewesenen Defekts und kann somit bei der außerordentlich großen Beweglichkeit der Oberlippe praktisch kaum in Betracht kommen. Da wir also beabsichtigen, die durch die Hasenschartenoperation erzeugte Lippenspannung bestimmten Zwecken nutzbar zu machen, so werden wir natürlicherweise von den verschiedenen Lippen-Entspannungsmethoden nur so weit Gebrauch machen, als es im Interesse einer sicheren Heilung der vereinigten Wundränder erforderlich erscheint. Niemals benützen wir äußere Entspannungsschnitte. Ausdrücklich soll aber hervorgehoben werden, daß weniger die eigentliche Lippenspannung, als vielmehr das Gewicht der neugebildeten, nunmehr auf dem Oberkiefer lastenden Oberlippe die causa movens für die nach der Hasenschartenoperation im Bereich der Spaltbildung sich vollziehenden Veränderungen darstellt.

Nur auf ein — von den übrigen Lippen-Entspannungsmethoden prinzipiell verschiedenes - Vorgehen soll mit wenigen Worten hingewiesen werden. Ich meine das Neumannsche Verfahren. Dieses ist von den übrigen Entspannungsmethoden 
insofern prinzipiell verschieden, als es am Knochensystem angreift. Neumann hat eine metallene Klammer konstruiert, mittels welcher er bei Hasenscharte III. Grades und durchgehender Gaumenspalte eine vorübergehende, mehr oder minder starke Verkleinerung bzw. auch vollständige Verschließung der Alveolarspalte erreicht. Wenn die Klammer liegt, gelingt es sodann die Wundränder der Lippenspalte nahezu ohne Spannung zu vereinigen. Die Klammer bleibt 3-4 Tage liegen; während dieser Zeit soll die Verklebung der Wundränder eine so feste geworden sein, daß ein Aufgehen der Naht nicht mehr zu be-

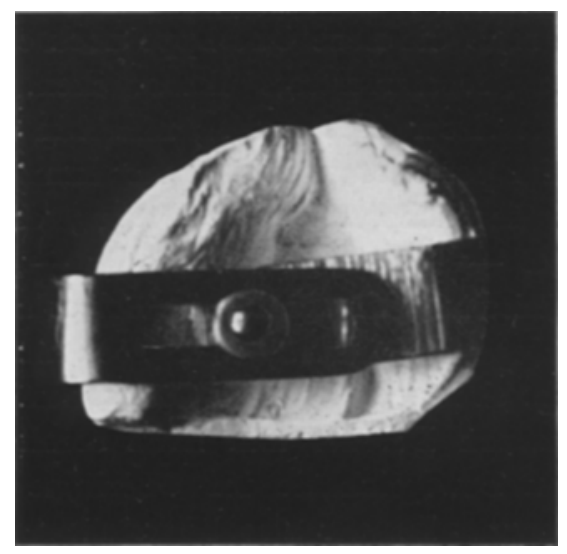

Fig. 25.

fürchten sei. Nach Entfernung der Klammer federn die aneinandergedrängt gewesenen Teile wieder mehr oder weniger in ihre frühere Lage zurück.

Fig. 25 ist schematisch und soll die Lage der Neumannschen Klammer an einem Gaumenspalten-Gipsmodell veranschaulichen. Ich selbst habe die Neumannsche Klammer nie benötigt, habe sie aber zum Zwecke des Versuches wiederholt verwendet. In einem Falle (Fig. I3), in welchem ich eine schon (von and. Seite) operierte, aber ausgerissene Hasenscharte III. Grades mit weit klaffender Alveolarspalte zu operieren hatte, hat mir die Klammer gute Dienste geleistet. Die Anwendung der Klammer ist aber $\mathrm{m}$. E. nicht ganz ohne Belang für den Patienten. Einmal werden doch - eigentlich vermeidbare - Wunden in dem Weichteilüberzug des 
Alveolarfortsatzes gesetzt, und dann scheint mir die Gefahr einer Verletzung von Zahnkeimen durch die scharfen Zacken der Klammer nicht ausgeschlossen zu sein. Dazu kommt, daß, solange die Klammer liegt, der Patient in hohem Maße durch dieselbe belästigt wird. Aus diesen Gründen verwende ich die Klammer nur in seltenen Ausnahmefällen.

Betrachtet man das Gipsmodell einer durch den Processus alveolaris gehenden Gaumenspalte, so gewinnt man den Eindruck, daß von den verschiedenen Teilen des gespaltenen Oberkiefers verhältnismäßig am leichtesten die Ränder der Alveolarspalte aneinander zu bringen sein dürften. Diese beiden Knochenteile ragen frei nach vorn hervor, der durch die Hasenschartenoperation erzeugte Lippendruck muß sich aus anatomischen Gründen in erster Linie auf diese Teile des Oberkiefers erstrecken.

In Wirklichkeit ist die durch die einfache Hasenschartenoperation gewonnene Kraft eine sehr bedeutende. Sie ist in mehrfacher Beziehung weit überlegen den Kraftquellen, auf welche der Orthodont bei seinen Kieferregulierungen angewiesen ist. Zwar werden auf orthodontischem Wege imponierende anatomische Veränderungen, wie Kieferdehnungen, Verschiebungen von Zähnen um mehrere Millimeter u.a. erreicht, mit Hilfe von Gummizügen, Schrauben- oder Federwirkung. Alle diese Maßnahmen aber setzen voraus, daß Zähne durchgebrochen sind, sind also nicht anwendbar gerade in dem Alter, in welchem die Knochen in ihrer gegenseitigen Lage noch am leichtesten zu beeinflussen sind, und in welchem die Korrektur der in Rede stehenden Mißbildung aus mehrfachen Gründen dringend geboten erscheint. Für den Chirurgen liegen die Verhältnisse günstiger als für den Orthodonten; er hat gewöhnlich seine Korrektur — soweit beabsichtigt - beendet, bevor die Zähne zum Durchbruch gekommen sind. Abgesehen von der Größe der Kraft, die wir durch die Vereinigung der Lippenspalte gewonnen haben, und abgesehen davon, daß wir nicht erst das Hervorbrechen der Zähne abwarten müssen, vielmehr schon in den ersten Lebenswochen bzw. Monaten auf den gespaltenen Oberkiefer einwirken können, bietet uns die einfache Lippenvereinigung im Vergleich zu den orthodontischen Methoden noch einen weiteren Vorteil von größter Tragweite, 
nämlich den, daß wir die durch die Hasenschartenoperation gewonnene Kraft direkt auf den Oberkiefer selbst einwirken lassen können, während der Orthodont den Angriffspunkt seiner Kraftquelle auf die Zähne verlegen muß. Mit Hilfe der Hasenschartenoperation kann daher ein Verschluß der Alveolarspalte erreicht werden, ohne daß zugleich eine Drehung der Alveolarfortsätze um eine sagittale Achse erfolgt, wie es bei Anwendung der orthodontischen Methode der Fall sein müßte. Helbing hat sich in Ausnahmefällen der orthodontischen Methode bedient zum Zweck einer temporären Verschmälerung des gespaltenen Oberkiefers in frontaler Richtung. Angriffspunkte der wirksamen Kraft waren die Backzähne, Kraftquelle ein Schraubengewinde. Die bei diesem Vorgehen gemachte Beobachtung Helbings, „daß eine dabei erreichte, gewisse Verschmälerung der Spalte nicht Hand in Hand geht mit der Annäherung der Oberkieferhälften, ist aus dem genannten Grunde verständlich und wird von $\mathrm{Hel}$ bing selbst damit erklärt, daß die Oberkiefer eine Drehung um eine sagittale Achse erfahren. Diese Drehung der Oberkiefer um eine sagittale Achse ist nach meiner Ansicht darauf zurückzuführen, daß bei der orthodontischen Methode die Angriffspunkte der wirksamen Kraft zu tief liegen.

Persönlich möchte ich bezweifeln, ob bei der genannten Methode überhaupt eine Verschmälerung der Spalte im Gaumen eintritt; jedenfalls habe ich bei ähnlichen Versuchen sogar eine - wenn auch minimale - Erweiterung der Spalte beobachten können. Nimmt man eine durch die Einwirkung der orthodontischen Apparate bedingte Hebelwirkung an, so läßt sich eine Erweiterung der Spalte damit ohne weiteres erklären. Die Drehungslinie des Hebels ist die genannte Sagittale (Fig. 26).

Auf Grund einfacher, physikalischer Gesetze tritt demnach - auf den praktischen Fall übertragen - Annäherung der Alveolarfortsätze mit Erweiterung der Spalte ein bei Einwirkung der Kraft unterhalb der Höhe der Sagittalen, parallele Annäherung der Alveolarfortsätze bei Einwirken der Kraft in der Höhe der Sagittalen selbst, Verschmälerung der Spalte und Auseinanderweichen der Alveolarfortsätze aber, wenn die Kraft oberhalb der Höhe der Sagittalen einwirkt. Es braucht wohl nicht besonders betont $\mathrm{zu}$ werden, daß in Wirklichkeit die Verhältnisse 
kompliziertere sind; es soll deshalb mit diesen Sätzen nur die im allgemeinen gültige Grundregel gekennzeichnet sein. Diese ist auch in all den Fällen gewahrt, in welchen mit einer starken Verkleinerung des Abstandes der Alveolarfortsätze eine absolute Verengerung der Spalte - die aber der gegenseitigen Annäherung der Alveolarfortsätze nicht entspricht - einhergeht: In solchen Fällen hat sich die wirksame Kraft in verschiedener Höhe geltend gemacht (Lippendruck nach Hasenschartenoperation). Vorausgreifend will ich noch erwähnen, daß3 die Langenbecksche Operation sehr wohl durch eine vorausgeschickte Annäherung der Alveolarfortsätze erleichtert werden

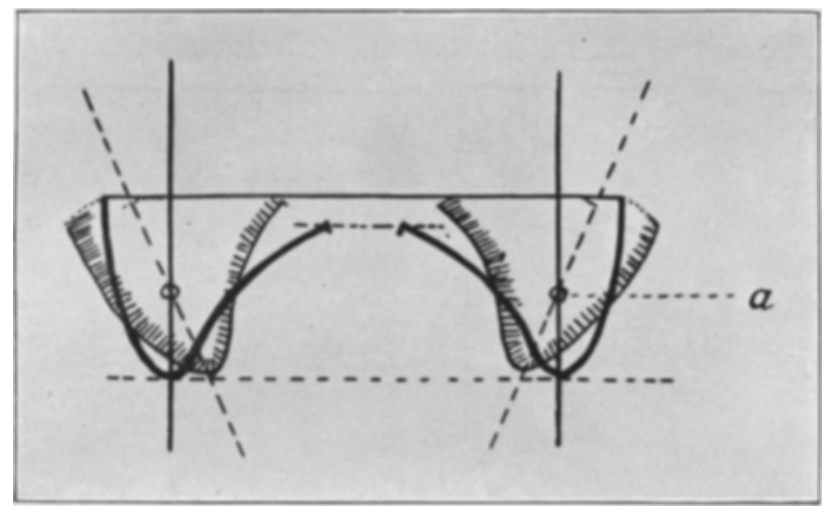

Fig. 26. (Schema.) a) Sagittale.

kann - wenigstens hinsichtlich der Vereinigung der Lappen --, auch wenn mit derselben eine Verbreiterung der Spalte einhergegangen sein sollte. Denn die Basis der abgelösten Lappen liegt ziemlich tief an den Alveolarfortsätzen und die Lappen selbst rücken in eine erheblich horizontalere Stellung.

Die sagittale Drehungslinie des genannten Hebels hat man sich, wie Fig. 26 zeigt, etwa in mittlerer Höhe zwischen Zahnkrone bzw. Limbus alveolaris, solange Zähne noch nicht vorhanden sind, einerseits, und Spalträndern andererseits zu denken.

Wenn auch früher schon bekannt und besonders auch von Langenbeck beobachtet worden war, daß bei Gaumenspalten nach Ausführung der Hasenschartenoperation eine Verschmäle- 
rung der Alveolarspalte eintreten kann, so war es mir bei meinen hierauf sich erstreckenden Untersuchungen vor allem darum zu tun, nachzuweisen, inwieweit und ob mit Regelmäßigkeit eine solche Verschmälerung der Spalte eintrete. Ich nehme das interessante Ergebnis meiner Untersuchungen voraus, und stelle den Satz auf:

„Durch eine in den ersten Lebensmonaten ausgefühte und gelungene Operation einer Hasenscharte III. Grades läBt sich in Fällen einseitig durchgehender Gaumenspalte die Alveolarspalte ungefähr innerhalb eines Zeitraums von $1 / 2{ }^{3 / 4}$ Jahren regelmäßig schließen."

Die Abbildungen Fig. 27a-34b sollen die Einwirkung der vereinigten Oberlippe auf den Spalt im Alveolarfortsatz demonstrieren.

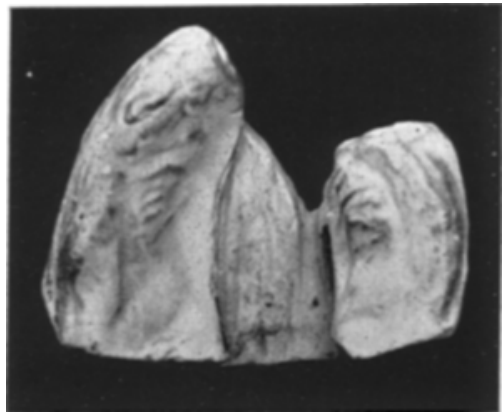

Fig. 27 a.

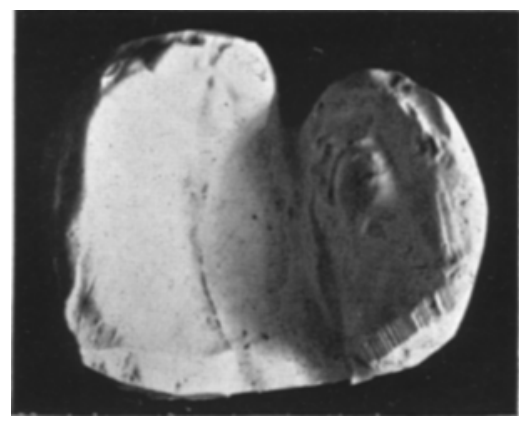

Fig. $27 \mathrm{~b}$.

Fig. 27a. 1I $1 \frac{1}{2}$ Monate alter Knabe. Hasenscharte III. Grades links. Fig. 27b. Derselbe Fall 4 Monate nach der Operation der Hasenscharte.

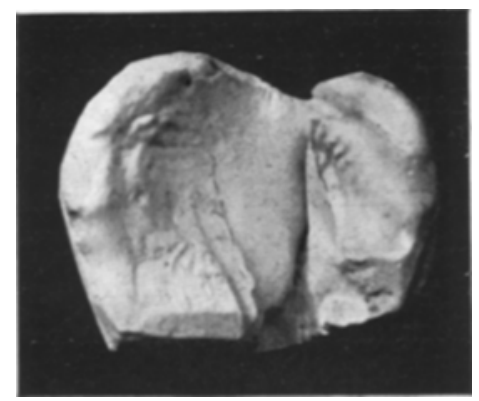

Fig. $28 \mathrm{a}$,

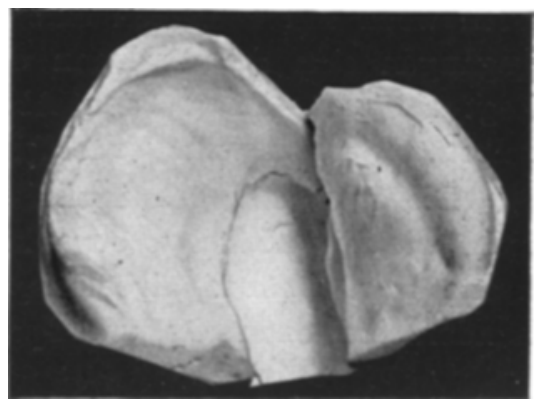

Fig. $28 \mathrm{~b}$.

Fig. 28 a. 2 Monate alter Knabe. Hasenscharte III. Grades links.

Fig. 28b. Derselbe Fall to Monate nach der Operation der Hasenscharte. 
Die Einwirkung der vereinigten Oberlippe auf den Spalt im Alveolarfortsatz äußert sich demnach dadurch', daß die Spalte ganz allmählich enger und enger wird, bis sich schließlich beide

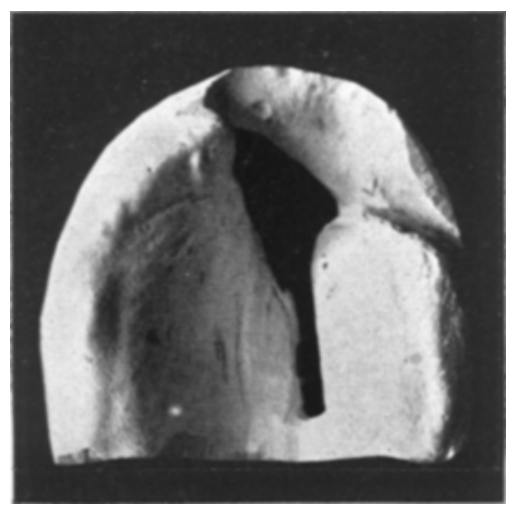

Fig. 29a.

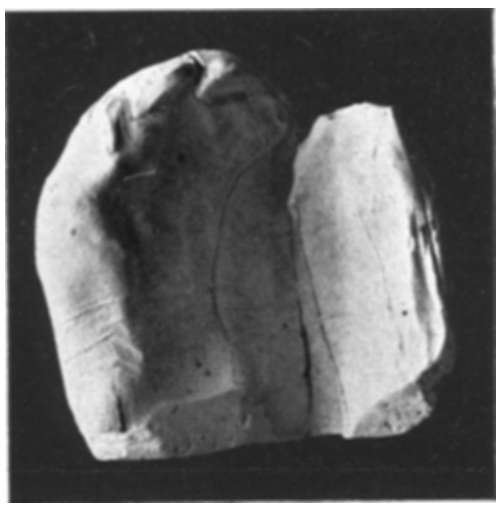

Fig. $29 \mathrm{~b}$.

Fig. 29a. Kieferabdruck eines 7 Monate alten Mädchens.

Fig. 29 b. Kieferabdruck dess. Kindes, ca. Io Mon. nach d. Hasenschartenoperation.

Seiten vollkommen berühren. Dabei rundet sich der Alveolarbogen in seinem vorderen Umfang mehr und mehr ab, die Form des Kiefers nähert sich stetig den normalen Verhältnissen. Auf welche Weise kommt nun dieser Verschluß der Alveolarspalte

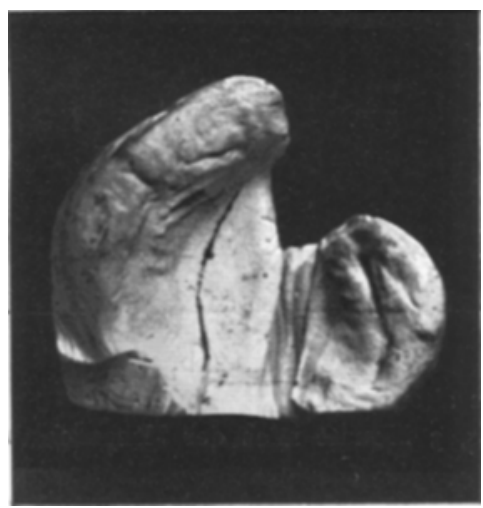

Fig. 30a.

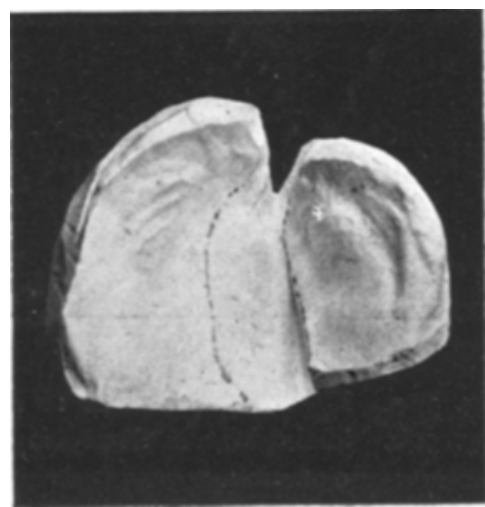

Fig. 3ob.

Fig. 30 a. Kieferabdruck eines I Monat alten Knaben.

Fig. 3ob. Kieferabdruck desselben Kindes, 4 Monate nach der Hasenschartenoperation. 
zustande? Bewegen sich beide Oberkieferhälften mit ihren $\mathrm{Al}$ veolarfortsätzen gleichmäßig nach der Mittellinie hin bis zur

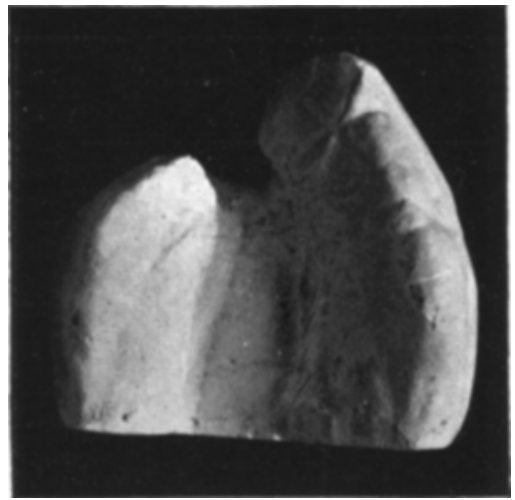

Fig. 3 I a.

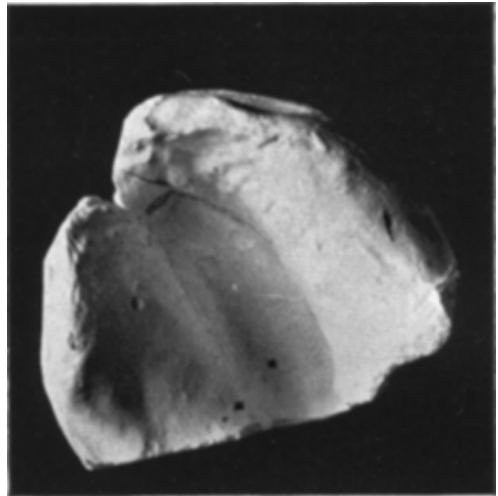

Fig. 3i b.

Fig. 3I a. Kieferabdruck eines ca. I6 Monate alten Mädchens.

Fig. 3I b. Kieferabdruck desselben Kindes I4 Tage nach der Hasenschartenoperation.

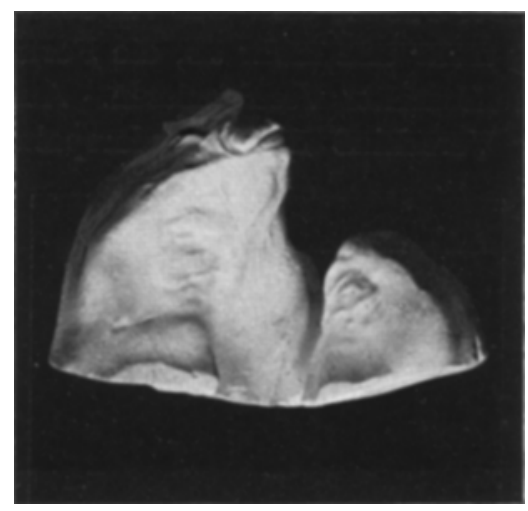

Fig. 32 a.

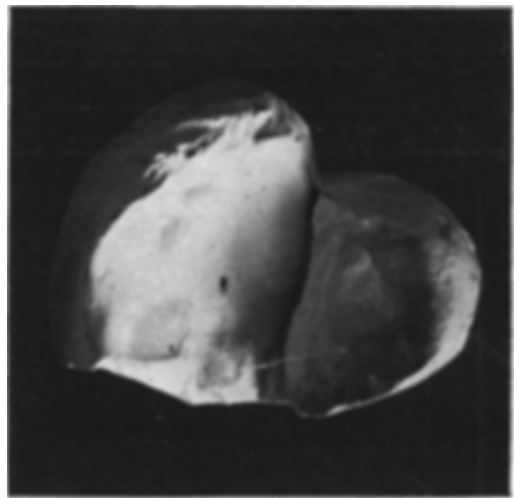

Fig. $32 \mathrm{~b}$.

Fig. $3^{2}$ a. Kieferabdruck eines I I Monate alten Knaben.

Fig. 32b. Kieferabdruck desselben Kindes, 3 Monate nach der Hasenschartenoperation.

gegenseitigen Berührung? Oder beruht der SpaltschluB auf der Lageveränderung des einen Oberkieferteils, und welches? Um diese Fragen zu beantworten, werfen wir zunächst einen Blick 
auf die Tabelle I, und zwar auf die Rubriken „Alveolarfortsatz, Zwischenkiefer". Wir ersehen aus diesen, daß in allen Fällen

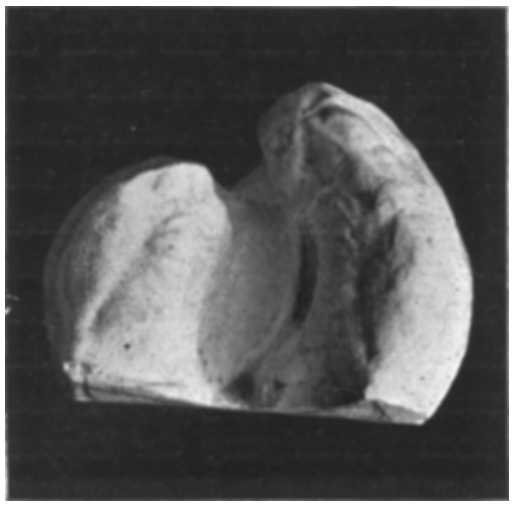

Fig. 33 a.

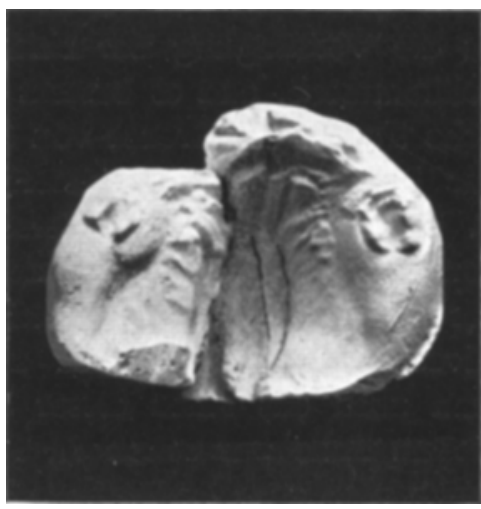

Fig. 33b.

Fig. 33 a. Kieferabdruck eines 8 Monate alten Knaben.

Fig. 33b. Kieferabdruck desselben Patienten 7 Monate nach der Hasenscharten operation.

einseitig durchgehender Spaltbildung der Alveolarfortsatz der einen Oberkieferhälfte in der Sagittalebene mehr oder weniger über den der anderen Seite hinausragt. Die weiter vorspringende

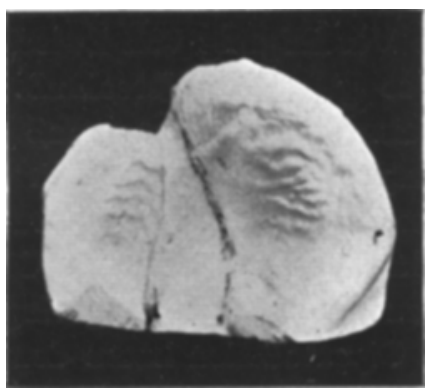

Fig. $34 \mathrm{a}$.

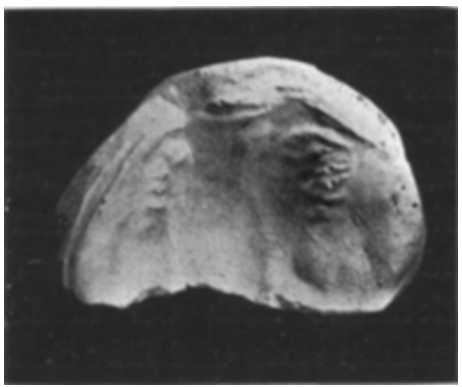

Fig. 34 b.

Fig. 34 a. Kieferabdruck eines 6 Monate alten Knaben.

Fig. 34 b. Kieferabdruck desselben Patienten 4 Monate nach der Hasenschartenoperation.

Seite ist stets diejenige, auf der die Vereinigung von Zwischenkiefer und Alveolarfortsatz zustande gekommen ist. In dem einen Falle ist diese Vereinigung eine sehr innige und vollkom- 
mene, so daB die früher deutlich erkennbar gewesene Grenze zwischen Zwischenkiefer und eigentlichem Alveolarfortsatz jetzt nicht mehr ohne weiteres zu sehen ist, in anderen Fällen dagegen ist die Vereinigung der beiden genannten Teile eine noch unvollkommene, und es besteht noch eine mehr oder minder deutliche Furche als Grenze von Zwischenkiefer und Alveolarfortsatz der betreffenden Oberkieferhälfte. Letztere Fälle zeigen uns, in welcher Weise der Verschluß der Alveolarspalte zustande kommt. In dem Falle I 8 der Tabelle I war bei der Operation der Hasenscharte die Verbindung von Zwischenkiefer und linkem Alveolarfortsatz eine noch auffallend lockere, besonders wenn man noch das Alter dieser Patientin berücksichtigte. In eben diesem Falle war schon I4 Tage nach Vereinigung der Lippenspalte eine ganz bedeutende Verschmälerung der Alveolarspalte erfolgt (vgl. Fig. 3I a und 3I b), und zwar dadurch, daß sich der Zwischenkiefer der Spalte zugewandt und damit der Oberkieferhälfte der anderen Seite sich genähert hatte. In ganz analoger Weise ist in den übrigen abgebildeten Fällen der Verschluß der Alveolarspalte zustande gekommen. Je unvollkommener die Verbindung von Zwischenkiefer und Alveolarfortsatz ist, um so leichter wird der erstere dem Druck der vereinigten Oberlippe nachgeben, d.h. sich dem Alveolarfortsatz der anderen Seite nähern. Ist schon eine vollkommene Vereinigung von Zwischenkiefer und Alveolarfortsatz erfolgt, so geht der Verschluß der Alveolarspalte in ganz ähnlicher Weise vor sich, nur muß der Druck der vereinigten Oberlippe entsprechend längere Zeit einwirken, damit ein vollkommener Verschluß der Spalte erreicht wird. Ein Herüberrücken des Spaltrandes der anderen Oberkieferhälfte nach der Medianlinie $\mathrm{zu}$ findet nur in geringem Ausmaße statt, und läßt sich an den Gipsmodellen kaum demonstrieren. Diesem Verschluß der Alveolarspalte können sich Hindernisse - allerdings stets überwindbare - in den Weg stellen. In erster Linie kommt als ein solches Hindernis in Betracht ein stark verbreiterter und weit nach vorn reichender Vomer. Wie weit die Vereinigung von $Z$ wischenkiefer und Alveolarfortsatz fortgeschritten ist, unterliegt individuellen Schwankungen. Im allgemeinen wird die Verbindung mit zunehmendem Alter eine festere; daß es aber davon Ausnahmen gibt, zeigt der oben 
zitierte Fall 18 der Tabelle I. Die Operation der Hasenscharte soll also - auch aus diesem Grunde - möglichst frühzeitig vorgenommen werden und nicht auf eine Zeit erst nach dem dritten Lebensmonat verschoben werden. Erfolgt sie innerhalb der ersten Lebensmonate, so pflegt die Alveolarspalte $1 / 2-3 / 4$ Jahre nachher geschlossen zu sein. Im weiteren legen sich beide Seiten einander so dicht an, daß nicht einmal mehr ein Blatt Papier zwischen ihnen passieren kann. Später kommt es ganz gewöhnlich zu einer organischen Vereinigung beider Seiten, die wohl nur so erklärt werden kann, daß infolge starken Druckes, unter welchem sich die Alveolarfortsätze der beiden Seiten berühren, Anämie der sie bedeckenden Schleimhaut und Nekrose derselben eintritt, so daß damit die Bedingungen zu einer Verwachsung beider Teile gegeben sind.

In Fällen von doppelseitig durchgehender Spalte, in welchen gewöhniich dẹ Zwischenkiefer weit nach vorn vorsteht und oft um einen Zentimeter oder mehr die Alveolarfortsätze der Oberkieferhälften überragt, liegen die Verhältnisse nicht so einfach. In der Regel liegt in solchen Fällen eine doppelseitige Hasenscharte vor. Wir operieren zuerst die Lippenspalte der einen Seite, beobachten, wie sich im Anschluß daran der Zwischenkiefer nach dieser Seite hin wendet und sich langsam dem Alveolarfortsatz dieser Seite nähert. Dabei dreht sich der Zwischenkiefer aus der frontalen Ebene um eine durch die Mitte des Zwischenkiefers zur Körperlängsachse parallele Gerade. Ist die Lippennarbe eine genügend widerstandsfähige und feste geworden, so operieren wir die Hasenscharte der anderen Seite. Der Zwischenkiefer folgt dem neuen Lippendruck und läßt sich allmählich immer mehr dem Alveolarfortsatz der anderen Seite nähern. Hat bisher ein exzessives Längenwachstum des Vomer bestanden, so stellt sich einem solchen nunmehr die mächtige Kraft des Lippendruckes entgegen; die übrigen Teile des Oberkiefers andererseits wachsen frei und ungehindert, bis schließlich der Zwischenkiefer ,sich in den Alveolarbogen eingereiht hat". Eine feste Konsolidation desselben mit den beiden Oberkieferhälften läßt sich durch Anfrischung der Berührungsstellen und Schleimhautnaht erreichen. 
Daß jedoch die Korrektur der Spaltbildung in solchen Fällen mit weit vorspringendem $Z$ wischenkiefer und doppelseitig durchgehender Spalte einer bedeutend längeren Krafteinwirkung be-

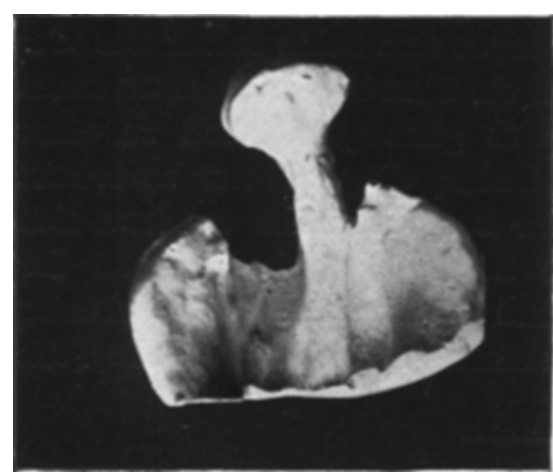

Fig. $35 \mathrm{a}$.

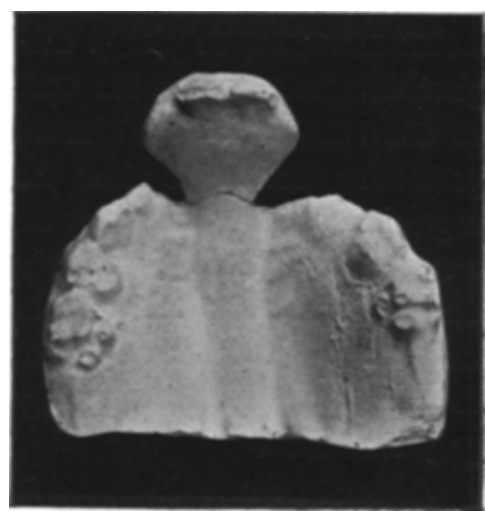

Fig. 35 b.

Fig. 35 a. I Tag alter Knabe. Doppelseitig durchgehende Gaumenspalte. Doppelseitige Hasenscharte III. Grades. Weit vorspringender Zwischen. kiefer.

Fig. 35 b. 5 Jahre alter Knabe. Wegen doppelseitiger Hasenscharte im Laufe des ersten Lebensjahres in 2 Zeiten operiert. Das Vorspringen des Zwischenkiefers ist ganz bedeutend zurückgegangen; hat vor der Hasenschartenoperation ca. $2 \mathrm{~cm}$. betragen.

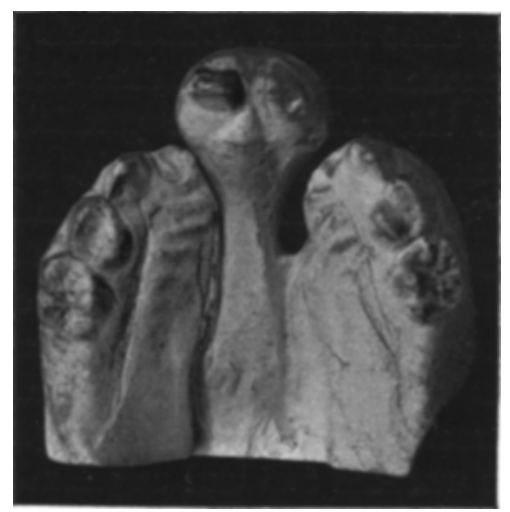

Fig. 35 c. 51/2 Jahre alter Knabe. Wegen doppelseitiger Hasenscharte III. Grades innerhalb der ersten beiden Lebensjahre in 2 Zeiten operiert. Der Zwischenkiefer, der sehr weit nach vorne vorstand, fügt sich immer mehr dem Alveolarbogen ein. 
darf, als wir zur Korrektur einer einseitig durchgehenden Spalte benötigen, liegt auf der Hand.

Dic vor der Operation der Hasenscharte vorzunehmende $\mathrm{Zu}$ rücklagerung des Zwischenkiefers nach $B$ ardeleben wird man bei doppelseitig durchgehender Spalte manchmal nicht entbehren können.

Die Fig. $35 \mathrm{a}, 35 \mathrm{~b}, 35 \mathrm{c}$ sollen die eben besprochenen Verhältnisse illustrieren. Ich bemerke ausdrücklich, daß die drei Gipsabdrücke von Kiefern verschiedener Patienten genommen sind.

Distanz der Alveolarfortsätze, Spalteim harten und weichen Gaumen.

Der vorderste Teil der Spalte des harten Gaumens wird infolge seiner unmittelbar dem Alveolarspalt sich anschließenden Lage naturgemäß in dem für den Alveolarspalt selbst gültigen und im vorhergehend beschriebenen Sinne beeinflußt. Ist die Verbindung von $Z$ wischenkiefer und der einen Oberkieferhälfte bei Vornahme der Hasenschartenoperation eine schon ziemlich feste gewesen, so wird auch der unmittelbar dem Zwischenkiefer anliegende Teil des Os maxillare und damit auch der Gaumenplatte dieser Seite durch' den Druck der vereinigten Lippe in ähnlicher Weise wie der Zwischenkiefer selbst etwas medianwärts und der anderen Oberkieferhälfte entgegen gedrängt. Bei beweglicherem Zwischenkiefer dagegen ist der Einfluß des Lippendrucks auf den Oberkiefer ein entsprechend geringerer. Für den vordersten Teil des Spaltes im harten Gaumen läßt sich eine gewisse Zeit nach Einwirkung des Lippendrucks regelmäßig eine Verschmälerung desselben als Zeichen eines mehr oder weniger ausgesprochenen Aneinanderrückens der Oberkieferhälften und der Spaltränder feststellen. Nicht so einfach und nicht so konstant liegen die Verhältnisse in bezug auf den übrigen Teil der Spalte des harten Gaumens. Daß aber auch dieser Teil der Spalte gewöhnlich eine Verschmälerung erfährt, geht aus den in Tab. III niedergelegten Messungsergebnissen hervor.

Eine Verschmälerung der Spalte im harten Gaumen kann a priori entweder durch ein Zusammenrücken der Ossa maxillaria oder durch ein Horizontaler-Treten der Gaumenplatten bedingt sein. Der Nachweis, welcher von diesen Faktoren im jeweils 
vorliegenden Falle allein oder hauptsächlich an der Verschmälerung der Spalte ursächlich in Frage kommt, ist nicht ganz einfach. Zwar können wir mit Hilfe der eingangs beschriebenen Methode die Winkelstellung der Gaumenplatten mit ziemlicher Genauigkeit angeben, die absoluten Zahlen jedoch, welche die Distanz der Alveolarfortsätze bezeichnen, sind nicht ohne weiteres verwertbar, um aus ihnen etwa ein Zusammenrücken der Ossa maxillaria in allen Fällen abzuleiten. Ist die Distanz der Alveolarfortsätze einige Zeit nach der Hasenschartenoperation eine kleinere als vor derselben, so können wir bei gleichzeitiger Verengerung der Spalte des harten Gaumens und gleichbleibendem Gaumenplatten-Neigungswinkel an einem Zusammenrücken der Ossa maxillaria nicht mehr zweifeln. Umgekehrt aber dürfen wir, wenn die Distanz der Alveolarfortsätze eine gewisse Zeit nach der Vereinigung der Lippenspalte unverändert geblieben ist, eine Annäherung der Ossa maxillaria deshalb noch nicht ausschließen, da wir ja eine Vergrößerung der Distanz der Alveolarfortsätze als Ausdruck des Schädelwachstums erwarten müssen. Tabelle IV gibt u.a. an, wie groß die Differenz der Alveolarabstände in den verschiedenen Monaten des Säuglingsalters unter normalen Kieferverhältnissen zu sein pflegt. Nur wenn eine diesen Zahlen ungefähr entsprechende Distanzvermehrung der Alveolarfortsätze nach der Hasenschartenoperation festgestellt werden kann, darf ein Zusammenrücken der Ossa maxillaria ausgeschlossen werden.

Spaltform. Charakteristisch ist die im Anschluß an die Hasenschartenoperation zu beobachtende Veränderung der Spaltform. Wie oben schon besprochen wurde, verlaufen die Spaltränder der unberührten Gaumenspalte einander parallel, nicht selten sogar hat die Spalte ihre maximale Breite im Bereich des Alveolarfortsatzes und verjüngt sich nach dem Zäpfchen zu. Ist aber der Verschluß der Kieferspalte in der beschriebenen Weise erfolgt, so endet die Spalte nach vorn unter einem spitzen Winkel. Die Spaltränder des harten Gaumens weichen nach rückwärts etwas mehr auseinander, die Spaltränder im Bereich des weichen Gaumens behalten zunächst noch ihren parallelen Verlauf. Besonders in denjenigen Fällen, in welchen der Verschluß der Kieferspalte nicht allein durch Nachgeben des Zwischenkiefers, sondern auch der demselben sich anschlie- 
Benden Teile der betreffenden Oberkieferhälfte zustande gekommen ist, endet der vordere Spaltrand unter einem scharfen, spitzen Winkel. Fig. 36, 37 und 38 zeigen die verschiedenen beschriebenen Spaltformen.

Die beiden Hälften des Zäpfchens sind nach der Medianlinie zu gerichtet und berühren sich in diesem „Stadium der Spaltbildung" gewöhnlich mit ihren Enden.

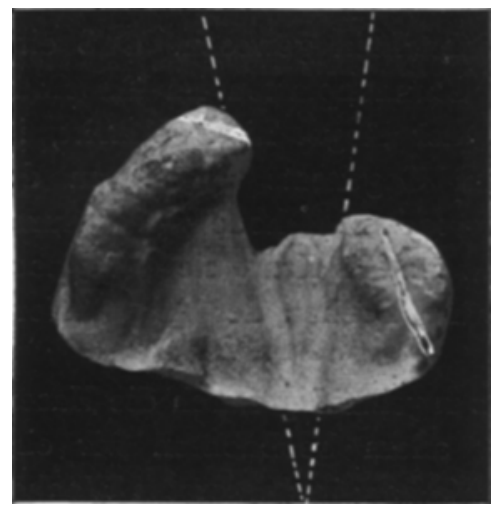

Fig. 36.

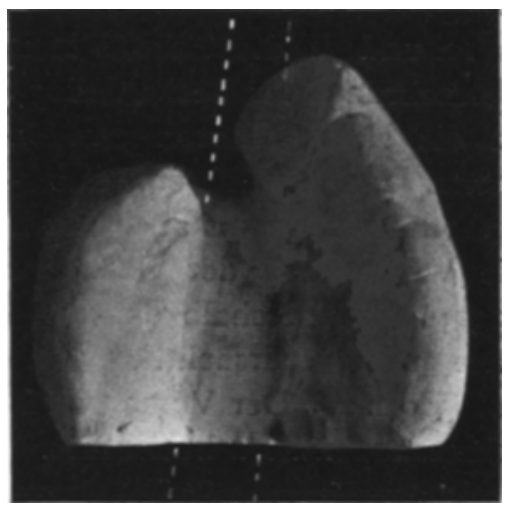

Fig. 37 .

Fig. 36. Kieferabdruck eines I Tag alten Mädchens. Hasenscharte III. Grades links. Größte Spaltbreite im Alveolarfortsatz.

Fig. 37. Kieferabdruck eines 6 Monate alten Mädchens. Hasenscharte III. Grades rechts. Ungefähr parallele Spaltränder.

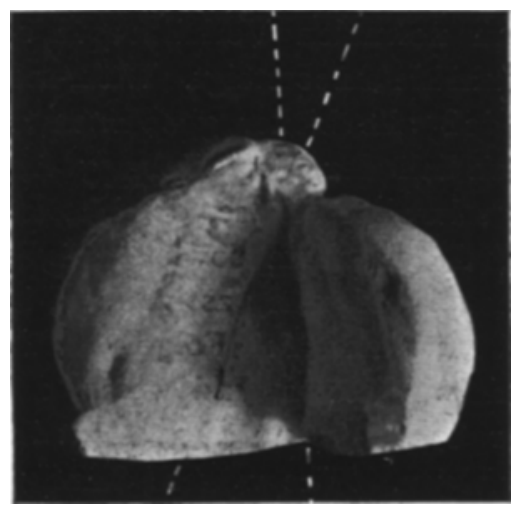

Fig. 38. Kieferabdruck eines ca. I 3 Monate alten Knaben. Hasenscharte III. Grades links vor 7 Monaten operiert. Dreiecksform des harten Gaumens. Parallele Spaltränder des weichen Gaumens. 
Neigung der Gaumenplatten. Der Neigungswinkel der Gaumenplatten erfährt unter dem Einfluß der vereinigten Oberlippe keine wesentlichen Veränderungen. Die näheren diesbezüglichen Zahlen zeigt die Tabelle II. Auch in denjenigen Fällen, in welchen meßbare Veränderungen des Gaumenplattenneigungswinkels im Anschluß an die Hasenschartenoperation auftreten, sind dieselben so gering, daß sie praktisch vernachlässigt werden können. Solche Veränderungen sind in den Fällen 7, Io und II der Tabelle II zu beobachten gewesen. Daß eine Vermehrung der Steilstellung der Gaumenplatten im Anschluß an die Hasenschartenoperation in der Regel nicht eintritt, ist darauf zurückzuführen, daß - im Gegensatz sowohl zu der orthodontischen, als auch der Brophyschen Methode — die durch die Vereinigung der Oberlippe gewonnene Kraft ziemlich hoch angreift und deshalb ein sich einwärts Drehen der Alveolarfort. sätze nicht verursacht.

Vomer. Der Vomer wird ganz regelmäßig durch die Hasenschartenoperation beeinflußt. Vor allem beobachten wir eine stetig zunehmende Steilstellung des Vomer; in den ersten Wochen nach der Vereinigung der Oberlippe ist diese vermehrte Steilstellung des Vomer eine recht geringgradige und kaum nachweisbare. Im weiteren Verlauf dagegen tritt sie in allen Fällen deutlich hervor, und ist bei Patienten im Alter von $11 / 2,2$ oder mehr Jahren ausnahmslos so weit vorangeschritten, daß der Vomer analog den normalen Verhältnissen senkrecht von der Mund- in die Nasenhöhle emporsteigt. Während aber kein Zweifel darüber besteht, daß alle bisher genannten anatomischen Veränderungen hinsichtlich der Verschiebung des Zwischenkiefers, der Abstände der Alveolarfortsätze, der Veränderungen hinsichtlich Spaltbreite und Spaltform sowie bezüglich des Neigungswinkels der Gaumenplatten rein passive sind, ist die zunehmende Steilstellung des Vomer zum Teil Folge und Teilerscheinung des allgemeinen Schädelwachstums, und würde demnach auch ohne Hasenschartenoperation - wenn auch nicht innerhalb derselben kurzen Zeit - erfolgen. Eine weitere, häufig zu beobachtende, mit der Vereinigung der gespaltenen Oberlippe in ursächlichem Zusammenhang stehende Erscheinung ist die, daß sich doppelseitige Spalten in einseitige verwandeln. Unter solchen „doppel- 
seitigen Spalten“ sind allerdings nicht „,doppelseitig durchgehende Spalten“ zu verstehen, sondern ,einseitig durchgehende“, bei denen aber auch auf der nicht durchgehend gespaltenen Seite ein Spalt des harten Gaumens besteht (Fig. 14, I 5, I6). Schon La ng en beck hat diese Beobachtung in mehreren Fällen gemacht.

Damit habe ich die wichtigsten und regelmäßigsten Veränderungen beschrieben, welche sich unter dem Einfluß der vereinigten Oberlippe vollziehen.

Von hohem theoretischen und praktischen Interesse aber ist es, $z$ u wissen, da $B$ damit keineswegs das definitive Schicksal der Spaltbildung.entschieden ist. Mit dem AbschluB der durch die Hasenschartenoperation verursachten Umwälzungen im Bereich der Spaltbildung ist diese nur in ein ,neues Stadium" getreten. Mit zunehmendem Alter und Wachstum des Patienten treten - wenn jetzt nicht eine operative Behandlung Platz greift - weitere Veränderungen auf, deren Kenntnis Voraussetzung ist zur Lösung wichtiger, noch schwebender Fragen in der Behandlung der Gaumenspalte.

\section{Spätere Veränderungen der Spaltbildung.}

Das dritte und definitive Stadium der Spaltbildung ist gekennzeichnet durch die Breite der Spalte und deren charakteristische Form bei geschlossenem Alveolarbogen. Aus unserem großen Material von Gaumenspaltenpatienten im Alter zwischen 2, 3 und I 4 Jahren greife ich die wenigen folgenden Abbildungen heraus, die sich auf verschiedene Altersstufen innerhalb der genannten Altersgrenze beziehen.

In allen diesen Fällen - mit Ausnahme von Fall 39 - ist die Alveolarspalte geschlossen, der Alveolarbogen in nahezu idealer Weise gerundet, beide Teile des Alveolarfortsatzes sind organisch miteinander vereinigt. Nur in dem in Fig. 39 dargestellten Falle besteht noch ein wenige Millimeter breiter Spalt im Alveolarfortsatz. In diesem Falle wurde die Hasenschartenoperation erst im Alter von 5 Monaten vorgenommen; bei Abnahme des abgebildeten Gipsabdruckes war Patient ca. 3 Jahre 
alt. Ich bilde diesen Fall absichtlich ab, um bei dieser Gelegenheit darauf hinweisen zu können, daß man die Langenbecksche Operation gelegentlich auch vornehmen kann, ohne daß eine vollkommene Vereinigung der beiden Alveolarfortsätze zustande ge-

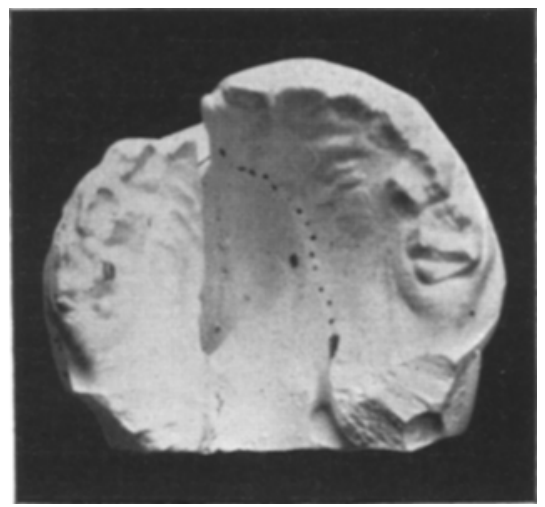

Fig. 39. Kieferabdruck eines 3 jährigen Mädchens. Hasenscharte II. Grades rechts im ersten Lebensjahre operiert. Alveolarspalt noch nicht völlig geschlossen. Dreiecksform der Spalte.

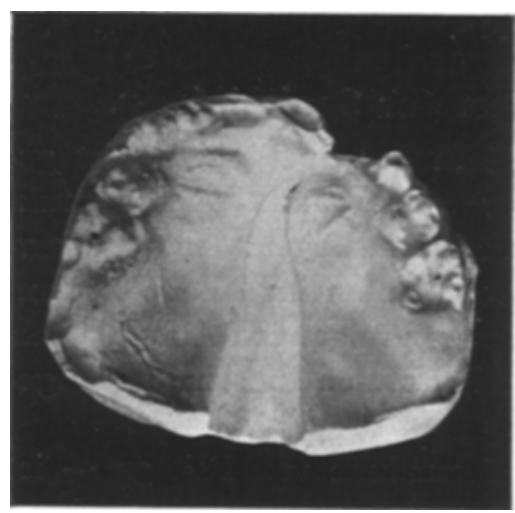

Fig. 40.

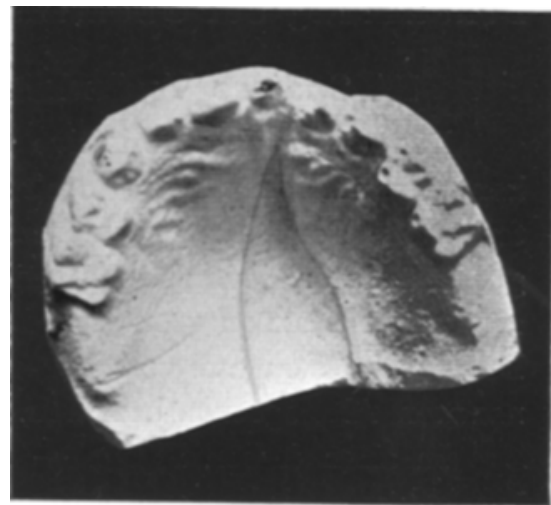

Fig. 4I.

Fig. 40. Kieferabdruck eines 4 jährigen Knaben. Hasenscharte II. Grades links im 13. Lebensmonat operiert. Alveolarfortsatz geschlossen. Dreiecksform der Spalte.

Fig. 41. Kieferabdruck eines 61/2 jährigen Knaben. Hasenscharte III. Grades links am Ende des ersten Lebensjahres operiert. Alveolarfortsatz gespalten. Dreiecksform der Spalte. 


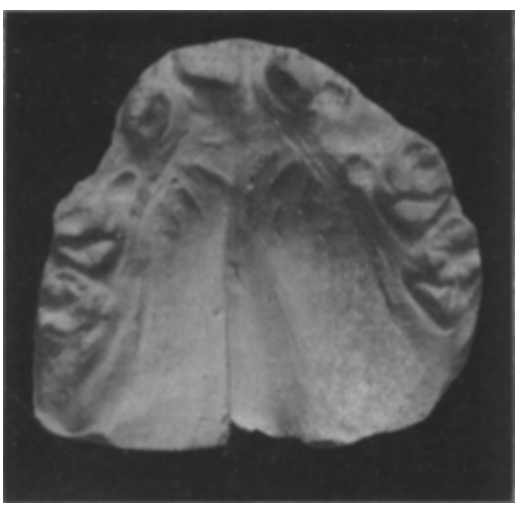

Fig. 42.

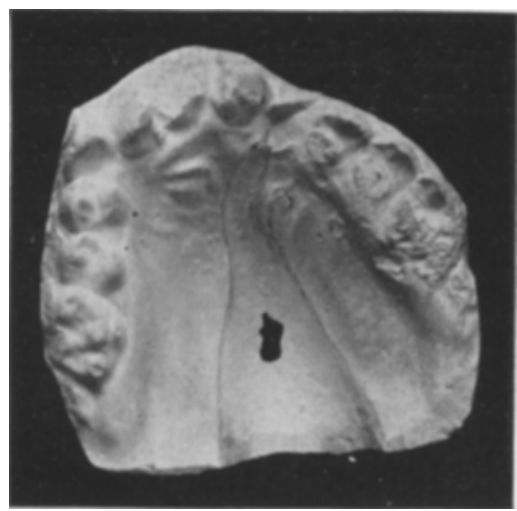

Fig. 43 .

Fig. 42. Kieferabdruck eines 9jährigen Knaben. Doppelseitige Hasenscharte III. Grades operiert in den ersten $I \frac{1}{4}$ Lebensjahren. Alveolarfortsatz geschlossen. Dreiecksform der Spalte.

Fig. 43. Kieferabdruck eines I I jährigen Mädchens. Hasenscharte III. Grades links im ersten Lebensjahre operiert. Alveolarspalte geschlossen. Dreiecksform der Spalte.

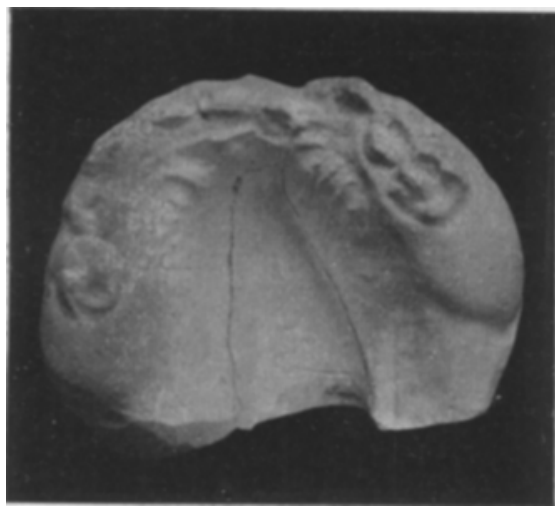

Fig. 44 .

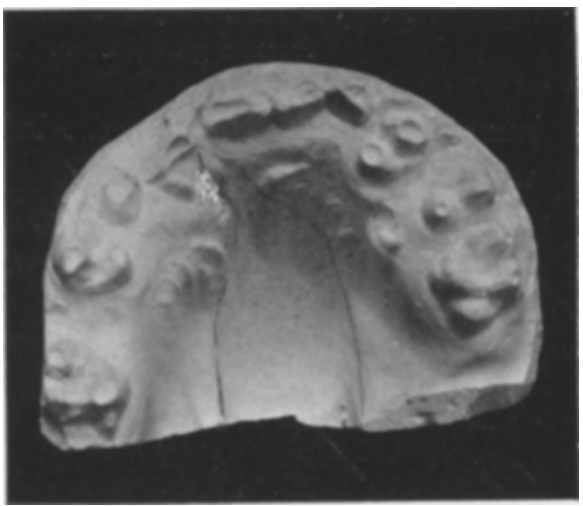

Fig. 45 .

Fig. 44. Kieferabdruck eines 7 jährigen Knaben. Hasenscharte III. Grades links im ersten Lebensjahre operiert. Alveolarspalte geschlossen. Dreiecksform der Spalte.

Fig. 45. Kieferabdruck eines I 2 jährigen Knaben. Doppelseitige Hasenscharte III. Grades in den beiden ersten Lebensjahren operiert. Alveolarspalte geschlossen. Dreiecksform der Spalte. (Größte Breite derselben zwischen den beiden Enden des gespaltenen Zäpfchens.) 
kommen ist. Fig. 47 zeigt den Kieferabdruck derselben $\mathrm{Pa}$ tientin 9 Monate nach Vornahme der Langenbeckschen Operation. Nahe dem Alveolarfortsatz besteht noch eine ovale Öff-

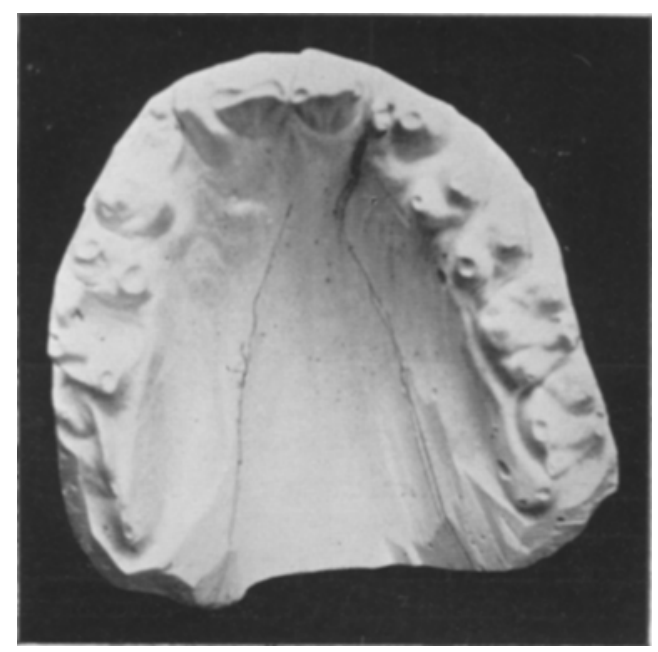

Fig. 46. Kieferabdruck eines I4 jährigen Knaben. Hasenscharte II. Grades rechts, III Grades links in den beiden ersten Lebensjahren operiert. Alveolarfortsatz geschlossen. Dreiecksform der Spalte.

nung im harten Gaumen, die bei der Operation nicht geschlossen wurde.

Interessant sind die Verhältnisse hinsichtlich der Spalte. In seiner im Jahre 1864 erschienenen Arbeit sagt Langen beck:

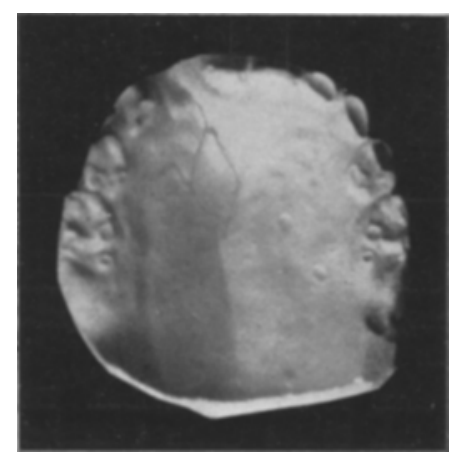

Fig. 47 . 
„Die absolute Breite der Knochenspalte nehme im Lauf der Jahre mit den Dimensionen des Oberkiefers zu, während allerdings die relative Breite derselben abnehme." Mit anderen Worten besagt diese Behauptung Langenbecks, daß das Wachstum der. beiden Oberkieferhälften und der Gaumenplatten schneller voranschreite, als die Erweiterung der Spalte. Langenbeck schreibt die mit dem Alter zunehmende Breite der Gaumenspalte der Wirkung der Gesichtsmuskeln zu; er sagt: „Diese ist, wie man sich leicht überzeugen kann, bei allen mimischen Gesichtsbewegungen, besonders beim Lachen und Weinen, eine exzessive, und hat, wie es scheint, eine Hypertrophie der Gesichtsmuskulatur zur Folge."

Besonders hervorgehoben muß jedoch werden, daß sich diese Äußerung Langenbecks nur auf solche Fälle von Gaumenspalte bezieht, in welchen eine Vereinigung der Oberlippe nicht vorgenommen wurde. Ja Langenbeck geht sogar so weit, daß er die mit dem Alter zunehmende Breite des Knochenspaltes direkt als eine Folge der Nichtvereinigung der Oberlippe betrachtet. Der in Fig. I abgebildete und der Langenbeckschen Arbeit entnommene Fall dient Langenbeck als Beweis für diese Behauptung. Der Autor stellt nämlich diesen Fall - der ein $9^{1} / 2$ jähr. Mädchen betraf, bei welchem die Ossa intermaxillaria entfernt worden waren, die Operation der Hasenscharte aber unterblieben war -- einem ähnlich gelagerten Falle mit operierter Hasenscharte gegenüber und stellt fest, daß sich in dem ersteren Falle der Gaumenspalt durchweg breiter erwies, als in dem zweiten, und daß sich in dem letzteren die vorderen Enden der Processus palatini fast berührten.

Ich habe bisher in zwei Fällen Gelegenheit gehabt, Patienten im Alter von mehreren Jahren mit „,noch bestehender doppelseitiger Hasenscharte III. Grades" zu sehen. Auch diese hatten ihre Hasenscharte nur aus dem Grunde noch, da die wiederholt von anderer Seite vorgenommene Operation derselben mißlungen war. Fig. 48 zeigt einen dieser beiden Fälle. Die Ansicht Langenbecks scheint durch denselben bestätigt zu werden, insofern wenigstens, als sich bei diesem Patienten eine im ganzen sehr breite Spalte fand, die auch im Bereich des Alveolarfortsatzes das gleiche Breitenmaß aufwies, als in den übrigen Teilen derselben; die Ränder der Spalte liefen einander parallel, 
zeigten also ein Verhalten, wie ich es oben als charakteristisch für die noch unberührte Gaumenspalte beschrieben habe.

Wenn man nun auch auf Grund solcher Fälle zugeben wird, daß eine derartige Verbreiterung der Gesamtspalte mit parallel bleibenden Spalträndern auf eine Nichtvereinigung der Oberlippe bezogen werden muß, so gilt andererseits der Satz, daß die absolute Breite der Knochenspalte im Laufe der Jahre mit den Dimensionen des Oberkiefers zunehme, während relativ die Breite der Spalte abnehme, aber auch für die Fälle, in denen die Ver-

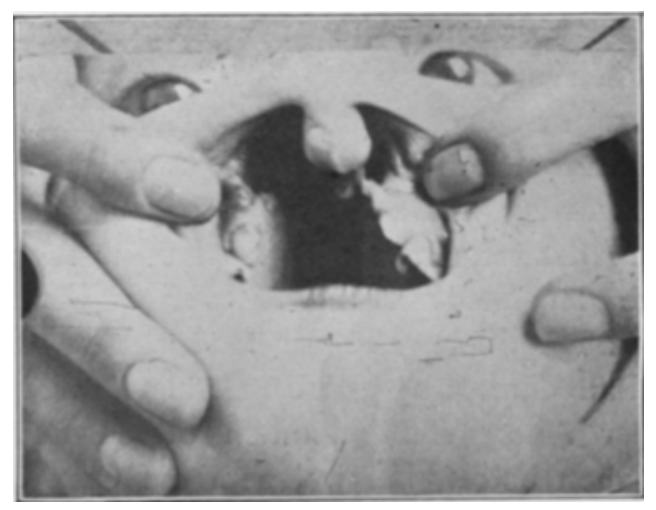

Fig. 48. 7 jähriger Knabe; wiederholt erfolglose Operation der doppelseitigen Hasenscharte III. Grades. Gleichmäßige Verbreiterung der Spalte in allen Abschnitten derselben. Parallele Spaltränder.

einigung der Oberlippe frühzeitig vorgenommen wurde. Die Art der Verbreiterung der Spalte allerdings ist eine wesentlich andere.

Der direkte Beweis dafür, daß sich die Spalte mit zunehmendem Alter verbreitert, ist nur dadurch zu erbringen, daß die Breite der Spalte an einem und demselben Falle an Gipsabdrücken gemessen wird, welche von dem Oberkiefer dieses Patienten in verschiedenen Lebensaltern - beispielsweise 4, 6,8 und I2 Jahre - gemacht worden sind. Ein von mir selbst durch so viele Jahre hindurch beobachteter Fall von Gaumenspalte steht mir leider nicht zur Verfügung. Indes läßt sich die Tatsache, daß mit zunehmendem Alter eine Verbreiterung der Spalte eintritt, auch auf indirektem Wege beweisen. Dieser Beweis wird uns ermöglicht durch das Studium der Veränderungen der Spaltform. Wie im 
Laufe dieser Abhandlung schon mehrfach betont wurde, zeigt die unberührte Gaumenspalte mit großer Regelmäßigkeit parallel zueinander verlaufende Spaltränder (I. Stadium der Spaltbildung). Ungefähr 1/2 Jahr nach der Hasenschartenoperation findet man gewöhnlich schon eine Dreiecksform der Spalte, wenigstens in sofern, als die Alveolarspalte jetzt geschlossen zu sein pflegt und die Spaltränder des harten Gaumens nach rückwärts sich etwas voneinander entfernen. Wie oben dargelegt wurde, ist dagegen in diesem zweiten Stadium der Gaumenspalte die Form der Spalte des weichen Gaumens noch nicht oder kaum nachweisbar beeinflußt, zeigt jedenfalls noch parallel verlaufende Spaltränder; die Zäpfchen stehen noch nach der Medianlinie zu gekehrt und berühren sich gewöhnlich mit ihren freien Enden. Das Maximum der Spaltbreite liegt während dieses Stadiums noch etwa am Übergang vom harten in den weichen Gaumen.

Ganz anders dagegen liegen die Verhältnisse nach einigen Jahren. Wie die Figg. 39-46 zeigen, besteht in allen diesen Fällen eine ausgesprochene ,,Dreiecksform der Gesamtspalte “1). Die Spitze des Dreiecks entspricht dem Alveolarfortsatz, die Basis des Dreiecks aber liegt zwischen den hintersten Enden des gespaltenen Zäpfchens. Hier hat die Spalte ihre maximale Breite. Bemerkenswert ist ferner noch, daß die Zäpfchen jetzt nicht mehr gegen die Mitte der Spalte zu gerichtet sind - geschweige sich berühren --, sondern daß deren mediale Ränder die direkte Fortsetzung der Richtung der immer mehr voneinander sich entfernenden Spaltränder sind. Die absolute Breite der Spalte im Bereiche der Zäpfchen ist eine bedeutende, sie ist in der Regel um so breiter, je älter der Patient ist.

Aus diesen Veränderungen der Spaltform geht mit Sicherheit hervor, daß mit zunehmendem Alter eine Erweiterung besonders des rückwärtigen Teils der Spalte eintritt.

Für das Zustandekommen dieser eben beschriebenen Spaltkonfiguration ist Voraussetzung, daß der VerschluB der Alveolarspalte eingetreten ist. Sobald dieser Zustand erreicht ist, werden die beiden Hälften des gespaltenen Oberkiefers in ihrem rück-

1) Leider läßt sich der weiche Gaumen und Zäpfchen am Gipsmodell nicht zur Darstellung bringen. 
wärtigen Teil und mit diesen die Gaumenplattenränder durch irgendeine Kraft um den Alveolarfortsatz als punctum fixum nach beiden Seiten und auswärts gezogen. Welches diese Kraft aber ist, sagt Langenbeck, es ist die ,exzessiv wirkende Kraft der mimischen Gesichtsmuskulatur".

Aus den bisherigen Untersuchungen geht somit hervor, daß es während der verschiedenen „Stadien der Gaumenspalte“ einen "Zeitpunkt der optimalen Spaltbreite" gibt. Dieser ist dann erreicht, wenn unter dem Einfluß der vereinigten Oberlippe beide Kieferspaltränder aneinander liegen, und der Spalt im harten Gaumen ev. auch der im weichen Gaumen gleichzeitig sich verschmälert haben.

\section{Stellungnahme $z u$ den verschiedenen Operations- prinzipien und Operationen.}

I. Zur Idee und Methode der Annäherung der Spaltränder.

Zur gegenseitigen Annäherung der Oberkieferhälften bzw. Gaumenplatten allein stehen uns zwei Wege zur Verfügung: der unblutige und der blutige.

Die von den alten Chirurgen geübte Methode durch permanenten Druck von außen die Oberkieferhälften einander zu nähern, erscheint mir auch heute noch von rein theoretischen Gesichtspunkten aus durchaus rationell. Jedenfalls müßte ein lange genug wirksamer und hinreichend kräftiger Druck - besonders bei möglichst hoch verlegten Angriffspunkten — imstande sein, die Oberkieferhälften einander mehr oder weniger zu nähern. Auch Kredel hält diese Methode „für ein Problem der Chirurgie, das sicher noch zu lösen sein werde“. Dagegen dürften sich der Anwendung und Durchführung des Verfahrens in der Praxis große, ja wohl meist unüberwindliche Schwierigkeiten in den Weg stellen. Diese Methode stellt zu große Anforderungen an das Verständnis der Eltern, sie ist sehr langwierig, mit großen Unannehmlichkeiten und Kosten verbunden. In diesen Momenten werden wohl auch die hauptsächlichsten Gründe zu suchen sein, wenn Langenbeck uns von Erfolgen, die mit diesem Verfahren erreicht worden sind, nichts berichten kann.

Wesentlich anders liegen die Verhältnisse bezüglich der 
orthodontischen Methode. Es unterliegt keinem Zweifel, daß mittels geeigneter orthodontischer Apparate die Alveolarfortsätze einander sogar um ein Bedeutendes genähert werden können. Die Eltern des kleinen Patienten haben - wenn die Apparate einmal liegen - mit denselben nichts zu tun, der beabsichtigte Erfolg läßt nicht allzu lange auf sich warten. Trotzdem kommt auch diese Methode im allgemeinen zur Korrektur der Gaumenspalte nicht in Betracht. Die orthodontischen Apparate können erst angebracht werden nach Durchbruch der Zähne; zwar ist nach zahnärztlichem Urteil nicht unbedingt erforderlich, daß schon dic bleibenden Zähne vorhanden sind, man kann die Apparate auch an den Milchzähnen anbringen. Aber auch nach Durchbruch dieser ist wohl fast in allen Fällen — und zwar mit Recht die Hasenscharte operiert, infolge davon der Spalt im Alveolarfortsatz geschlossen. Die Apparate könnten demnach nur noch die Aufgabe haben, den Spalt im harten und weichen Gaumen zu beseitigen. Dazu sind sie aber aus den oben dargelegten Gründen nicht imstande. Daß jedoch eine Verringerung der Distanz der Alveolarfortsätze die Vereinigung der von den knöchernen Gaumenplatten abgelösten und von einer mehr oder weniger starken abnormen Steilstellung in eine annähernd horizontale Ebene heruntergeklappten Gaumenplattenüberzüge erleichtert, habe ich schon erwähnt. Trotz dieses Umstandes stehe ich aber auf dem Standpunkt Helbings, daß es unzweckmäßig wäre, dieses Verfahren etwa auf alle Gaumenspalten ausdehnen zu wollen, daß vielmehr nur in den allerseltensten Fällen die Notwendigkeit eines solchen Vorgehens gegeben sei.

Hier ist auch der Ort, die Frage zu überlegen, ob nicht etwa schon während des ersten Lebensjahres durch im Munde liegende und an den Alveolarfortsätzen selbst angreifende Apparate die gewünschte Wirkung erzielt werden könnte. Ich selbst habe einen in dieser Richtung sich bewegenden Versuch - auf dessen Einzelheiten ich hier nicht eingehen will - gemacht, kann aber vorerst wenigstens nicht zu einem solchen Vorgehen raten. Solche im Munde liegende Fremdkörper geben, wenn sie auch noch so klein, glatt und anscheinend belanglos sind, doch zu Zersetzungsprozessen Anlaß, denen die Kinder erliegen können. Keinesfalls möchte ich riskieren, einen Säugling mit einem für längere Zeit 
im Munde angebrachten Apparat in die oft mangelhafte häusliche Pflege zu geben; schwere Magen-Darmstörungen wären die wahrscheinliche Folge. Als unblutige Methode zur Verschließung der Kieferspalte, Annäherung der Oberkieferhälften und Verengerung der Spalte im harten Gaumen bleibt uns also nur noch die Hasenschartenoperation. Welche umwälzenden Veränderungen zu verursachen diese imstande ist, habe ich ausführlich dargelegt. Abgesehen von ihrer Einwirkung auf die Spaltbildung des Oberkiefers muß die Hasenschartenoperation aus verschiedenen Gründen in frühem Alter vorgenommen werden. Die Mortalitätsziffer der Kinder mit Cheilognatopalatoschisis wird verbessert durch die Operation der Hasenscharte, die Eltern solcher Kinder verlangen frühzeitig die Operation. Führen wir sie aus, so fallen uns alle die genannten, in höchstem Maße erwünschten Veränderungen, wie Schluß der Alveolarspalte, Annäherung beider Oberkieferhälften, Verengerung der Spalte des harten Gaumens, völlig gratis zu.

Damit ist die Frage entschieden, ob zuerst die Hasenscharte oder die Gaumenspalte zu operieren sei : stets ist zuerst die Hasenscharte zu operieren, und zwar sobald der Allgemeinzustand des Patienten und die speziellen Verhältnisse der Mißbildung die Operation aussichtsreich genug erscheinen lassen.

Unter den blutigen Methoden, welche eine Annäherung der Spaltränder bezwecken, ist die älteste die Dieffenbachsche. Nach Langenbeck beschreibt Dieffenbach sein Verfahren folgendermaßen: „Bei sehr breiten Spalten des harten Gaumens kann die Vereinigung durch vorläufige Verkleinerung oder Schließung der Gaumenknochenspalte bewirkt werden; man durchbohrt den Rand eines jeden Gaumenknochens mit einem dreieckigen, geraden, starken Pfriemen und führt durch die Öffnungen einen dicken, weichen Silberdraht hindurch, dessen Enden man zusammendreht. Hierauf durchschneidet man die Schleimhaut an der Grenze der Verbindung der Gaumenknochen mit dem Processus alveolaris, setzt einen dünnen, flach konkaven Meißel auf den Knochen und stemmt ihn auf beiden Seiten durch. Jetzt setzt man das Zusammendrehen des Drahtes fort und bringt die Ränder der Knochenspalte ganz oder teilweise aneinander. Letzteres ist gewöhnlich nur ausführbar." 
Langenbeck glaubt, daß Dieffenbach selbst diese Operation nicht ausgeführt hat; dagegen hat Wutzer im Jahre I 834 und Langenbeck im Jahre 1849 und ein zweitesmal im Jahre 1856 je an einem Kranken die Dieffenbachsche Operation ausgeführt. Wutzer soll mit glücklichem Erfolg operiert haben, Langenbeck dagegen hatte so unglückliche Erfolge, daß er sich dadurch von weiteren Versuchen mit der Dieffenbachschen Methode abschrecken ließ.

Wir selbst haben keine eigenen Erfahrungen mit der Dieffenbachschen Methode.

Prinzipiell verschieden von der Dieffenbachschen Methode sind die neueren Methoden, welche eine Annäherung der Spaltränder auf blutigem Wege zu erreichen suchen. Während Dieffenbach nur die Gaumenplatten einander nähern will, gehen die im folgenden zu besprechenden Methoden darauf aus, zugleich mit den Gaumenplatten auch die Alveolarfortsätze beider Oberkieferhälften gegeneinander zu verschieben. Die Schöpfer der Methoden sind zu diesem Zwecke in verschiedener Weise vorgegangen.

Ich will zuerst auf das von Brophy beschriebene Verfahren näher eingehen und folge dabei der von Helbing gegebenen Darstellung des Brophyschen Verfahrens.

Am geeignetsten für die Brophysche Methode sind Fälle im Alter von wenigen Wochen bis zu drei Monaten. Das Prinzip der Operation ist, wie ich eingangs schon erwähnt habe, eine gewaltsame, ev. blutige, gegenseitige Annäherung der unteren Oberkieferfortsätze mitsamt den Gaumenplatten, so weit, bis die Spaltränder sich berühren. Brophy beginnt die Operation mit der Anfrischung der Spalte im Bereich des harten Gaumens. Bei durchgehender Spalte wird auch der beiderseitige Rand der Kieferspalte angefrischt. Nun legt sich Brophy die ganze bukkale Seite des Alveolarfortsatzes dadurch frei, daß er sich die Wange möglichst weit nach hinten abheben läßt. Jetzt werden mehrere Silberdrähte durch beide Alveolarfortsätze durchgeführt, so, daß ein hinterer Draht hinter dem Processus zygomaticus, ein vorderes Drahtpaar vor demselben liegt. Fig. 49 veranschaulicht die Lage der Drähte.

Um nun die Spaltränder einander zu nähern, übt man einen 
starken Druck gegen die Außenseite der beiden Oberkieferhälften aus, was nach Brophy mit den beiden Daumen, oder - falls die beiden Seiten unter deren. Druck nicht nachgeben - mittels eigens konstruierter Zange zu geschehen hat. Gelingt unter solcher Druckwirkung eine gegenseitige Annäherung der Spaltränder nicht, so wird der ganze Alveolarfortsatz auf beiden Seiten submukös durchmeißelt; daß man diesen überall vom Oberkiefer abgetrennt habe, soll durchaus nicht erforderlich sein. Jetzt soll es leicht gelingen, die Alveolarfortsätze medianwärts $z u$ verschieben. Nun werden die Silberdrähte über beiden Alveolarfortsätzen anliegenden Bleiplatten geknotet; damit die Spaltränder einander

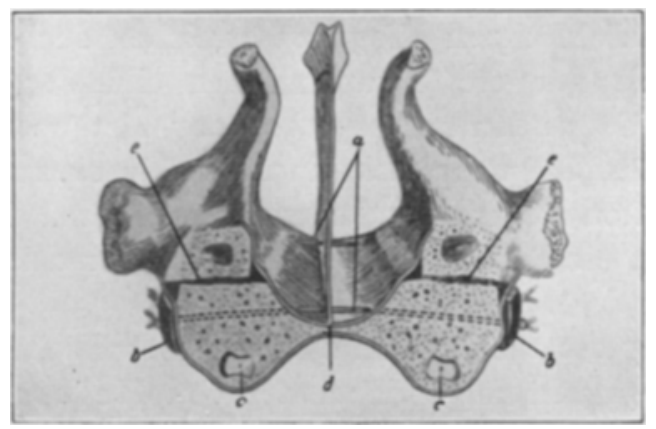

Fig. 49. Nach Brophy. e) submuköse Durchtrennung des Alveolarfortsatzes vom Oberkiefer. Nasen- und Mundschleimhaut verlaufen intakt über die Bruchstelle. Die Alveolarfortsätze sind beiderseits bis zum Verschwinden des Spalts nach innen verschoben.

möglichst genau anliegen, werden ev. einige Seidenknopfnähte hindurchgelegt. Letztere werden nach 8 Tagen entfernt, die Bleiplatten und Silberdrähte dagegen bleiben 4-8 Wochen liegen. Etwa $1 / 2$ Jahre nach dieser Operation wird der Verschluß der Spalte des weichen Gaumens vorgenommen.

Liest man diese in gekürzter Form wiedergegebenen Brophyschen Ausführungen, so gewinnt man den Eindruck, daß ein Zusammenpressen der Oberkieferhälften mittels der Daumen oder ev. mittels eigens konstruierter Zange, und damit ein Aneinanderbringen der Spaltränder in der Regel ohne Schwierigkeiten ausführbar wäre. Um so mehr war ich deshalb erstaunt, als ich eine solche gegenseitige Annäherung der Spaltränder 
an dem in Betracht kommenden Gaumenspaltenmaterial der Münchner Kinderklinik weder manuell noch unter Anwendung einer geeigneten Zange absolut nicht erreichen konnte. Im Gegenteil zeigte sich bei diesen Versuchen, wie ungeheuer fest die Oberkieferhälften an ihrem Platze verankert waren, wie wenig ,nachgiebig" sie auch bei nur wenige Tage alten Kinder waren. Was mit Daumen- oder mit Zangendruck erreicht werden konnte, bestand lediglich in einer Annäherung der Alveolarfortsätze, die Gaumenspalte selbst wurde durch diese Umbiegung der Alveolarfortsätze in kaum merkbarer Weise beeinflußt. Von einem völligen Aneinanderbringen der Gaumenplattenränder - also der Beseitigung der Spalte durch den angewandten Druck - war nicht entfernt die Rede. Nur in Ausnahmefällen konnte bei einseitig durchgehender Spalte mit breitem, horizontalem Vomer und schmaler relativer Spalte der freie Gaumenplattenrand dem betreffenden Vomerrand durch starken Druck vorübergehend genähert werden. Darin sehe ich aber keine Beseitigung der Spalte; eine solche ist vielmehr nur dann erreicht, wenn Gaumenplattenrand an Gaumenplattenrand liegt, d. h. der Vomer an der Bildung des Gaumendaches nicht beteiligt ist.

$\mathrm{DaB}$ dagegen auf blutigem Wege, $d$. h. durch submuköse Durchmeißelung der Alveolarfortsätze, eine Verschieblichkeit derselben nach der Mitte hin ermöglicht wird, unterliegt wohl keinem Zweifel. Erfolgt diese Durchmeißelung jedoch nicht in ziemlich ausgiebiger Weise, so ist nach unseren Erfahrungen die Verschieblichkeit der abgemeißelten Knochenteile eine ungenügende. Es bleibt immerhin zu berücksichtigen, daß bei bilateraler Spalte der zu verschließende Spalt gewöhnlich sehr breit ist, demnach eine starke Verschiebung der Alveolarfortsätze erfordert, daß die auf allen Seiten das Knochenstück umgebenden Weichteile der Verschiebung einen Widerstand entgegensetzen, und daß bei einseitiger Spalte auch noch eine Verbindung des einen zu verschiebenden Teiles mit dem Vomer besteht. In einem Falle von Hasenscharte III. Grades mit einseitiger Spaltbildung habe ich nach weitgehender Durchmeißelung nach Brophy doch noch nicht die genügende Verschieblichkeit des Alveolarfortsatzes erhalten, so daß ich in diesem Falle auf die Fortführung der Operation nach Brophy verzichtete und die Hasenscharte in der- 
selben Narkose operierte. In zwei anderen Fällen, die nach der Brophyschen Methode operiert werden sollten, bestätigten sich unsere theoretischen Bedenken; weitere Schwierigkeiten und Nachteile der Methode traten zutage. In dem ersten dieser beiden Fälle - dessen Gipsabdruck Fig. 50 zeigt - war es uns unmöglich die Spaltränder vollkommen aneinander zu bringen.

In dem zweiten Falle, dessen Kiefergipsabdruck Fig. 5I zeigt, konnten unter weitgehender Zuhilfenahme des Meißels die Gaumenplattenränder aneinander gebracht werden. Das Kind starb aber 14 Tage nach der Operation, im Anschluß an welche es immer mehr und mehr verfiel. Das Sektionsprotokoll verzeichnete als Diagnose: ,Myodegeneratio cordis, atrophierender Ka-

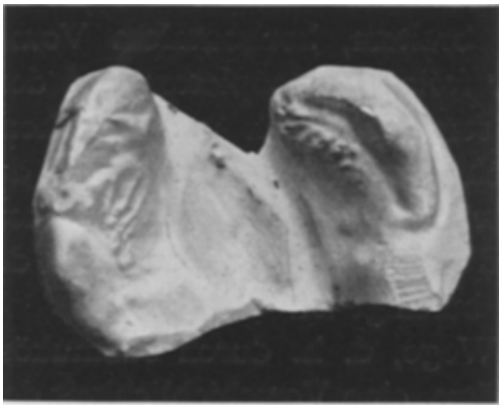

Fig. 50.

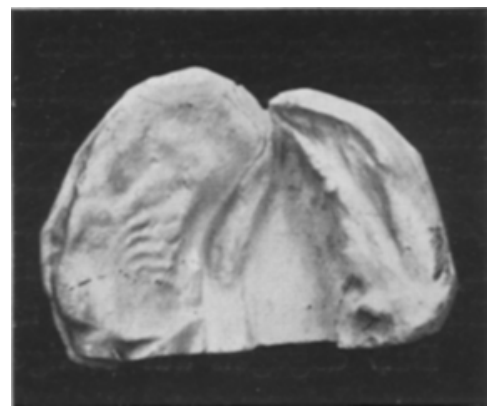

Fig. 5 I.

tarrh des Magens und Darmes, Anämie“. Die Operation war sehr blutreich, dauerte reichlich $3 / 4$ Stunden; alle bei derselben Beteiligten hatten den Eindruck, daß es sich hier um einen sehr gefährlichen Eingriff handele.

Schon die Durchleitung der Silberdrähte gestaltete sich gar nicht einfach. Einstich- und Ausstichöffnungen für diese müssen naturgemä $B$ mindestens in der Höhe der Gaumenplattenränder liegen. Liegen sie nämlich tiefer, so gelangt man bei horizontalem Durchstechen der Alveolarfortsätze durch die Gaumenplatten selbst; führt man aber die Drähte von einer niedriger als die Gaumenplattenränder gelegenen Einstichöffnung aus - etwa mit einer stark gekrümmten Nadel - in schräg aufsteigender Richtung durch den Knochen, so daß die Nadel über dem Gaumenplattenrand in der Spalte zum Vorschein kommt, so schneiden die Drähte 
beim Anziehen derselben in die Gaumenplattenränder ein. Nach der schematischen Zeichnung Brophys (Fig. 49) scheinen die Drähte ganz leicht anzubringen zu sein. Betrachtet man aber die Verhältnisse an dem Schädel eines wenige Wochen alten Kindes (Fig. 52), so ergibt sich, daß der Oberkiefer in diesem Alter von sehr geringer Höhe ist, und es wird klar, daß der Rand der mehr oder weniger abnorm steil gestellten Gaumenplatten nahezu in der Höhe des Bodens der Orbitae liegt.

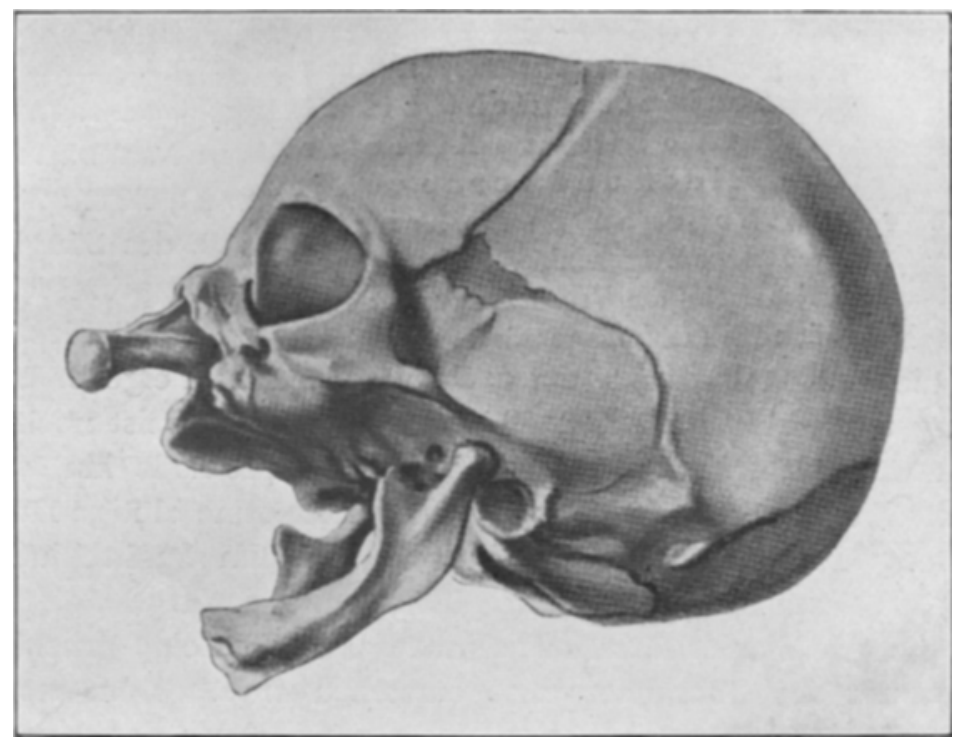

Fig. 52. Nach Lexer. Vorstehender Zwischenkiefer. (Präparat von einem 2 Wochen alten Kinde.)

Will man also die Drähte in genügender Höhe durchleiten, so muß man sich besonders vor einer Verletzung der intraorbitalen Gewebe hüten.

Die Blutung war in allen unseren Fällen eine bedeutende, in den beiden Fällen, in denen die Operation fortgeführt wurde, sogar eine bedrohliche. Sie ist um so mehr zu fürchten, als man den Umfang derselben zu Beginn der Operation nicht genügend kennt, und besonders insofern, als diese Blutung, da aus einer unzugänglichen, breiten Knochenwunde erfolgend, so gut wie unstillbar sein kann. 
Entsprechend den technischen Schwierigkeiten ist besonders unter Berücksichtigung der zu erwartenden starken Blutung die Dauer der Operation für den wenig widerstandsfähigen, wenige Wochen alten Säugling eine zu lange, und wird dies auch trotz zunehmender Übung des Operateurs in dieser Methode bleiben.

Ein weiterer, schwerwiegender Nachteil der Operation ist der, daß eine Verletzung und Zerstörung von Zahnkeimen sich dabei nicht vermeiden läßt. Brophy selbst muß zugeben, daß eine Zerstörung von Zahnkeimen auch bei größter Übung und allergrößter Sorgfalt nicht zu vermeiden sei. Daß die Gefahr der Infektion der breiten, durch die Operation geschaffenen Knochenwunden bei der unmittelbaren Nachbarschaft der Bakterienflora der Mundhöhle keine geringe ist, liegt auf der Hand. Die 4-8 Wochen lang in der Mundhöhle des Säuglings liegenden Drähte und Bleiplatten lassen Zersetzungsprozesse mit ihren Folgen für Magen und Darm des Säuglings befürchten. Alle diese schweren Bedenken drängten sich uns in eigener Überlegung und eigener Beobachtung auf. Helbing weist noch auf einen weiteren Nachteil der Brophyschen Methode hin, wenn er schreibt: „Gelingt es, die Alveolarfortsätze ohne blutige Durchtrennung durch Händedruck einander bis zum Spaltschluß zu nähern, so findet die Zusammenziehung nur dadurch statt, daß sich die Alveolarfortsätze nach innen umlegen, eine erhebliche Deformität des Oberkiefers also entstehen muß." Dem möchte ich noch hinzufügen, daß auch eine Abmeißelung der Alveolarfortsätze und Verschiebung derselben nach der Mittellinie hin nicht korrigierend, sondern deformierend wirken muß! Sind doch an der durchgehenden Gaumenspalte nicht nur die Alveolarfortsätze und Gaumenplatten, sondern sämtliche Knochen des Gesichtsschädels beteiligt (Engel).

Die Schwierigkeiten, die sich dem Durchführen der Brophy schen Methode in den Weg stellen, beruhen demnach auf den anatomischen Verhältnissen der Spaltbildung selbst. Die großen Gefahren der Operation werden sich auch nicht durch die größte Übung, die Einzelne sich in dieser Methode aneignen könnten, zu umgehen sein. Mißerfolge und hohe Mortalitätsziffern haben auch Schoemaker, Murray, Sebileau u. a. gehabt; auch 
Helbing betont die Gefährlichkeit dieser Methode und hat wiederholt vor ihr gewarnt.

Kurz vor Abschluß der vorliegenden Arbeit hat Kärger über cine seit September I9I I in der Bierschen Klinik geübte Methode berichtet, bei der das B rophysche Verfahren besondere Berücksichtigung findet. Wie Kärger mitteilt, hat Brophy in der Berliner Chirurgischen Klinik einen Vortrag über seine Methode gehalten, den Gang seiner Operation an Modellen genau demonstriert und auch einige Fälle voroperiert.

Bei der „doppelten Hasenscharte mit doppeltem Spalt des Kiefers und des Gaumens" beginnt Kärger die Operation - der die Patienten am liebsten im Alter von 3 Wochen unterzogen werden - mit der Zurücklagerung des vorspringenden Zwischenkiefers nach Bardeleben. „Sodann erfolgt durch langsamen, vorsichtig dosierten allmählichen Druck der Finger eine Mobilisierung des Oberkiefers und seiner Zahnfortsätze so weit nach innen, daß die Gaumenplatten möglichst nahe aneinanderrücken und die Näherung der Oberkieferfortsätze so weit durchgeführt wird, daß der $Z$ wischenkiefer gerade eben noch in den Spalt hineinpaßt." Nun folgt die Einführung der Drähte, was mittels besonders konstruierter Nadel geschieht. Nachdem die Drähte durchgezogen sind, werden die durch Modellierung vorbereiteten Alveolarfortsätze durch Zusammendrücken der Oberkieferfortsätze einander genähert und die Drähte in ähnlicher Weise wie bei der Brophyschen Methode - über Bleiplatten, die den Alveolarfortsätzen anliegen, geknotet. Die beiden Seiten werden einander jedoch nur so weit genähert, daß der Zwischenkiefer wie erwähnt - zwischen die vorderen Enden der Alveolarfortsätze des Oberkiefers hineinpaßt. Nach Beendigung dieser Operation beträgt der Abstand der Gaumenplatten am Übergang des harten und weichen Gaumens je nach der Entwicklung der Platten $1 / 2^{--} \mathrm{I} \mathrm{cm}$, während die gespaltenen Zäpfchen sich in der Regel berühren.

In den Fällen ,einseitiger Hasenscharte, Kiefer- und Gaumenspalte" beginnt die Operation ebenfalls mit „einer sorgfältigen Modellierung des Oberkiefers", die sich besonders auf den nach außen und vorn ragenden $Z$ wischenkiefer erstreckt und diesen nach der gespaltenen Seite hinüber zu drängen sucht. Kärger betont, ,daß es auch hierbei nicht auf einen vollkommenen Ver- 
schluß des harten Gaumens ankommt, und da $\beta$ er aus einer Reihe wichtiger Gründe das von Brophy selbst zuweilen vorgenommene und von $\mathrm{Schoemaker}$ weiter ausgebaute Abtrennen und Verschieben der Alveolarfortsätze nach innen zu ängstlich vermeide“. Es folgt nun wiederum Durchführung der Drähte und Knoten derselben über den Alveolarfortsätzen anliegenden Bleiplatten. Als Hauptzweck der Operation betrachtet Kä rger „die sorgfältige Bildung des Kieferbogens und den Verschluß der Spalte“. Die Ränder der Alveolarspalte werden stets angefrischt. Der Verschluß des harten Gaumens wird zunächst nicht angestrebt. Nach Kärger erfolgt derselbe im vorderen Drittel wenn man die zusammenstehenden Ränder des Vomer und der Gaumenplatten etwas anrauht - stets. Aber auch Fälle, wo der ganze harte Gaumen vereinigt wurde, hat $\mathrm{Kärger}$ beobachtet.

Aus den letztgenannten Angaben geht offenbar hervor, daß hier -- bei einseitig durchgehender Spalte - soweit überhaupt Spaltränder aneinander gebracht wurden, nicht die Ränder der absoluten Spalte, d.h. Gaumenplattenrand an Gaumenplattenrand gebracht wurde, sondern der Gaumenplattenrand der Spaltseite mit dem Vomerrand vereinigt wurde, der Vomer also mit verwendet wurde zur Konstruktion des Gaumendaches.

Bei doppelseitig durchgehender Spalte werden die Drähte nach 6 Wochen entfernt, bei einseitig durchgehender Spalte nach 3-4 Wochen.

Der zweite Akt der Operation wird nach einigen Monaten vorgenommen und nach der von Langenbeck angegebenen Methode durchgeführt. Kärger bevorzugt dabei die Ablösung der mukös-periostalen Überzüge von den Spalträndern aus. Bei der gotischen Form des Gaumens genügt dann das Herunterklappen der abgelösten Lappen, bei der romanischen Form dagegen können ,ausgiebige Entspannungsschnitte entlang den Zahnreihen entweder ein- oder doppelseitig" unbedingt notwendig werden, um eine spannungslose Vereinigung der inneren Ränder der Gaumenplatten zu ermöglichen.

Auch bei einfachen Spalten des harten und weichen Gaumens nähert Kärger beide Seiten einander durch seitliches Zusammendrücken der hinteren Teile der Oberkieferzahnfortsätze und erhält sich diese Näherung durch über Bleiplatten geknotete Draht- 
nähte. Zum Schluß berichtet Kär ge r noch über Fälle des harten und weichen Gaumens, in denen der Spaltverschluß nur durch Ablösung und Naht geschlossen wurde. Zur Gaumennaht selbst wird die Bleiplattennaht entschieden bevorzugt (vgl. Fig. 3). Kärger verwendet für seine Operationen lokale Anästhesie.

In ähnlicher Weise wie Brophy, aber unter noch ausgiebigerer Mobilisation der „Oberkiefer", hat Schoemaker den Verschluß der Spalte durch Aneinanderbringen der Spaltränder erreicht. Ausdrücklich hervorheben will ich jedoch, daB Schoe$\mathrm{m}$ ake $\mathrm{r}$ in der Einleitung seiner Arbeit über Uranoplastik schreibt: „Wenn man zu tun hat mit einer Spaltbildung des harten und weichen Gaumens, wird man im allgemeinen mit der Langenbeckschen Methode wohl am weitesten kommen, wenn sie auch nicht immer beim ersten Versuch die Resultate gibt, welche man gewünscht hat." Demnach will Schoemaker seine Methode der Annäherung der Spaltränder nur für die Fälle durchgehender Spaltbildung angewandt wissen. $\mathrm{Zu}$ seinen neuen Operationsplänen wurde Schoemaker angeregt durch die Brophyschen Arbeiten, insbesondere durch die von Brophy aufgestellte Behauptung, daß in Fällen von Gaumenspalte die Decke des Mundes genau so viel zu breit sei, als die Weite der Spalte beträgt. Schoemaker versuchte nun die Brophysche Operation und scheint damit ähnliche Erfahrungen gemacht zu haben, wie wir und andere. Er kam in seinem ersten Falle nicht zum Zieleebenso wie Murray, den Schoe maker zitiert. Darnach konnte Murray die Brophysche Operation im Leichenhause ausführen an einem Kinde, an dem die Uranoplastik ausgeführt worden war. „,Trotz ausgiebiger lateraler Incisionen -- berichtet der Autor ließen sich die Knochen wieder nicht aneinander schieben." Hierzu bemerkt Schoemaker: „Meine Erfahrungen schließen sich an die von Murray an."

Es erging also auch diesen Autoren mit der Brophyschen Methode genau so, wie uns, d.h. sie mußten sich überzeugen, daß die Mobilisation der abgemeißelten Oberkieferteile eine zum Verschluß der Spalte - d.h. der absoluten Spalte - völlig unzureichende war. Schoemaker beabsichtigte nun unter Beibehaltung der Idee des Gaumenspaltverschlusses durch Annähe- 
rung der Spaltränder eine Kieferhälfte so weit zu mobilisieren, daß jede Spannung aufgehoben war, und somit auch Silberdrähte und Bleiplatten in Wegfall kommen konnten. „Die Gaumenhälften sollten um ihre anteroposteriore Achse gedreht werden, aber im umgekehrten Sinne, als es bei der Brophyschen Methode nur allzu leicht geschieht, daß also nicht die Alveolarfortsätze sich nach der Mittellinie wandten, sondern im Gegenteil die Gaumenplatten sich in die horizontale Ebene legten."

Der erste Fall, den Schoemaker auf diese Art behandelte, betraf ein zwei Tage altes Kind mit linkseitiger Spalte der Lippe, des Alveolarrandes und des Gaumens. Die Operation beschreibt Schoemaker in folgender Weise: „Rosersche Hängelage. Die Absicht war, den linken Kiefer durch submuköse Durchmeißelung so beweglich zu machen, daß er nach der Medianlinie geführt werden konnte, und an den rechten Kiefer, der mit dem Zwischenkiefer und der Nasenscheidewand zu einem viel größeren Knochenstück verwachsen war, befestigt werden konnte. Es war dabei nicht meine Absicht, die ganze Maxilla zu verschieben, sondern nur die Gaumenplatte und den Alveolarfortsatz, darum mußte die Durchtrennung in der Linie stattfinden, welche im beigegebenen Schema (Fig. 53) angegeben wird.

Es wurde ein ganz schmaler Meißel genommen und dieser am Rande des ganz weit ausgezogenen Nasenloches durch die Schleimhaut gestochen, bis er den Knochen traf. Mit ganz leichten Hammerschlägen wurde er nach hinten getrieben und dabei jedesmal durch Hebelbewegungen versucht, ob der Oberkiefer schon ins Wanken geriet; sobald das der Fall war, wurde der Meißel herausgenommen und um ein stumpfes Instrument ich gebrauche dazu eine Schere, die im geschlossenen Zustand aussieht wie eine Kropfsonde - durch die Spalte unter die Gaumenplatte geschoben. Durch Heben des Griffes wurde nun erst der Oberkiefer nach außen umgelegt, wodurch der Gaumenteil ganz horizontal gestellt wurde und durch Anstemmen des Instruments an den rechten Kiefer und Senken des Griffes wurde die Beweglichkeit des linken Kiefers vergrößert. Es stellte sich dabei heraus, daß es nicht schwierig war, das Knochenstück so frei zu machen, daß es sich nach der Medianlinie hinüberführen ließ, aber dabei blieb es zu weit nach hinten zurück. Um das 
zu verbessern, wurde wiederum die Sondenschere eingeführt und nun, während ich mit der rechten Hand hebelnde und ziehende Bewegungen machte, der linke Zeigefinger an die Außenseite des Kiefers gelegt. Dieser Finger arbeitete nun mit der Spitze des Instruments so zusammen, daß eine dehnende Wirkung auf die Weichteile ausgeübt wurde. Als das genügend geschehen war, wurde der mediale Rand des nun ziemlich frei beweglichen Knochenstückes wund gemacht, dasselbe wurde nun an dem größeren festgelassenen Oberkiefer ausgeführt, und nun das erstgenannte Knochenstück an das zweite befestigt. Ich führte das auf die denkbar einfachste Weise aus. Mit einer kleinen krummen, aber sehr kräftigen Nadel, in einer Doyenschen Ar-

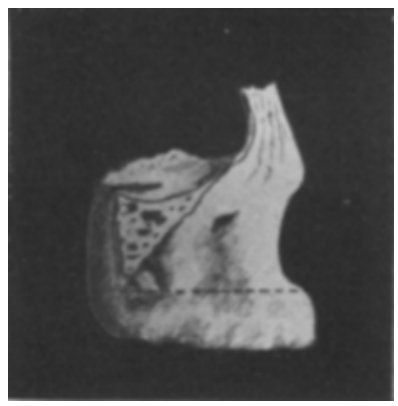

Fig. 53. Nach Schoemaker.

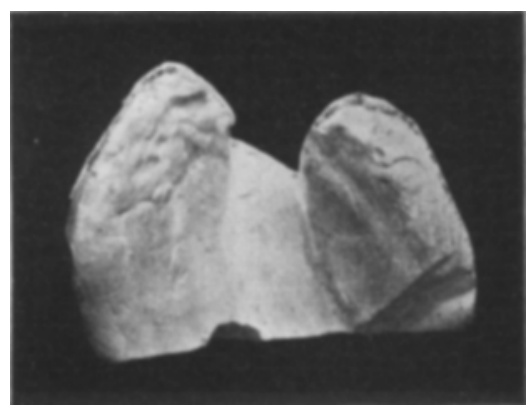

Fig. 54 .

terienklemme gefaßt, durchstach ich Schleimhaut und Knochen des harten Gaumens von beiden Oberkiefern und nähte so mit zwei Knopfnähten die Stücke aneinander; der Verlauf war ganz einfach; nach ı Tagen wurden die Nähte entfernt, der linke Kiefer war an dem rechten festgewachsen." 3 Wochen später wurde die Lippenplastik, und Io Monate darnach die Staphylorrhaphie ausgeführt.

In seinen späteren Fällen mobilisierte $\mathrm{Sch}$ oemaker beide Alveolarfortsätze, um nicht, wie es in dem erwähnten Fall geschah, den Vomer zur Bildung des Gaumendaches mit benützen zu müssen; letzteres Vorgehen - Mobilisation beider Alveolarfortsätze - ist, wie ich oben schon erwähnt habe, das allein richtige, da nur durch Aneinanderbringen der Gaumenplattenränder die Naht dieser in der Mittellinie erfolgen kann. 
Wir haben Gelegenheit gehabt, die Schoemakersche Operation einmal an der Leiche und einmal an einem Säugling auszuführen. In beiden Fällen ließ sich die Operation ohne besondere technische Schwierigkeiten durchführen. Trotzdem starb das Kind $1 / 2$ Stunde post operationem. Fig. 54 zeigt das Kiefergipsmodell dieses Kindes vor der Operation.

Wodurch wird der Verschluß der Spaltbildung bei der Schoemakerschen Operation ermöglicht? Erstens dadurch, daß die Alveolarfortsätze mit den Gaumenplatten einander genähert werden, und zweitens dadurch, daß die Gaumenplatten in eine mehr horizontale Ebene eingestellt werden. Letzteres geschieht durch ein nach Außen-gedreht-werden der abgemeißelten Alveolarfortsätze um die bekannte Sagittale. Gerade in diesem horizontaleren Einstellen der Gaumenplatten liegt ein wichtiger Unterschied der Schoemakerschen Operation gegenüber der von Brophy. Gelegentlich soll allein durch das horizontalere Einstellen der Gaumenplatten der Verschluß der Spalte erzielt werden können, so daß in diesen Fällen keine Verringerung der Distanz der Alveolarfortsätze einzutreten braucht. Je steiler der Neigungswinkel der Gaumenplatten vor der Operation gewesen ist, um so eher wird der Spalt durch eine horizontalere Einstellung der Gaumenplattenüberzüge zu decken sein. Die in Tabelle I niedergelegten Messungsresultate zeigen aber einwandfrei, daß nahezu in allen Fällen der Spalt zu breit ist, als daß er auf diese Weise geschlossen werden könnte. Würde überdies die horizontale Einstellung der Gaumenplatten zur Beseitigung der Spalte genügen, so wäre die Schoemakersche Operation gar nicht notwendig; die Gaumenspalte wäre in diesem Falle zu behandeln nach der von Langenbeck angegebenen ,Methode der unterbrochenen Seiteneinschnitte".

Da bei der Schoemakerschen Operation die bukkale Weichteilbekleidung der Alveolarfortsätze völlig intakt bleibt, kann eine Verschiebung der Alveolarfortsätze nach der Mitte hin nur durch eine Dehnung dieser Weichteilbekleidung des losgemeißelten Knochenstückes geschehen. In diesem Umstande scheint mir auf Grund der beiden von uns operierten Fälle ein schwacher Punkt der Schoemakerschen Operationsmethode zu liegen. Wiewohl in unseren beiden Fällen die Vereinigung der 
Gaumenplattenränder in der Mittellinie gelang, so stellten sich doch dieser die seitlichen Weichteile hemmend in den Weg. Bei breiter Spalte und von vornherein nicht sehr steil stehenden Gaumenplatten wäre demnach ein Mißlingen der Operation leicht $\mathrm{zu}$ erklären. Tatsächlich hat Schoemaker selbst in 33 Proz. der Fälle einen Mißerfolg zu verzeichnen gehabt, insofern, als die Knochen nach Entfernung der Nähte nicht aneinander gewachsen waren oder die Nähte einfach durchgeschnitten hatten. Trotzdem halten wir die Schoemakersche Operation für technisch einfacher als die Brophysche. Weitere Vorteile hat sie vor dieser insofern, als die Gaumenplatten eher horizontal dabei gestellt werden und deshalb die Verringerung der Distanz der Alveolarfortsätze eine geringere ist. Da Drähte und Bleiplatten in Wegfall kommen, ist die Gefahr der Zerstörung von Zahnkeimen bei der Schoemakerschen Operation entschieden geringer als bei der Brophyschen, wenigstens in den Fällen, in denen letztere unter Zuhilfenahme des Meißels durchgeführt werden muß. Die Schoemakersche Methode hat aber auch große Nachteile. Vor allem gilt für sie hinsichtlich der Gefahr der Blutung ungefähr dasselbe, was bei der Brophyschen Methode gesagt werden mußte. Wenn Schoemaker schreibt, „die Blutung sei bei seiner Methode im allgemeinen weniger stark als beim Ablösen der Lappen nach der Langenbeckschen Methode, und werde durch Tamponade leicht gestillt", so können wir dem Autor darin nicht beistimmen, insofern wir in der methodischen Kompression nach Wolff ein ausgezeichnetes Mittel zur Verhinderung der Blutung beim Ablösen der Lappen haben. Schoemaker selbst hat infolge großen Blutverlustes unter I2 Kindern eins verloren; ich habe dagegen unter zahlreichen Operationen nach Langenbeck niemals eine gefahrdrohende, geschweige denn tödliche Blutung erlebt. Ein Mißlingen der Operation in 33 Proz. der Fälle in der Hand des Autors selbst gibt auch zu schweren Bedenken Anlaß. Daß manchmal Zahnkeime verloren gehen, führt Schoemaker selbst als Nachteil seiner Methode an.

Vom prinzipiellen Standpunkte aus aber lehnen wir sowohl die Brophysche als auch die Schoemakersche Operationsmethode $\mathrm{ab}$, da beide Methoden verzichten auf den durch die ein- 
fache Hasenschartenoperation erreichbaren Verschluß der Kieferspalte und die Verengerung der Gaumenspalte. Wird aber eine Annäherung beider Oberkieferhälften ohne blutige Mobilisation der Alveolarfortsätze vorgenommen (Kärger, Brophy), so müssen sich die beiden Alveolarfortsätze nach innen umbiegen und -- wie Helbing mit Recht bemerkt - die Deformität noch vermehren. Das Durchführen von Drähten durch die Alveolarfortsätze halten wir nach wie vor für eine schwere Gefahr für die Zahnkeime, deren Verletzung unter allen Umständen vermieden werden muß. Dazu kommt noch, daß die Beseitigung der Gaumenspalte in so frühem Alter, wie es Brophy, Schoemaker und Kärger erstreben, gar nicht empfohlen werden kann, da eine so frühzeitig vorgenommene Korrektur eine Verengerung des Oberkiefers besonders in dessen vorderen Teil befürchten läßt.

Schoemaker selbst betont übrigens, wie erwähnt, in seiner Einleitung, daß man wohl am weitesten komme mit der Langenbeckschen Operation, sofern man es zu tun habe nur mit einer Spaltbildung des harten und weichen Gaumens! Ich glaube, durch die vorliegende Arbeit den Beweis erbracht zu haben, daß wir mit Hilfe der Hasenschartenoperation die einseitig durchgehende Kiefergaumenspalte in eine einfache Spalte nur des harten und weichen Gaumens umwandeln und darüber hinaus die Spalte selbst sogar noch erheblich verengern können.

Codivilla und Helbing haben ebenfalls auf blutige Weise den Spalt durch Aneinanderbringen der Spaltränder beseitigt; in beiden Fällen wurde jedoch nur die eine Oberkieferhälfte mobilisiert und verschoben. Das Vorgehen dieser beiden Autoren läßt sich jedoch nicht in Parallele setzen zu den Methoden von Brophy und Schoemaker, insofern die beiden erstgenannten Autoren ihr Verfahren keineswegs zu einer Normalmethode erhoben haben und es auch nicht an Kindern im ersten Lebens. jahre anwandten.

Codivillas Patient war 5 Jahre alt, litt an schwerer, angeborener Spaltbildung der Lippe, des Oberkiefers, des harten und weichen Gaumens. Codivilla glaubte, die weite Dehiszenz 
der Oberkiefer nur durch eine blutige Mobilisierung der einen Seite beheben zu können. Dies gelang ihm durch eine osteoplastische Resektion des rechten Oberkiefers, wobei er die Verbindung von Oberkiefer mit dem Os zygomaticum nach Freilegung derselben durch einen Wangenschnitt durchtrennte.

In dem Falle von Helbing handelte es sich um einen $5^{1} / 2$ jähr. Knaben, bei welchem der Alveolarfortsatz geschlossen war (oder wenigstens beide Alveolarfortsätze aneinanderlagen) und bei welchem $2^{1 / 2}$ Jahre vorher die Spalte ohne Erfolg operiert worden war. Nach Helbing waren die Gaumenplattenüberzüge so schmal, daß die Langenbecksche Operation allein keinen Erfolg versprach. Über sein operatives Vorgehen in diesem Falle sagt Helbing: „In der Überlegung, daß die festeste Verbindung der Oberkieferhälften bei Gaumenspalten mit den übrigen Gesichtsschädelknochen das Os zygomaticum ist, habe ich auf der rechten Seite von der bukkalen Schleimhaut-Umschlagfalte aus in der Höhe des II. Prämolaren den Processus zygomaticus ossis maxillaris submukös durchmeißelt." Bei stärkerem Druck auf die rechte Oberkieferhälfte ließ sich darnach diese der linken so weit nähern, daß die Spalte fast vollkommen ausgefüllt war. In ähnlicher Weise wie Brophy, legte nun Helbing Silberdrähte durch die beiden Oberkieferhälften, welche den Zweck hatten, den bei Nachlassen des Druckes in seine alte Stellung zurückfedernden rechten Oberkiefer in der gewünschten Lage zu erhalten. Eine vollkommene Berührung beider Gaumenplattenränder wurde nicht erreicht; der schmale Spalt wurde nach der Langenbeckschen Methode überbrückt.

Den beiden letztgenannten Methoden muß zugestanden werden, daß sie in Ausnahmefällen gelegentlich Verwendung finden können. Um jedoch Mißverständnissen vorzubeugen, bemerke ich, daß ich bisher überhaupt nur einen einzigen Fall von Gaumenspalte gesehen habe, in welchem die Langenbecksche Operation nicht hätte angewandt werden können. In diesem Falle, den Fig. 48 zeigt, bestand im sechsten Lebensjahr die doppelseitige Hasenscharte noch, nachdem die von verschiedener Seite vorgenommene Operation derselben wiederholt mißglückt war. 
2. Stellungnahme zur Idee und den Methoden der Spaltausfüllung.

Unsere Untersuchungen haben ergeben, daß tatsächlich eine Verbreiterung des Oberkiefers in toto bei Fällen von Kiefergaumenspalte besteht. Das therapeutische Handeln wird demnach darauf ausgehen, diese abnorm große Oberkieferbreite zu beseitigen oder wenigstens zu verringern. Vom prinzipiellen Standpunkte aus kämen also Ausfüllungsmethoden erst dann in Betracht, wenn die Verschmälerung des Oberkiefers so weit fortgeschritten ist, als im einzelnen Falle verlangt werden muß. Jedenfalls werden wir nach dem Gesagten nicht in die Lage kommen, einen Spalt im Alveolarfortsatz ausfüllen zu müssen.

Die Ausfüllung der Gaumenspalte kann, wie in der Einleitung erwähnt wurde, auf mannigfache Art erreicht werden. Zweck der vorliegenden Arbeit ist es jedoch nicht, auf die hier in Betracht kommenden Methoden im einzelnen einzugehen. Es sei aber darauf hingewiesen, daß die Mehrzahl der eingangs erwähnten Spaltausfüllungsmethoden auch von ihren Urhebern weniger für die angeborenen, als für die - vor der Einführung der Quecksilber- und Salvarsanbehandlung der Syphilis noch häufiger als heutzutage beobachteten - Fälle von erworbenen Gaumendefekten bestimmt war.

Ein allen Ausführungsmethoden gemeinsamer Nachteil, der in geringerem Grade natürlich allen Gaumenoperationen überhaupt zukommt, ist die Unmöglichkeit in der Mundhöhle aseptische Heilungsbedingungen zu schaffen.

Der Spalt kann ausgefüllt werden entweder durch Transplantation oder mit Hilfe plastischer Operationen.

Unter Transplantation verstehen wir mit $\mathrm{Pay} \mathbf{r}$ die operative freie Übertragungen von Teilen, die von ihrem Mutterboden gänzlich losgelöst sind, auf eine andere Stelle. Auch mit Hilfe dieser Methode läßt sich eine Verschlußbildung der Gaumenspalte denken. Ich selbst habe in einem Falle (Fig.48) den Spalt mittels eines der Tibia entnommenen Periostknochenläppchens zu verschließen versucht. Der Erfolg war ein teilweiser.

Die Technik einer solchen Operation ist schwierig, die Heilungsbedingungen sind denkbar ungünstige. Solche Methoden 
werden ferner noch dadurch außerordentlich kompliziert, daß man zuerst eine genügende Wundfläche als Basis für das Transplantat schaffen muß. In dem angeführten Falle konnte ich dieser Bedingung dadurch gerecht werden, daß ich die Schleimhautbekleidung der rechten unteren Muschel und des Vomer nach Ablösung und Umklappen derselben als Wundbasis verwandte.

Erheblich leichter gelingt die Einheilung gesticlter Lappen aus der näheren oder aber auch aus der entfernteren Umgebung. Ist jedoch ein solcher Lappen aus Zunge, Wange oder Haut gebildet, so ist der neugebildete Gaumen kein knöcherner, seine Funktion eine entsprechend minderwertige. Füllt man nur den Spalt im harten Gaumen aus, so wird die Staphylorrhaphie sehr erschwert. Die Einheilung eines kleinen Fingers ist technisch nicht gerade einfach und entschieden zu verstümmelnd. Eher könnte man die große Zehe zur Einheilung bringen.

3. Stellungnahme zu der Überbrückungsmethode, mit besonderer Berücksichtigung der Langenbeckschen Operation.

Unter den eingangs als Methoden der Spaltüberbrückung bezeichneten Operationen hat neben dem Langenbeckschen Verfahren nur die Lanesche Methode noch praktische Bedeucung. Die Lanesche Operation $m u ß$ in sehr frühem Alter am besten innerhalb der ersten Lebenstage - ausgeführt werden. Vom prinzipiellen Standpunkte aus gilt deshalb auch für dieses Verfahren, daß es wichtige, durch die Vornahme der Hasenschartenoperation erreichbare Vorteile nicht ausnützt. Ein für die gesamte Chirurgie des Kindesalters - soweit es sich nicht um vitale Indikationen handelt - sehr beherzigenswerter Grundsatz lautet: „Die Größe des Eingriffes muß zur vitalen Energie des Kindes in einem vernünftigen Verhältnis stehen" (Spitzy). Auch von diesem Standpunkte aus möchten wir eine so komplizierte Operation, wie sie die Lanesche ist, einem 24 stündigen oder 48 stündigen Säugling nicht zumuten. Man wende nicht ein, daß eben gerade durch die so frühzeitig vorgenommene Operation günstige Ernährungs- und Atmungsbedingungen geschaffen 
werden sollen. Für Hasenscharten-Kinder mit Gaumenspalte gilt die Erfahrungstatsache, daß ein gewisser Prozentsatz derselben einen Mangel an vitaler Energie aufweist, der die Kinder nach der Operation sich nicht nur nicht erholen läßt, sondern sogar das Gelingen der Operation selbst nicht selten vereitelt. Solche Kinder werden durch den großen Eingriff nicht gesünder, sondern schwer gefährdet; ein anderer Teil der Patienten aber entwickelt sich überraschend gut trotz der Mißbildung. Bei diesem eilt es mit der Operation in den ersten Tagen oder Wochen aber vollends nicht. Im übrigen haben wir in der Langenbeckschen Operation ein einfacheres und sicherer zum Ziele führendes Verfahren; zahlreiche Chirurgen ziehen dieses der La n eschen Operation vor.

Die Krimersche Methode, die für die damalige Zeit eine große Tat war, besonders insofern, als sie die Idee einer rationellen operativen Behandlung der Gaumenspalte in sich barg, hat heute nur noch historisches Interesse.

Die souveräne Methode ist bis zum heutigen Tage das Verfahren nach v. Langenbeck geblieben. Diese Methode ist in allen Fällen anwendbar, in welchen die Vereinigung der Lippenspalte die erforderliche Zeit vorher mit Erfolg ausgeführt worden ist. Unter den zahlreichen Fällen von schweren Gaumenspalten, die ich zu operieren Gelegenheit hatte, befand sich nur ein einziger Fall, in welchem die Langenbecksche Operation nicht ohne weiteres auszuführen gewesen wäre; es ist das der in Fig. 48 abgebildete Patient, der eben seine Hasenscharte noch besaß. Durch Beseitigung dieser wäre auch in diesem Falle die durchgehende Spalte in eine einfache Spalte umzuwandeln, und der Fall mit Hilfe der Langenbeckschen Operation zu heilen gewesen. Eine Ausnahme können gelegentlich Fälle machen, in denen die Operation der Gaumenspalte nach Langenbeck schon ohne Erfolg vorgenommen wurde; in der Regel können aber auch diese Fälle noch mit Erfolg dem Langenbeckschen Verfahren unterzogen werden.

Von hervorragender Bedeutung für das volle Gelingen der Langenbeckschen Operation ist nach unseren Erfahrungen die Berücksichtigung des Allgemeinzustandes. Nur ein Patient mit gutem Allgemeinbefinden verfügt über das nötige $\mathrm{MaB}$ an Heilungstendenz. Dieser Satz gilt insbesondere in Fällen, in 
denen, wie nach der Langenbeckschen Operation, Wunden heilen müssen unter ungünstigen Bedingungen, Wunden, die der Infektion von der Mundhöhle aus stets zugänglich sind, Wundränder, deren blutzuführende Gefäße kurz vorher durch die Ablösung der Lappen teilweise funktionell ausgeschaltet oder doch sehr beeinträchtigt worden sind. Dazu kommt eine Änderung in der Ernährung des Patienten $1 \frac{1}{2}-2$ Wochen lang im Anschluß an die Operation, ein Umstand, der bei vorher schon ungenügender Heilungstendenz sehr in die Wagschale fallen kann. Post operationem tritt das Vorhandensein oder das Fehlen einer genügenden Heilungstendenz oft eklatant in Erscheinung. Im ersteren Falle bleiben Wundränder und Stichkanäle ohne jeden Belag, heilen fast reaktionslos, in letzterem Falle dagegen bedecken sich Nahtlinie und Fäden mit dicken, weißlich-gelben Belägen. Es kommt zu entzündlichen Reizerscheinungen und ev. Einschneiden und sogar Ausreißen der Fäden. Solche Mißerfolge vermeidet man am besten durch Berücksichtigung des mächtigen Faktors einer genügenden Heilungstendenz. Günstiges absolutes Gewicht, aufsteigende Gewichtskurve, Appetit und regelmäßige Verdauung, sowie gute Durchblutung der Haut und sichtbaren Schleimhäute lassen die erforderliche Heilungstendenz erwarten, wogegen uns abnehmende Gewichtskurve, Durchfälle, Schleimhautkatarrhe und anämisches Aussehen veranlassen sollten, die Operation auf einen günstigeren Zeitpunkt zu verlegen.

Von weitgehendster Bedeutung sowohl für das anatomische als auch funktionelle, nach der Langenbeckschen Operation zu erwartende Resultat ist das Alter des Patienten. Bis heute ist noch keine Einigkeit erzielt hinsichtlich der Frage, in welchem Alter die Langenbecksche Operation am zweckmäßigsten vorzunehmen sei. Wolff und $\mathrm{Helbing}$ befürworten entschieden die Frühoperation - womöglich im ersten Lebensjahre - andere, wohl noch die Mehrzahl der Chirurgen, wollen die Operation erst im Alter von mehreren Jahren vorgenommen haben. Mehrfache Überlegungen sind bei Entscheidung dieser Frage zu berücksichtigen. Bisher ist die Frage besonders von physiologischen und technischen Gesichtspunkten aus beleuchtet worden. So machten die Anhänger der Frühoperation mit Recht darauf aufmerksam, daß das funktionelle Resultat ein bedeutend besseres werde, wenn 
die Uranoplastik und besonders auch die Staphylorrhaphie möglichst früh oder wenigstens noch im ersten Lebensjahre vorgenommen würde. Besonders nach den Untersuchungen Wolffs und Gutzmanns darf diese Tatsache als erwiesen betrachtet werden. Zum Teil ist sie darauf zurückzuführen, daß sich die in Betracht kommende Muskulatur, durch deren funktionelle Inanspruchnahme besser entwickelt, zum Teil darauf, daß mit dem Gelingen der Operation die sekundäre Verschlimmerung der ursprünglichen Deformität verhindert wird. Bei der Frühoperation lernt ferner das Kind das Sprechen unter anatomischen Verhältnissen des Gaumens, die sich nicht mehr wesentlich ändern, während der Patient, der das Sprechen unter den anormalen und dem Sprechakt ungünstigen Verhältnissen einer Spaltbildung des Gaumens erlernt hat, sich bei einem später vorgenommenen Verschluß der Spalte an völlig neue und gewaltig veränderte Verhältnisse erst gewöhnen muß. So ist es zu erklären, daß bei erst in späteren Jahren vorgenommenem Verschluß der Spaltbildung oft das funktionelle Resultat hinter dem anatomischen zurückbleibt. Daß auch das anatomische Resultat in so spät operierten Fällen - besonders was die Länge des weichen Gaumens und des Zäpfchens anbelangt regelmäßig ein ungünstigeres ist, als in rechtzeitig operierten Fällen, soll an dieser Stelle nur kurz angedeutet werden.

Auch technische Gründe sprechen für die Frühoperation. Manchem mag es vielleicht auffallend erscheinen, daß die Technik der Langenbeckschen Operation bei kleinen Kindern entschieden leichter ist, als bei mehrjährigen. Der Blutverlust ist gewöhnlich ein geringer, die mukös-periostalen Überzüge lassen sich in der Regel leichter von der Unterlage abheben, als in späteren Jahren. Auch die genaue Adaption der Wundränder ist leichter zu erreichen, da die Gaumenplattenüberzüge in frühem Alter relativ dicker sind.

Psychische Momente veranlassen uns nicht weniger zur Vornahme der Operation in frühem Alter. Solche psychische Momente gelten für Eltern und Patienten in gleicher Weise. Der Wunsch der Eltern ein Kind mit einer so schweren Mißbildung bald geheilt zu sehen, ist begreiflich, die Kinder selbst aber sollte man nicht zum Bewußtsein ihres Zustandes kommen lassen. 
Kann man sich diesen für die Frühoperation sprechenden Gründen um so weniger verschließen, als diese keine wesentlich höhere Mortalitätsziffer aufweist, als die in späterem Alter vorgenommene Operation (Helbing), so will ich die Vornahme der Frühoperation auch noch vom anatomischen und anatomischtechnischen Standpunkt aus begründen. Nachdem nämlich durch die vorliegenden Untersuchungen erwiesen ist, daß die Spalte bei durchgehender Gaumenspalte keineswegs eine gleichbleibende Größe ist, sich vielmehrohne unser Zutun mit $z$ unehmendem Wachstum von selbst verändert, und andererseits durch das einfache Mittel der Hasenschartenoperation leicht in einem gewollten Sinne beeinfluBt werden kann, ergibt sich für uns hinsichtlich des Zeitpunktes, an welchem der operative VerschluB vorzunehmen ist, eine bestimmte Forderung, durch die ich die bisher strittige Frage der Lösung näher zu bringen hoffe; diese Forderung lautet: „Die Gaumenspalte ist zu verschließen zur Zeit des Optimums der Spaltbreite."

Nach Kenntnisnahme der mitgeteilten Untersuchungen erscheint diese Forderung - sonst günstige Verhältnisse vorausgesetzt - geradezu als eine selbstverständliche. Wenn sie nicht bisher schon die Frage bezüglich des Zeitpunktes der Vornahme der Operation entscheiden konnte, so liegt dies meines Erachtens daran, daß die im Vorhergehenden besprochenen Verhältnisse noch nicht hinreichend geklärt waren.

Wann das Optimum der Spaltbreite erreicht ist, ist in den bisherigen Mitteilungen schon gesagt, nämlich dann, wenn die beiden Teile des gespaltenen Alveolarfortsatzes unter der Wirkung der vereinigten Oberlippe sich berühren. Von da ab beginnt wieder eine Verbreiterung der Spalte.

Der Vorteil, den wir haben, wenn wir zur Zeit der optimalen Breite operieren, ist ein eklatanter: Je schmäler der Spalt, desto leichter seine Überbrückung. Die Verschiebung der abgelösten Lappen braucht keine so weitgehende zu sein, der Kontakt derselben mit ihrer Unterlage wird wieder ein ausgiebiger, die Ernährung der Lappen ist demnach eine günstige. Die Operation 
selbst wird technisch einfacher und im Erfolg um so sicherer. Das Entstehen von Seitenfisteln wird sicher vermieden. Insbesondere aber sind spätere, nach Vornahme der Langen beckschen Operation etwa auftretende quere Verengerungen des Oberkiefers am wenigsten zu befürchten, wenn im Stadium der optimalen Spaltbreite operiert wird.

Das Stadium der optimalen Spaltbreite ist zeitlich' abhängig von der Hasenschartenoperation; im allgemeinen ist es erreicht gegen Ende des ersten Lebensjahres und erstreckt sich bis etwa zur Mitte ev. auch zum Ende des zweiten Lebensjahres.

Bezüglich der Technik der Langenbeckschen Operation ist dem Bekannten wenig hinzuzufügen. Zugegeben muß werden, daß mit zunehmender Erfahrung und Übung die Erfolge sich bessern. Für die Mehrzahl der Chirurgen wird es allerdings bei der relativen Seltenheit der Mißbildung nicht möglich sein, sich in dieser speziellen Operation eine größere Erfahrung anzueignen. Das gilt aber auch ebenso für die anderen Methoden zur Operation der Gaumenspalte. Die Operation wird sehr erleichtert und in ihrer Dauer vermindert durch Anwendung einer Narkosenart, wie sie Helbing beschreibt. Darnach wird die Narkose mit Hilfe des Roth-Drägerschen Apparates eingeleitet; ein dicker Nelaton-Katheter wird mit dem Apparat verbunden und durch das eine Nasenloch in den Nasenrachenraum eingeführt; die perorale Intubation ist völlig überflüssig. Wir sind in allen Fällen ohne Ausnahme mit dieser Art Narkose ausgekommen. Als Narkotikum dient Chloroform. Das Offenhalten des Mundes und Niederdrücken der Zunge geschieht am besten mittels modifizierten Whitheadschen Mundspekulums. Bei einseitig durchgehenden Spalten durchtrennt man zuerst mit geradem scharfen Messer die Schleimhaut am Übergang von Gaumenplattenrand auf Vomer. Die Ablösung der Lappen erfolgt in ausgiebiger Weise und muß besonders an den Ossa palatina sorgfältig durchgeführt werden. Bisweilen kommt es vor, daß bei einseitig durchgehender Spalte der Lappen der nicht gespaltenen Seite nach seiner Ablösung an einer Stelle einen sehr dünnen Rand zeigt. Diese dünne Stelle entspricht dann dem hinteren Ende des Vomer, in dessen Bereich eben die Gaumenplattenüberzüge allmählich den Charakter der Vomerschleimhaut an- 
nehmen (dünn und fest auf der Unterlage aufsitzend). Genau an dieser Stelle schneidet in solchen Fällen bisweilen die erste Naht durch, auch wenn vielleicht ohne jede Spannung genäht wurde. In der Regel operieren wir jetzt zweizeitig, nachdem wir früher stets einzeitig operiert hatten. In den Fällen, in welchen, wie eben angedeutet, eine Verdünnung des Überzugs der einen Gaumenplatte entsprechend der Stelle des hinteren Vomerendes vorliegt, sollte man unter allen Umständen zweizeitig vorgehen. Nur bei sehr engen Spalten ziehen wir die einzeitige Operation vor. Von den verschiedenen Gründen, die zugunsten der zweizeitigen Methode angeführt werden, schätzen wir am meisten den ein, daß die Patienten die zweizeitige Operation entschieden leichter ertragen, als die einzeitige. Von der Seitentamponade sind wir abgekommen; das Haltebändchen dagegen kann in Ausnahmefällen gute Dienste leisten. Die Naht erfolgt ausschließlich mit geflochtener (Turner) Seide Nr. O, I und 2. Silk und Pferdehaare wenden wir nach mehrfachen Versuchen nicht mehr an. Hat man mit Seide genäht, so dürfen die Kinder ca. 8- Io Tage post operationem keine Milch bekommen. Durchschnittlich legen wir für harten und weichen Gaumen inkl. Zäpfchen 8-ı Nähte ein; mehr wie I 4 haben wir nie eingelegt. Es empfiehlt sich die erste Naht an der Stelle einzulegen, an welcher sie am bequemsten anzubringen ist, und besonders an welcher sich die Wundränder am genauesten und leichtesten adaptieren lassen. Zwischen den einzelnen, durch die ganze Dicke des mukösperiostalen Überzuges gehenden Nähten lege ich, bevor letztere geknüpft werden, Nähte an, die nur die oral gelegenen Schleimhautränder fassen. Bevor eine durchgreifende Naht geknüpft wird, wird der vor und hinter derselben gelegene Faden stark angezogen. Durch diese beiden letzten Maßnahmen wird eine möglichst breite Adaption der Wundränder ermöglicht. Stark gebogene Darmnadeln und ein dünner gewöhnlicher Nadelhalter bilden das ganze Instrumentarium. Nur für die Anlegung der Nähte in der vorderen Spaltecke verwenden wir eine von mir konstruierte Nadel, ähnlich wie sie Trélat verwendet. Stütznähte verwenden wir nicht mehr, wo sie wünschenswert erscheinen, ersetzen wir sie durch das Bändchen. Daß sich das Bändchen mit einem Belag bedeckt, ist keine Kontraindikation gegen seine 
Anwendung in den wenigen Fällen, wo es notwendig erscheint; die angeblichen Zersetzungen, die es während seines nur 4-bis 6 tägigen Aufenthaltes in der Mundhöhle veranlaßt, haben bei unseren Fällen noch nie irgendwelche lokale oder allgemeine Störung verursacht ${ }^{1}$ ); wichtig ist, daß das Bändchen von Anfang an ziemlich weit gelassen wird, da es sonst nach kurzer Zeit zu enge ist und die Wundränder in der Mitte übereinander schiebt. Das Bändchen wirkt nicht lediglich entspannend wie die Stütznaht, vielmehr glaube ich seine Hauptwirkung darin sehen zu müssen, dab es die Anlegung der Lappen an ihre Basis verlangsamt und damit deren Retraktion verringert. In einigen Fällen kann dies aber ausnahmsweise wünschenswert sein. Seitenfisteln verursacht das Bändchen nur, wenn es zu lange liegt, eben aus dem erwähnten Grunde; ich habe nie eine Seitenfistel gesehen, jedenfalls deshalb nicht, weil wir vor der Langenbeckschen Operation durchgehende Spalten in einseitige verwandelt und den Spalt selbst bis zur optimalen Breite verschmälert haben.

Zur kritischen Beurteilung der Langen beckschen Methode ist erforderlich, daß wir uns klar werden, in welcher Weise im einzelnen der Verschluß der Spalte mit Hilfe dieser Methode zustande kommt. Verschiedene Momente sind an der Verschlußbildung beteiligt.

Die allgemeine Ansicht geht wohl dahin, daß die Verschiebung der abgelösten Gaumenplattenüberzüge nach der Mittellinie hin am meisten zum Verschluß der Spalte beiträgt. Sicherlich ist diese Ansicht für die Mehrzahl der Fälle richtig. Lang enbeck selbst sah in dieser Verschiebung der Gaumenplattenüberzüge nach der Spaltmitte hin das Mittel zur Verschließung der Spalte. Es wäre aber ein großer Irrtum, wenn wir in dieser Verschiebung allein das Zustandekommen der Überbrückung sehen wollten. Wohl in keinem Falle erfolgt nämlich die Verschlußbildung der Spalte durch die Verschiebung allein. Betrachten wir schon wenige Tage nach Ablösung der Lappen die Stellen der Seiteneinschnitte, so fällt vor allem auf, wie schmal die durch die Verschiebung der Überzüge nach der Mittellinie hin entstandenen Defekte geworden sind; ja, nähen wir nicht gleich im Anschluß an die Ablösung der Lappen die verwundeten Spaltränder,

1) Wiederholte Bepinselung mit 2o proz. Argyrollösung ist sehr empfehlenswert. 
so sind schon nach wenigen Tagen die Stellen der Seitenincisionen kaum noch erkennbar, oft nur von linearer Breite. Trotzdem aber ist regelmäßig der Spalt selbst ein engerer geworden. Hätten wir schon die Naht ausgeführt, so wäre man versucht, eine Dehnung der Lappen in ihrem Breitendurchmesser zur Erklärung dieser Erscheinung heranzuziehen; daß eine solche Dehnung, besonders wenn unter einer gewissen Spannung die Naht erfolgte, zustande kommen kann, kann nicht ohne weiteres bestritten werden. Ist jedoch die Naht noch nicht angelegt, so wird man an eine Dehnung der Lappen nicht denken können. Die auch in solchen Fällen regelmäßig zu beobachtende Spaltverschmälerung ist in erster Linie zurückzuführen auf ein Tiefertreten der Gaumenspaltränder: Die Lappen, die von ihrer Unterlage abgelöst sind, fallen, dem Gesetz der Schwere folgend, so weit herab, als es ihre noch vorhandene Befestigung gestattet. Hat man die Ablösung der Lappen - wie es gewöhnlich geschieht — von langen Seitenincisionen aus, nicht vom Spaltrand selbst aus vorgenommen, so treten nicht einfach die Spaltränder tiefer, sondern die durch die Seitenincisionen gesetzten Wundränder der abgelösten Gaumenweichteilplatten treten zugleich höher. Infolge des Tiefertretens der medialen und des in die Höhe-Rückens der lateralen Wundränder steht das neue Gaumendach oft nahezu horizontal. Je steiler vor der Operation die Gaumenplatten standen, um so mehr ist das Tiefertreten der Gaumenplattenüberzüge ursächlich mit an der Spaltüberbrückung beteiligt. In einem gewissen Prozentsatz der Fälle läßt sich allein durch das Herunterklappen der von den Spalträndern aus abgelösten Gaumenüberzüge der Spalt überbrücken. Im jeweiligen Falle lassen sich diese Verhältnisse mit ziemlicher Genauigkeit am Gipsmodell abmessen. Das Höhertreten der lateralen Gaumenplattenwundränder - und damit des ganzen abgelösten Gaumenlappens - hat auch noch insofern eine gewisse Bedeutung, als die Distanz zwischen beiden Oberkieferhälften nach oben hin schnell abnimmt, somit die Spaltüberbrückung dadurch erleichtert wird. Endlich wird durch ein Höhertreten der beiden Lappen die Raumverminderung, die durch das Tiefertreten der Spaltränder in der Mundhöhle bedingt wird, zum Teil wieder ausgeglichen. 
Tabelle I. Fälle von durchgehender Spalt -

\begin{tabular}{|c|c|c|c|c|c|c|c|}
\hline$\dot{4}$ & $\begin{array}{l}\text { Vor- } \\
\text { und } \\
\text { Zuname }\end{array}$ & Alter & Diagnose & 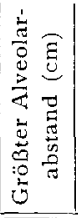 & 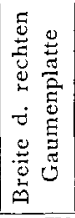 & 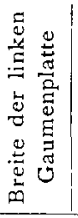 & 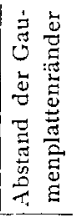 \\
\hline I & R., Th. & I Tag & $\begin{array}{l}\text { Hasenscharte III. Gr. lks. Links- } \\
\text { seitig durchgeh. Gaumenspalte. }\end{array}$ & 3,9 & $\mathrm{I}, 4$ & 1,3 & 1,7 \\
\hline 2 & H., H. & I Tag & $\begin{array}{l}\text { Doppelseitige Hasenscharte III.Gr. } \\
\text { Bilaterale, durchgehende Gaumen- } \\
\text { spalte. Weit vorspringender } \\
\text { Zwischenkiefer. }\end{array}$ & 3,7 & $I, 4$ & $\mathrm{I}, 4$ & 2,0 \\
\hline 3 & $\mathrm{H}$, A. & $\begin{array}{l}\text { I Mon., } \\
6 \text { Tage }\end{array}$ & $\begin{array}{l}\text { Hasenscharte III. Gr. lks. Links- } \\
\text { seitig durchgeh. Gaumenspalte. }\end{array}$ & 3.9 & $\mathrm{I}, 8$ & $\mathrm{I}, 8$ & $\mathrm{I}, 3$ \\
\hline 4 & G., M. & $\begin{array}{l}\text { I Mon., } \\
\text { 20 Tage }\end{array}$ & $\begin{array}{l}\text { Hasenscharte III. Gr. lks. Links- } \\
\text { seitig durchgeh. Graumenspalte. }\end{array}$ & 3,8 & 2,0 & $\mathrm{I}, 5$ & $I, 3$ \\
\hline 5 & St., R. & 3 Mon. & $\begin{array}{l}\text { Hasenscharte II. Gr. r. Rechts- } \\
\text { seitig durchgeh. Gaumenspaite. }\end{array}$ & 3,9 & $I, 6$ & 1,7 & $\mathrm{I}, 4$ \\
\hline 6 & P., E. & $\begin{array}{l}4 \text { Mon., } \\
\text { I2 Tage }\end{array}$ & $\begin{array}{l}\text { Hasenscharte III. Gr. lks. Links- } \\
\text { seitig durchgeh. Gaumenspalte. }\end{array}$ & 4,2 & $\mathbf{I}, 8$ & $I, 6$ & I, 6 \\
\hline 7 & M., S. & $\begin{array}{l}4 \text { Mon., } \\
\text { 29 Tage }\end{array}$ & $\begin{array}{l}\text { Hasenscharte II. Gr. lks. Links- } \\
\text { seitig durchgeh. Gaumenspalte; } \\
\text { rechts nur etwa die hint. } 6 / 6 \text { d. } \\
\text { harten Gaumens gespalten. }\end{array}$ & 4,2 & 2,0 & $I, 7$ & $\mathrm{I}, 5$ \\
\hline 8 & R., J. & $\begin{array}{l}5 \text { Mon., } \\
\text { Io Tage }\end{array}$ & $\begin{array}{l}\text { Doppelseitige Hasenscharte II. Gr. } \\
\text { Rechtsseitig durchgeh. Gaumen- } \\
\text { spalte; links hintere Hälfte des } \\
\text { harten Gaumens gespalten. }\end{array}$ & $4, I$ & 2,0 & 2,0 & I, 4 \\
\hline 9 & H., E. & $\begin{array}{l}5 \text { Mon., } \\
\text { I6 Tage }\end{array}$ & $\begin{array}{l}\text { Hasenscharte III. Gr. lks. Links- } \\
\text { seitig durchgeh. Gaumenspalte. }\end{array}$ & 4,0 & 2,0 & $\mathrm{I}, 7$ & $I, I$ \\
\hline to & H., S. & $\begin{array}{l}5 \text { Mon., } \\
\text { I } 8 \text { Tage }\end{array}$ & $\begin{array}{l}\text { Hasenscharte III. Gr. lks. Links- } \\
\text { seitig durchgeh. Gaumenspalte. }\end{array}$ & $4, \mathrm{I}$ & $x, 9$ & 1,9 & 1,2 \\
\hline
\end{tabular}


bildung vor der Hasenschartenoperation.

\begin{tabular}{|c|c|c|c|c|c|}
\hline Alveolarfortsatz & Zwischenkiefer & Vomer & 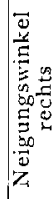 & 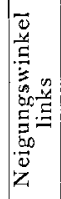 & 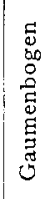 \\
\hline $\begin{array}{l}\text { Links gespalten; Spalt- } \\
\text { breite I,4 cm. Alveolar- } \\
\text { fortsatz d. recht. Seite } \\
\text { uberragt den d. linken } \\
\text { nach vorn um } 0,7 \text { bis } \\
0,8 \mathrm{~cm} \text {. }\end{array}$ & $\begin{array}{l}\text { Mit dem Alveolarfortsatz } \\
\text { der rechten Seite ver- } \\
\text { einigt. }\end{array}$ & $\begin{array}{l}\text { Horizontal; } 0,8 \mathrm{~cm} \text { br. } \\
\text { mit d. recht. Gaumen- } \\
\text { plattenrand vereinigt. }\end{array}$ & 55 & 40 & 4,4 \\
\hline $\begin{array}{l}\text { Doppelseitig gesp. Spalt- } \\
\text { breite rechts I, I cm, } \\
\text { links } I, 0 \mathrm{~cm} \text {. }\end{array}$ & $\begin{array}{l}\text { Uberragt die Alveolar- } \\
\text { fortsätze beider Ober- } \\
\text { kieferhälften nach vorn } \\
\text { um I } 5 \mathrm{~cm} \text {. }\end{array}$ & $\begin{array}{l}\text { Exzessiv lang. } 0,5 \mathrm{~cm} \\
\text { breiter, rundl. Balken } \\
\text { etwas näher d. linken } \\
\text { Gaumenplattenrand. }\end{array}$ & 35 & 40 & 4,8 \\
\hline $\begin{array}{l}\text { Links gespalten; Spalt } \\
\text { I, } 2 \mathrm{~cm} \text { breit. Alveolar- } \\
\text { fortsatz der recht. Seite } \\
\text { überragt den der linken } \\
\text { nach vorn um } 1,3 \mathrm{~cm} \text {. }\end{array}$ & $\begin{array}{l}\text { Mit dem Alveolarfortsatz } \\
\text { der rechten Oberlkiefer- } \\
\text { hälfte vereinigt. }\end{array}$ & $\begin{array}{l}\text { Horizontal; } 0,9 \mathrm{~cm} \text { br. } \\
\text { mit d. recht. Gaumen- } \\
\text { plattenrand verbund. }\end{array}$ & 55 & 50 & 4,9 \\
\hline $\begin{array}{l}\text { Links gespalten; Spalt- } \\
\text { breite } \mathrm{I}, 3 \mathrm{~cm} \text {. Alveolar- } \\
\text { bogen gerundet. }\end{array}$ & $\begin{array}{l}\text { Mit dem Alveolarfortsatz } \\
\text { der rechten Seite ver- } \\
\text { einigt. }\end{array}$ & $\begin{array}{l}\text { Horizont.; verbreitert; } \\
\text { o,9 cm breit; mit dem } \\
\text { r. Gaumenplattenrd. } \\
\text { vereinigt. }\end{array}$ & 40 & 35 & 4,8 \\
\hline $\begin{array}{l}\text { Rechts gespalten. Spalt- } \\
\text { breite } 0,9 \mathrm{~cm} \text {. Alveolar- } \\
\text { fortsatz der linken Seite } \\
\text { überragt den d. rechten } \\
\text { nach vorn um } 0,4 \mathrm{~cm} \text {. }\end{array}$ & $\begin{array}{l}\text { Mit dem Alveolarfortsatz } \\
\text { der linken Oberkiefer- } \\
\text { hälfte vereinigt. }\end{array}$ & $\begin{array}{l}\text { Horizontal; } 0,9 \mathrm{~cm} \text { br.; } \\
\text { linker Rand mit dem } \\
\text { l. Gaumenplattenrand } \\
\text { verbunden. }\end{array}$ & 50 & 55 & 4,7 \\
\hline $\begin{array}{l}\text { Links gespalten; Spalt- } \\
\text { breite I,5 cm. Rechte } \\
\text { Seite überragt d. linke } \\
\text { nach vorn um o, } 5 \mathrm{~cm} .\end{array}$ & $\begin{array}{l}\text { Mit dem Alveolarfortsatz } \\
\text { der rechten Oberkiefer- } \\
\text { hälfte vereinigt. }\end{array}$ & $\begin{array}{l}\text { Horizontal; I, I cm br.; } \\
\text { in seiner ganz. Länge } \\
\text { mit dem rechten Gau- } \\
\text { menplattenrd. verbd. }\end{array}$ & 50 & 45 & 5,0 \\
\hline $\begin{array}{l}\text { Links gespalten; Spalt- } \\
\text { breite o,3 cm. Rechte } \\
\text { Seite überragt d. linke } \\
\text { etwas nach vorn. }\end{array}$ & $\begin{array}{l}\text { Mit dem Alveolarfortsatz } \\
\text { der rechten Oberkiefer- } \\
\text { hälfte vereinigt. }\end{array}$ & $\begin{array}{l}\text { Horizontal; } 3 \mathrm{~mm} \text { br.; } \\
\text { im vord. Teil mit dem } \\
\text { r. Gaumenplattenrd. } \\
\text { verbunden. }\end{array}$ & 40 & 35 & 5,2 \\
\hline $\begin{array}{l}\text { Rechts gespalten; Spalt- } \\
\text { breite } 3 \mathrm{~mm} \text {. Links am } \\
\text { Ubergang v. Zwischen- } \\
\text { kiefer in den Alveolar- } \\
\text { fortsatz Einkerbung }\end{array}$ & $\begin{array}{l}\text { Grenze links noch deut- } \\
\text { lich erkennbar; Einker- } \\
\text { bung. }\end{array}$ & $\begin{array}{l}\text { Horizontal; } 4 \mathrm{~mm} \text { br.; } \\
\text { ungefähr mit d. vord. } \\
\text { Hälfte des linken Gau- } \\
\text { menplattenrandes } \\
\text { verbunden }\end{array}$ & 35 & 50 & 5,4 \\
\hline $\begin{array}{l}\text { Links gespalten; Spalt- } \\
\text { breite I,o cm. Rechte } \\
\text { Seite überragt d. linke } \\
\text { nach vorn um } 0,5 \mathrm{~cm} \text {. }\end{array}$ & $\begin{array}{l}\text { Mit dem Alveolarfortsatz } \\
\text { der rechten Oberkiefer- } \\
\text { hälfte vereinigt. }\end{array}$ & Horizontal; $0,9 \mathrm{~cm}$ br. & $5^{\circ}$ & $4^{\circ}$ & 4,8 \\
\hline $\begin{array}{l}\text { Links gespalten; Spalt- } \\
\text { breite } \mathrm{I}-2 \mathrm{~mm} \text {. Rechte } \\
\text { Seite überragt d. linke } \\
\text { nach vorn um } 0,6 \mathrm{~cm} .\end{array}$ & $\begin{array}{l}\text { Nach außen gedreht. Mit } \\
\text { dem Alveolarfortsatz d. } \\
\text { rechten Seite verbund. }\end{array}$ & $\begin{array}{l}\text { Vomer von unregelm. } \\
\text { Form, horizontal, } \\
\text { größte Breite } 0,9 \mathrm{~cm} .\end{array}$ & $5^{\circ}$ & $4^{\circ}$ & 5,0 \\
\hline
\end{tabular}




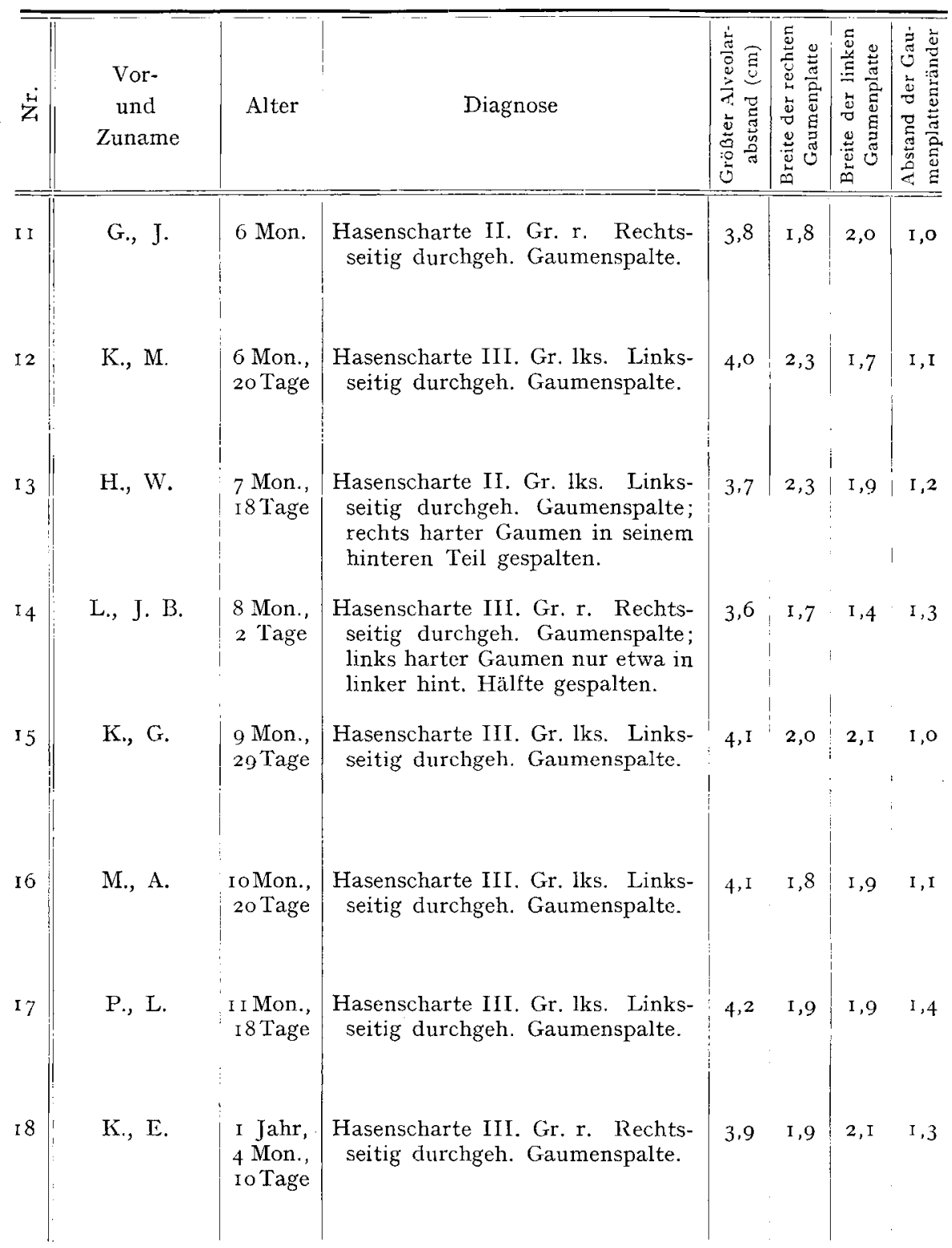




\begin{tabular}{|c|c|c|c|c|c|}
\hline Alveolarfortsatz & Zwischenkiefer & Vomer & 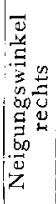 & 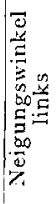 & 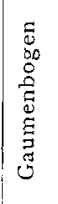 \\
\hline $\begin{array}{l}\text { Rechts gespalten; Spalt- } \\
\text { breite } 4 \mathrm{~mm} .\end{array}$ & $\begin{array}{l}\text { Mit dem Alveolarfortsatz } \\
\text { der linken Oberkiefer- } \\
\text { hälfte vereinigt. }\end{array}$ & $\begin{array}{l}\text { Leicht aufwärts ge- } \\
\text { richtet (nicht deutl. } z \text {. } \\
\text { Geltung kommend auf } \\
\text { d. Gipsabdr.) }\end{array}$ & 45 & 55 & 4,8 \\
\hline $\begin{array}{l}\text { Links gespalten; Spalt- } \\
\text { breite I,6 cm. Rechte } \\
\text { Seite überragt d. linke } \\
\text { nach vorn um } 0,8 \mathrm{~cm} \text {. }\end{array}$ & $\begin{array}{l}\text { Mit dem Alveolarfortsatz } \\
\text { der rechten Seite ver- } \\
\text { einigt. }\end{array}$ & Horizontal; $0,8 \mathrm{~cm} \mathrm{br}$. & 55 & 45 & $5, \mathrm{I}$ \\
\hline $\begin{array}{l}\text { Links gespalten; Alveo- } \\
\text { larbogen schön gerun- } \\
\text { det. }\end{array}$ & $\begin{array}{l}\text { Mit dem Alveolarfortsatz } \\
\text { der rechten Oberkiefer- } \\
\text { hälfte verbunden. }\end{array}$ & Horizontal; $0,5 \mathrm{~cm}$ br. & 50 & 45 & 5,4 \\
\hline $\begin{array}{l}\text { Rechts gespalten; linke } \\
\text { Seite überragt d. rechte } \\
\text { nach vorn ca. } 6-7 \mathrm{~mm} \text {. }\end{array}$ & $\begin{array}{l}\text { Mit dem Alveolarfortsatz } \\
\text { der linken Seite ver- } \\
\text { bunden. }\end{array}$ & $\begin{array}{l}\text { I-2 mm breit; dem } \\
\text { 1. Gaumenplattenrd. } \\
\text { genähert, im vorderen } \\
\text { Teil mit dems. verb. }\end{array}$ & 45 & 50 & 4,4 \\
\hline $\begin{array}{l}\text { Links gespalten; Spalt- } \\
\text { breite I,0 cm. Rechte } \\
\text { Seite überragt d. linke } \\
\text { nach vorn um } 0,6 \text { bis } \\
0,7 \mathrm{~cm} \text {. }\end{array}$ & $\begin{array}{l}\text { Stark nach außen ge- } \\
\text { dreht; mit d. Alveolar- } \\
\text { fortsatz d. linken Seite } \\
\text { verbunden. }\end{array}$ & $\begin{array}{l}\text { Verbreitert; leicht auf- } \\
\text { steigend; } 0,8 \mathrm{~cm} \text { breit. } \\
\text { Mit d. recht. Gaumen- } \\
\text { plattenrand verbun- } \\
\text { den. }\end{array}$ & $5^{\circ}$ & 55 & 5,1 \\
\hline $\begin{array}{l}\text { Links gespalten; Spalt- } \\
\text { breite ca. I cm. Rechte } \\
\text { Seite überragt d. linke } \\
\text { nach vorn um I, I cm. }\end{array}$ & $\begin{array}{l}\text { Stark nach außen ge- } \\
\text { dreht; mit d. Alveolar- } \\
\text { fortsatz d. recht. Seite } \\
\text { vereinigt. }\end{array}$ & $\begin{array}{l}\text { Horizont. ; verbreitert; } \\
0,9 \mathrm{~cm} \text {. breit. Mit d. } \\
\text { rechten Spaltrand ver- } \\
\text { einigt. }\end{array}$ & $5^{\circ}$ & 45 & 4,8 \\
\hline $\begin{array}{l}\text { Links gespalten; Spalt- } \\
\text { breite } \mathrm{I}, 2 \mathrm{~cm} \text {. Rechte } \\
\text { Seite überragt d. linke } \\
\text { nach vorn um } \mathrm{I}, 3 \mathrm{~cm} .\end{array}$ & $\begin{array}{l}\text { Mit dem Alveolarfortsatz } \\
\text { der rechten Seite ver- } \\
\text { bunden. }\end{array}$ & $\begin{array}{l}\text { Stark verbreit.; I, I cm } \\
\text { breit; mit d. rechten } \\
\text { Gaumenplattenrand } \\
\text { verbunden. }\end{array}$ & 50 & 45 & 5,2 \\
\hline $\begin{array}{l}\text { Rechts gespalten; Spalt- } \\
\text { breite o,9 cm. Linke } \\
\text { Oberkieferseite über- } \\
\text { ragt die rechte nach } \\
\text { vorn ca. I cm. }\end{array}$ & $\begin{array}{l}\text { Mit dem Alveolarfortsatz } \\
\text { der linken Seite ver- } \\
\text { bunden. Grenze deut- } \\
\text { lich. }\end{array}$ & $\begin{array}{l}\text { Horizont.; verbreitert; } \\
0,9 \mathrm{~cm} \text { breit. }\end{array}$ & $4^{\circ}$ & 55 & 5.3 \\
\hline
\end{tabular}


Tabelle II. Fälle von durchgehender Spaltbildung

\begin{tabular}{|c|c|c|c|c|c|c|c|}
\hline $\mathrm{Nr}$. & Vor- und Zuname & Alter & $\begin{array}{c}\text { Operation der } \\
\text { Hasenscharte } \\
\text { vor }\end{array}$ & 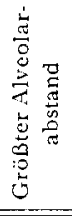 & 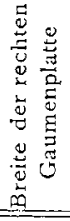 & 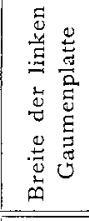 & 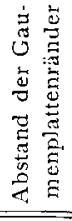 \\
\hline $\begin{array}{l}\text { I } \\
(3) \\
1)\end{array}$ & $\mathrm{H}_{1}, \mathrm{~A}$. & $\begin{array}{l}5 \text { Monate, } \\
\text { ro Tage }\end{array}$ & 4 Monaten & 3,9 & $I, 9$ & 2,0 & $I, O$ \\
\hline $\begin{array}{l}2 \\
(4)\end{array}$ & G., M. & $\begin{array}{c}7 \text { Monate, } \\
20 \text { Tage }\end{array}$ & $61 / 2$ Monaten & 3,7 & 2,0 & 1,5 & $\mathrm{I}, 2$ \\
\hline $\begin{array}{c}3 \\
(5)\end{array}$ & S., R. & $\begin{array}{l}3 \text { Monate, } \\
\text { I } 4 \text { Tage }\end{array}$ & 14 Tagen & 3,9 & $I, 6$ & $I, 7$ & $I, 4$ \\
\hline $\begin{array}{l}4 \\
(8)\end{array}$ & R., J. & I Jahr & 6 Monaten & 4,4 & 2,0 & 2,0 & $I, 5$ \\
\hline $\begin{array}{c}5 \\
5 \\
(10)\end{array}$ & H., S. & $\begin{array}{l}\text { I } 2 \text { Monate, } \\
27 \text { 'lage }\end{array}$ & 7 Monaten & 3,8 & $2, \mathrm{I}$ & 2,3 & 0,9 \\
\hline $\begin{array}{c}6 \\
(\mathrm{I} I)\end{array}$ & G., J. & ro Monate, & 4 Monaten & 3,6 & 1,8 & 2,0 & 0,8 \\
\hline $\begin{array}{c}7 \\
(\mathrm{I} 2)\end{array}$ & $\mathrm{K}, \mathrm{M}$. & $\begin{array}{c}\text { I Jahr, } \\
5 \text { Monate }\end{array}$ & Io Monaten & 3,8 & 2,3 & $\mathrm{I}, 9$ & $\mathrm{I}, \mathrm{I}$ \\
\hline $\begin{array}{c}8 \\
(\mathrm{I} 4)\end{array}$ & L., J. B. & $\begin{array}{l}\text { I Jahr, } \\
3 \text { Monate }\end{array}$ & 7 Monaten & 3,6 & I, 8 & I, 6 & $I, O$ \\
\hline$\stackrel{9}{16)}$ & M., A. & $\begin{array}{l}\text { I Jahr, } \\
2 \text { Monate }\end{array}$ & 3 Monaten & 3,8 & $I, 9$ & 2,0 & 0,9 \\
\hline $\begin{array}{l}\text { Io } \\
\text { (I } 7)\end{array}$ & P., L. & $\begin{array}{l}\text { I Jahr, } \\
4 \text { Monate }\end{array}$ & 4 Monaten & 4,2 & $I, 9$ & $\mathrm{I}, 9$ & $\mathrm{I}, 4$ \\
\hline $\begin{array}{l}\text { I I } \\
\text { (I } 8)\end{array}$ & K., E. & $\begin{array}{l}\text { I Jahr, } \\
5 \text { Monate }\end{array}$ & 14 Tagen & 3,8 & $I, 9$ & $2, I$ & $I, I$ \\
\hline
\end{tabular}

I) Die eingeklammerten Zahlen bezeichnen die entsprechenden Fälle der 
nach der Hasenschartenoperation.

\begin{tabular}{|c|c|c|c|c|c|}
\hline Alveolarfortsatz & Zwischenkiefer & Vomer & 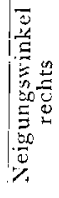 & 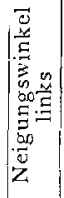 & $\mid \begin{array}{l}0 \\
0 \\
\infty \\
0 \\
0 \\
0 \\
0 \\
0 \\
0 \\
0 \\
0 \\
0\end{array}$ \\
\hline $\begin{array}{l}\text { Alveolarbog. vorn gleich- } \\
\text { mäßig gerundet; Spalt- } \\
\text { breite } 0,4 \mathrm{~cm} \text {. }\end{array}$ & $\begin{array}{l}\text { Hat sich dem linken Al- } \\
\text { vcolarbogen bedeutend } \\
\text { genähert. }\end{array}$ & $\begin{array}{l}\text { Horizontal; } 0,9 \mathrm{~cm} \text { br.; } \\
\text { sein freier link. Rand } \\
\text { hat sich dem linken } \\
\text { Gaumenplattenrand } \\
\text { genähert. }\end{array}$ & 55 & $5^{\circ}$ & 4,9 \\
\hline $\begin{array}{l}\text { Alveolarbogen schön ge- } \\
\text { rundet; nur mehr } 3 \mathrm{~mm} \\
\text { breiter Spalt im Alveo- } \\
\text { larfortsatz. }\end{array}$ & $\begin{array}{l}\text { Hat sich dem Alvcolar- } \\
\text { fortsatz der link. Seite } \\
\text { bedeutend genähert. }\end{array}$ & $\begin{array}{l}\text { Horizontal; } 0,8 \mathrm{~cm} \text { br.; } \\
\text { beginnt sich etwas } \\
\text { steiler zu stellen. }\end{array}$ & $i^{55}$ & $5^{\circ}$ & 4,7 \\
\hline $\begin{array}{l}\text { Spalt im Alveolarfortsatz } \\
\text { etwas verschmäl.; jetzt } \\
0,4 \mathrm{~cm} \text { breit. }\end{array}$ & $\begin{array}{l}\text { Mehr dem Alveolarfort- } \\
\text { satz der rechten Seite } \\
\text { zugekehrt; Alveolar- } \\
\text { bogen mehr gerundet. }\end{array}$ & Horizontal; 0,9 cm br. & $5^{\circ}$ & 55 & 4.7 \\
\hline Unverändert. & Unverändert. & Unverändert. & 35 & 50 & 5,5 \\
\hline $\begin{array}{l}\text { Alveolarfortsatz ge- } \\
\text { schlossen. }\end{array}$ & $\begin{array}{l}\text { Mit d. Alveolarfortsatz } \\
\text { der linken Oberkiefer- } \\
\text { hälfte vereinigt. }\end{array}$ & $\begin{array}{l}\text { In eine mehr steile Stel- } \\
\text { lung gerückt; freier } \\
\text { Rand nicht mehr } \\
\text { sichtbar. }\end{array}$ & $5^{\circ}$ & 40 & 5,3 \\
\hline $\begin{array}{l}\text { Alveolarfortsatz ge- } \\
\text { schlossen. }\end{array}$ & $\begin{array}{l}\text { Liegt d. Alveolarfortsatz } \\
\text { der rechten Seite eng } \\
\text { an. }\end{array}$ & $\begin{array}{l}\text { In eine etwas steilere } \\
\text { Stellung gerückt. }\end{array}$ & 45 & 55 & 4,6 \\
\hline $\begin{array}{l}\text { Alveolarbogen schön ge- } \\
\text { rundet; Schneidezähne } \\
\text { durchgebrochen; Spalt- } \\
\text { breite } 0,5-0,6 \mathrm{~cm} \text {. }\end{array}$ & $\begin{array}{l}\text { Hat sich dem Alveolar- } \\
\text { fortsatz der link. Ober- } \\
\text { kieferhälfte bedeutend } \\
\text { genähert. }\end{array}$ & $\begin{array}{l}\text { In eine ctwas steilere } \\
\text { Stellg. gerückt; freier } \\
\text { Rand nicht erkennb. }\end{array}$ & 45 & 45 & 5,3 \\
\hline $\begin{array}{l}\text { Beide Seiten liegen ein- } \\
\text { ander an; sind nur noch } \\
\text { durch eine Inzisur ge- } \\
\text { trennt; Zähne vorhand. } \\
\text { Alveolarbog. gerundet. }\end{array}$ & $\begin{array}{l}\text { Berührt den Alveolar- } \\
\text { fortsatz d. recht. Seite; } \\
\text { eine keilförmige Ein- } \\
\text { kcrbung des Alveolar- } \\
\text { bogens besteht noch. }\end{array}$ & $\begin{array}{l}\text { Liegt d. link. Gaumen- } \\
\text { plattenrand in ganzer } \\
\text { Ausdehnung an; etw. } \\
\text { steiler. }\end{array}$ & 45 & 50 & 4,4 \\
\hline $\begin{array}{l}\text { Beide Seiten liegen ein- } \\
\text { ander an; nur durch } \\
\text { eine Inzisur keilförmig } \\
\text { eingeschnittener Alveo- } \\
\text { larfortsatz. }\end{array}$ & $\begin{array}{l}\text { Hat sich dem Alvcolar- } \\
\text { fortsatz d. linken Seite } \\
\text { bcdleutend genähert. }\end{array}$ & $\begin{array}{l}\text { In eine etwas steilere } \\
\text { Stellung gerückt. }\end{array}$ & & 40 & 4,8 \\
\hline $\begin{array}{l}\text { Alveolarbogen schön ge- } \\
\text { rundet; Spalt bedeut. } \\
\text { verengt; } 0,5 \mathrm{~cm} \text { breit. }\end{array}$ & $\begin{array}{l}\text { Hat sich dem Alveolar- } \\
\text { fortsatz der recht. Seite } \\
\text { bedeutend genähert. }\end{array}$ & $\begin{array}{l}\text { In eine etwas steilere } \\
\text { Stellung gerückt. }\end{array}$ & 50 & $5^{\circ}$ & 5,2 \\
\hline $\begin{array}{l}\text { Alveolarbogen schön ge- } \\
\text { rundet; Spalt nahezu } \\
\text { geschlossen. }\end{array}$ & $\begin{array}{l}\text { Hat sich dem Alveolar- } \\
\text { fortsatz der recht. Seite } \\
\text { bedcutend genähert. }\end{array}$ & Horizontal; $0,9 \mathrm{~cm}$ br. & $5^{\circ}$ & 55 & 5,1 \\
\hline
\end{tabular}

Tabelle 1 . 


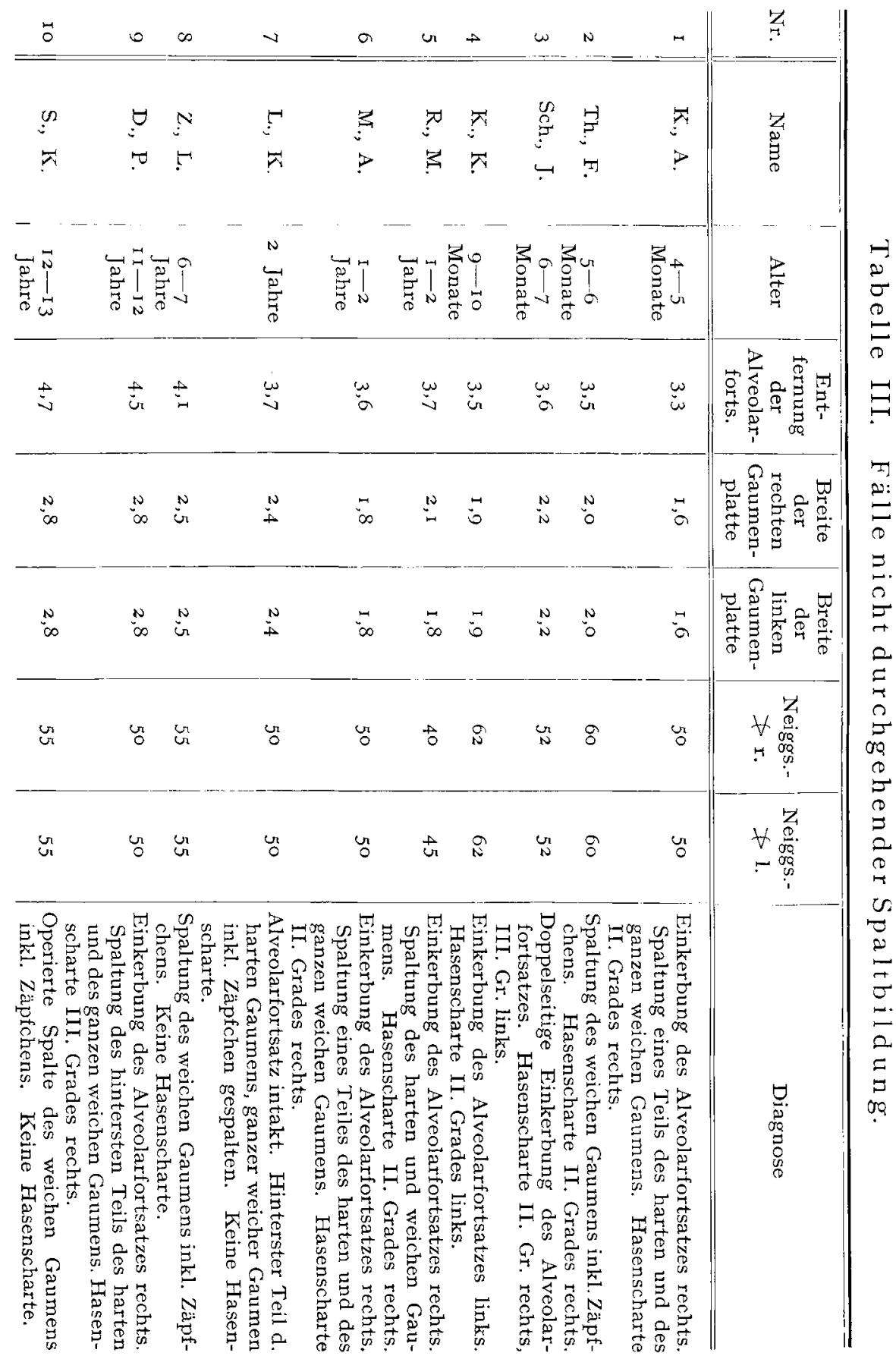


Tabelle IV. Messungsresultate an Kiefern von Säuglingen und Kindern im I.-2. Lebensjahre.

\begin{tabular}{|c|c|c|c|}
\hline $\begin{array}{l}\text { Alter } \\
\text { in Monaten }\end{array}$ & $\begin{array}{c}\text { GröBte Entfernung } \\
\text { der } \\
\text { Alveolarfortsätze }\end{array}$ & $\begin{array}{c}\text { Breite der } \\
\text { Gaumenplatten } \\
\mathrm{cm}\end{array}$ & $\begin{array}{c}\text { Neigungswinkel } \\
\text { der } \\
\text { Gaumenplatten }\end{array}$ \\
\hline $0-I$ & 2,87 & 1,65 & $61^{0}$ \\
\hline $\mathrm{I}-2$ & $2,9 \mathrm{I}$ & 1,70 & $59^{\circ}$ \\
\hline $2-3$ & 2,90 & $\mathrm{I}, 7 \mathrm{I}$ & $5^{8^{0}}$ \\
\hline $3-4$ & $2,9 \mathrm{I}$ & 1,77 & $55^{0}$ \\
\hline $4-5$ & 3,01 & I, 82 & $5^{0}$ \\
\hline $5-6$ & 3,08 & $\mathrm{I}, 8 \mathrm{I}$ & $56^{\circ}$ \\
\hline $6-7$ & 3,23 & 1,86 & $60^{\circ}$ \\
\hline $7-8$ & 3,26 & $\mathrm{I}, 85$ & $62^{\circ}$ \\
\hline $8-9$ & $3,2 \mathrm{I}$ & 1,88 & $59^{\circ}$ \\
\hline $9-10$ & 3,28 & 1,9 & $60^{\circ}$ \\
\hline IO-II & $3,4 \mathrm{I}$ & 1,95 & $6 \mathrm{I}^{0}$ \\
\hline $\mathrm{I} \mathrm{I}-\mathrm{I} 2$ & 3,46 & 2,0 & $60^{\circ}$ \\
\hline I $2-24$ & 3,50 & 2,2 & $53^{\circ}$ \\
\hline
\end{tabular}

\section{Zusammenfassung.}

I. Die bisher geübten Operationsmethoden bei angeborener Gaumenspalte sind ihrem Wesen nach:

Überbrückungs-Methoden,

Ausfüllungs- ",

Annäherungs -

2. Es ist zweckmäßig, unter den zahlreichen Typen der Miß. bildung zu unterscheiden zwischen „durchgehenden“ und „nicht durchgehenden“ Gaumenspalten. Erstere können einseitig oder doppelseitig durchgehende sein.

3. Der gespaltene Oberkiefer ist abnorm breit. Die Distanz der Alveolarfortsätze ist bei im ersten Lebensjahre stehenden Kindern mit durchgehender Gaumenspalte erheblich größer als bei gleichalterigen Kindern mit normalem Oberkiefer. Durchschnittlich beträgt die Distanzvermehrung der Alveolarfortsätze $0,8 \mathrm{~cm}$.

4. Bei einseitig durchgehender Spalte sind die Gaumenplatten von normaler Breite, sie stehen aber steiler als die Gaumenplatten des normalen Oberkiefers. Die individuellen Schwankungen hinsichtlich des Neigungswinkels der Gaumenplatten bewegen sich bei Gaumenspalten innerhalb derselben Grenzen $\left(20^{0}\right)$ wie unter normalen Kieferverhältnissen. 
Die Schwankungen bewegen sich aber bei Gaumenspalte innerhalb höherer Breiten.

5. Den Abstand der Gaumenplattenränder voneinander bezeichnen wir als ,absolute Spaltbreite".

Den eigentlichen Spalt im engeren Sinne dagegen als „r elative Spaltbreite“.

Nur die absolute Spaltbreite kann uns ein Bild von der Bedeutung der Mißbildung geben; die relative Spaltbreite ist praktisch ohne Bedeutung.

Die absolute Spaltbreite entspricht nicht der Vermehrung der Alveolardistanz. Erstere ist vielmehr größer als letztere.

Was an Spaltbreite übrig bleibt, kann in der Regel auf Rechnung der abnorm steil gestellten Gaumenplatten gesetzt werden.

Eine parallele gegenseitige Annäherung der Oberkieferhälften bis zur Berührung der Gaumenplattenränder müßte demnach eine pathologische Verschmälerung des Oberkiefers zur Folge haben. Besonders hochgradig muß diese pathologische Verschmälerung werden, wenn bei der gegenseitigen Annäherung der beiden Oberkieferhälften eine Drehung des einen oder der beiden Teile um die Sagittale nach innen erfolgt.

Die vermehrte Steilstellung der Gaumenplatten ist keine so hochgradige, daß ein einfaches Herunterklappen der Gaumenplattenüberzüge etwa bis zur horizontalen zur Deckung des Spaltes ausreichen würde. Nur in einzelnen Fällen mit steilgestellten Gaumenplatten und geringer absoluter Spaltbreite wird die Überbrückung auf die genannte Art und Weise möglich sein.

Die gewöhliche Form der absoluten Spalte ist die mit parallelen Spalträndern. Nur die Zäpfchen sind ganz regelmäßig nach der Spaltmitte zugekehrt und berühren sich nicht selten in der Medianlinie.

6. Unter dem EinfluB der vereinigten Oberlippe verwandeln sich einseitig durchgehende Spalten in nicht durchgehende Spalten. Beide Oberkieferhälften nähern sich einander, der Spalt im harten Gaumen wird verschmälert.

Auch bei doppelseitig durchgehenden Spalten kann sich die 
Alveolarspalte unter dem Einfluß der vereinigten Oberlippe schließen. In diesem Falle erfordert aber der Spaltverschluß eine viel längere Einwirkung der vereinigten Oberlippe.

7. Von besonderer Wichtigkeit ist das Studium der Form der absoluten Spalte vor der Hasenschartenoperation, im Anschluß an dieselbe und einige Jahre später. Die Gaumenspalte ist keine gleichbleibende Größe. Wir haben vielmehr dreiverschiedene Stadien der Mißbildung zu unterscheiden. Die Charakteristika der verschiedenen Stadien sind folgende:

I. Stadium (Stadium der unberührten Gaumenspalte).

I.

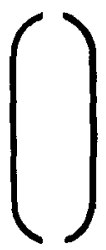

Kieferspalte.

Parallele Spaltränder, sowohl im Bereich des harten als des weichen Gaumens.

Zäpfchen einander zugekehrt.

Spaltbreite in allen frontalen Ebenen dieselbe.

II. Stadium (Stadium der optimalen Spaltbreite).

II.

Kieferspalte unter der Einwirkung der Oberlippe

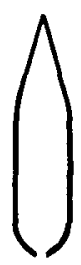
geschlossen.

Dreiecksform der Spalte des harten Gaumens. Parallele Spaltränder im Bereich des weichen Gaumens.

Größte Breite der Gesamtspalte am Übergang vom harten in den weichen Gaumen. Zäpfchen einander zugekehrt.

III. Stadium (Definitives Stadium der Spalte).

Geschlossener Alveolarbogen.

III.

Dreiecksform der Gesamtspalte.

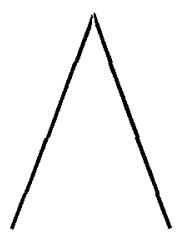

Größte Breite der Spalte zwischen den hintersten Enden des gespaltenen Zäpfchens.

Die Ränder des weichen Gaumens und des gespaltenen Zäpfchens bilden die Verlängerung der Spaltränder des harten Gaumens nach hinten.

Zäpfchen nicht mehr einander zugekehrt.

8. Die modernen Methoden der blutigen Annäherung der Alveolarfortsätze (Brophy, Schoemaker) 
können nicht empfohlen werden. Sie sind als gefährliche Eingriffe zu bezeichnen und sind oft von Mißerfolgen begleitet.

Wird die Annäherung beider Seiten so weit getrieben, daß sich die Gaumenplattenränder berühren, so wird der Oberkiefer über das normale Maß hinaus verschmälert. Außerdem wird bei einem solchen Vorgehen die fehlerhafte Stellung des Zwischenkiefers nicht gebührend berücksichtigt.

Aber auch die Annäherung beider „Oberkieferhälften" ohne blutige Mobilisation der Alveolarfortsätze ist eine nicht empfehlenswerte Methode. Die Alveolarfortsätze werden dabei nach innen umgebogen, die Gaumenplatten stellen sich steiler, d.h. die Deformität wird vergrößert.

Sowohl bei der blutigen (Brophy, Schoemaker), als unblutigen (Brophy, Kärger) Annäherungsmethode ist die Gefahr einer Zerstörung von Zahnkeimen eine sehr große. Bei den unblutigen Methoden können die Zahnkeime gefährdet oder zerstört werden durch die Anwendung der durch die Alveolarfortsätze gehenden Drähte.

Außerdem findet bei solchen unblutigen Methoden ein vollständiger Verschluß der absoluten Spalte in der Regel nicht statt; der Spalt muß also doch noch mit Hilfe der Langen beckschen Operation geschlossen werden.

Für die Behandlung der Gaumenspalte möchte ich unter Berücksichtigung des Gesagten folgendes Vorgehen empfehlen:

Nicht durchgehende Gaumenspalten sind dem Langenbeckschen Verfahren zu unterziehen.

Einseitig durchgehende Spalten sind mit Hilfe der Hasenschartenoperation in nicht durchgehende Spalten zu verwandeln. Dies geschieht dadurch, daß der Zwischenkiefer unter der Einwirkung der vereinigten Oberlippe in die richtige Stellung gerückt wird.

Doppelseitig durchgehende Spalten mit geringer Prominenz des Zwischenkiefers sind ebenfalls mit Hilfe der Hasenschartenoperation in nicht durchgehende Spalten zu verwandeln. In Fällen von weit vorspringendem Zwischenkiefer empfiehlt es sich, den 
Zwischenkiefer in der von Bardeleben angegebenen Weise vor der Operation der Hasenscharte zurückzuverlagern.

Die Spalte des harten und weichen Gaumens ist im Stadium der optimalen Spaltbreite (Ende des 1., Anfang des 2. Lebensjahres) zu schließen.

Wird im Stadium der optimalen Spaltbreite nach v. Langenbeck operiert, so stellt sich unser Vorgehen darals eine Kombination von Spalt-Annäherung und Spalt-Überbrückung mit gleichzeitigem horizontalerem Einstellen der Gaumenplatten. 